\title{
Wissenssemantische Analyse: die evozierten Frames
}

\section{Zusammenfassung}

Die wissens- bzw. frame-semantische Analyse der Ausdrücke, wie sie im untersuchten Diskursausschnitt in Pressetexten gebraucht werden, zeigt: Steht der Ausdruck Geflüchtete_ $r$ in einem engen konzeptuellen wie sprachlichen Verhältnis zu dem zwar nicht unproblematisierbaren, jedoch zukunftsorientierten sowie konstruktiven Themenkomplex der Integration, kennzeichnen Flüchtling eine stärkere Passivität der bezeichneten Personen sowie, in Verbindung dazu, der Umgang politischer Akteur_innen mit ihnen. Die Analyse zweier politischer Reden zeigt jedoch, dass Flüchtling nicht per se eine negative Konnotation zugeschrieben werden sollte. So perspektiviert etwa Heiko Maas das Konzept hinsichtlich Chancen und Perspektiven in der Aufnahmegesellschaft und verbindet dies mit (einem Aufruf zu) politischen Handlungen. Ein zentraler Unterschied zwischen Geflüchtete_r und Flüchtling besteht darin, dass mit ersterer Bezeichnung weitaus häufiger auf Personen verwiesen wird, die sich bereits in Deutschland befinden. Migrant_in gleicht sich hinsichtlich des kognitiv-semantischen wie epistemischen Gehalts und auch quantitativ stark an Flüchtling an. Dies ist u. a. an dem Umstand zu erkennen, dass - trotz seinem Dasein als Sammelbegriff - der Ausdruck im Gros der Fälle auf Menschen referiert, deren Fluchtbewegung noch andauert. Dieses sich im Diskurs zur sog. Flüchtlingskrise sprachlich manifestierende Wissen in der vorliegenden Studie evoziert durch die jeweiligen instantiierten oder

Ergänzende Information Die elektronische Version dieses Kapitels enthält Zusatzmaterial, auf das über folgenden Link zugegriffen werden kann https://doi.org/10.1007/978-3-658-36719-0_4. 
token-Frames der Ausdrücke Flüchtling, Geflüchtete_r und Migrant_in - kann in Form von type-Frames zu den jeweiligen Konzepten abgebildet werden.

\subsection{Frames in der politischen Sprache}

Wie in Abschnitt 2.3 bereits erwähnt, zeigt sich die Perspektivierung und Fokussierung bestimmter Elemente von Frames mitunter in Reden politischer Amtsträger_innen. Der Großteil solcher Reden adressiert nicht nur das vor Ort anwesende Publikum, sondern richtet sich auch und insbesondere an die breite Öffentlichkeit. Wörter, Texte, Textnetze und somit Frames werden eingesetzt, um den eigenen Standpunkt deutlich zu machen, die Aufmerksamkeit der Adressat_innen zu bekommen und Zustimmung sicherzustellen (vgl. Girnth 2002: 57). Sprache dient in der Politik als Instrument zu einer durch Intentionen und Interessen geleiteten - ideologisch geprägten - Konstruktion von Wirklichkeit. ${ }^{1}$ Dabei ist Sprache auch dann politisch, wenn Laien und „einfache“ Bürger_innen im privaten bis halb-öffentlichen Raum über Politik sprechen. Politische Sprache bezeichnet also allgemein die Ausdrucksmittel, die beim Sprechen über politisch relevante Sachverhalte gebraucht werden. Bezugspunkt und Untersuchungsgegenstand der folgenden Zeilen ist jedoch das, was Burkhardt (1996: 81) konkretisiert Politikersprache nennt: eine auf Außenwirkung berechnete „Meinungssprache“ der durch den Besitz öffentlicher Ämter definierten Personengruppe, die am physisch anwesenden Publikum und/oder den Gesprächspartner_innen vorbei ,auf letztlich monologische Einbahnstraßenkommunikation mit dem Bürger" (ebd.) zielt. Es kann sich dabei um Reden, Interviews, Auftritte in Talk-Shows u.v.m handeln. Der Politikersprache kann deshalb im Gegensatz zum „Sprechen über Politik“ ubiquitäre Intentionalität unterstellt werden.

Der Begriff des Frames ist nicht nur auf die Kompetenz, sondern auch auf die Performanz anwendbar. Bei genauerer Betrachtung wird deutlich, wie eng Sprachsystem und Sprachgebrauch in der Frame-Semantik aneinander gekoppelt sind: Wie Frames konstruiert und eingesetzt werden (auch Framing genannt) ist nur durch eine detaillierte Analyse des Sprachgebrauchs erklärbar. Insbesondere in der politischen Kommunikation ist eine solche enge Kopplung zu beobachten: Politiker_innen versuchen, bei den Adressat_innen die Frames zu evozieren, die sich mit ihrer Einstellung zum Sachverhalt decken. ${ }^{2}$ Wie Sprache verwendet

\footnotetext{
${ }^{1}$ Vgl. an diesem Punkt auch die These „Recht ist Gelten der Sprache“ in Unterabschnitt 3.1.1.

${ }^{2}$ In den Kommunikationswissenschaften wird zwischen simpler Überzeugungsveränderung (,belief change') und Framing unterschieden. Es heißt, dass hinsichtlich ersterer Handlung
} 
wird, hängt somit in gewisser Hinsicht unmittelbar davon ab, was Politiker_innen denken, wie das Gesagte bei den Adressat_innen ankommen könnte bzw. soll. Kurz: Die Art und Weise der Sprachverwendung, im vorliegenden Zusammenhang genauer der Frame-Konstruktion, ist vom durch die Sprachverwender_innen angenommenen oder intendierten Verständnis der Adressat_innen abhängig. So schreibt auch Scherner (1997: 51; zit. nach Felder 2006b: 162):

Der Textproduzent vollzieht eine komplexe Handlung [...] gegenüber dem Textrezipienten, indem er 1. ein bestimmtes kognitiv verfügbares Handlungsmuster aktiviert, indem er 2. eine Reihe von kognitiv verfügbaren Konzepten und Konzeptrelationen aktiviert, indem er 3. eine Linearität verketteter sprachlicher Mittel erzeugt, von der er erhofft, daß ihre Verarbeitung beim Rezipienten die gewünschte Handlung [d.h. auch Einstellungsänderung oder -festigung; PN] auslöst.

Der Text ${ }^{3}$ kann bei den Rezipient_innen nur dann die gewünschte Handlung auslösen, wenn im Zuge der Verarbeitung des Textes durch die Rezipient_innen diese auch den Text verstehen, in dem Sinne, dass sie Kohärenz bilden (entweder überspringt Scherner den Schritt des Verstehens gedanklich oder er schließt ihn in „Verarbeitung“ mit ein). Das soll aus Rezipient_innensicht heißen, dass weder durch die Verarbeitung noch durch das Verstehen der einzelnen aufeinanderfolgenden Äußerungen oder Sätze die Intention des_der Sprecher_in bereits deutlich wird, sondern dies erst dann der Fall ist, wenn auch der Zusammenhang zwischen diesen Äußerungen, also der Textsinn als solches, erkannt wird. Das Verstehen von Textkohärenz ist dabei stets an die Fähigkeiten der Rezipient_innen geknüpft, wobei diese Fähigkeiten variieren und sich ändern können: Ein Individuum kann je nach Wissensgebiet weniger oder mehr Wissen aufweisen, sich neues Wissen durch andere Texte aneignen etc. (Busse 1992b: 8). Zudem kann die Rezeption (wie auch die Produktion) von Texten stets auch vom Wissen über weitere Texte

die Aussage der Sprachproduzent_innen die Meinung der Rezipient_innen aus dem Grund affiziert, dass sie eine positive oder negative Information zum Einstellungsobjekt enthält, die noch nicht bereits Teil des Rezipient_innenwissens ist; beim Framing dagegen aktivieren Frames Informationen, die den Rezipient_innen bereits zur Verfügung stehen und im Langzeitgedächtnis gespeichert sind (Nelson et al. 1997: 225). U.E. erscheint es aus linguistischer Sicht jedoch plausibel, dass beide Arten des strategischen Handelns mit Frames arbeiten: So geht es (nach der obigen Definition) bei der Überzeugungsveränderung um das (persistente) Überschreiben von Standardwerten bzw. das Entstehen neuer Standardwerte, beim Framing um die bloße Evokation (einer spezifischen zur Handlungsintention des_der Produzent_in passenden Auswahl) von Standardwerten.

${ }^{3}$ Text soll im Rahmen dieser Arbeit, auch wenn das Untersuchungskorpus ausschließlich aus schriftsprachlichen Daten besteht, nicht auf eine Modalität beschränkt gemeint sein: Sowohl Gehörtes als auch Gelesenes wird als Text verstanden. 
abhängig sein (ders.: 11). Dies trifft neben der individuellen auch auf der kollektiven Basis zu: An Politik Interessierte mögen politische Texte „leichter“ und „besser“ verstehen können als Nicht-an-Politik-Interessierte. (Möchte man diesen Gedanken weiterspinnen hin zur ,höchsten“ kollektiven Basis, langt man bei kulturspezifischem/kulturabhängigem Textverstehen an.)

\subsection{Zur Untersuchungsmethode}

Mit Fraas (1996: 5) werden Frames verstanden ,als systematisch aufgestellte Listen von Fragen, die das Kontextualisierungspotential von Konzepten und konzeptgebundenes Wissen detailliert veranschaulichen können“; Leerstellen werden auf der Basis sinnvoller Fragen gebildet, d. h. ,wie syntaktische Valenzstellen von Verbschemata behandelt“ (dies.: 17). So stellt auch Busse (2012: 680) bzgl. Frames für Nomina fest: „Ihre Frame-Struktur kann [...] auch Teile bzw. Aspekte von Argumentstrukturen integrieren“. Die Ermittlung der Leerstellen soll jedoch nicht nur auf der Basis von Argumenten geschehen, sondern methodisch durch die Anwendung eines Teils der klassischen, bei jeder semantischen Untersuchung nützlichen, analytischen Fragen angereichert werden: „Warum, woher, wozu, wohin, wann, wie (mit welchen Mitteln), wie lange, unter welchen Bedingungen flüchte(te)n/migrier(t)en wie viele?" Im Duktus der Valenztheorie: Argumente und Angaben (bzw. Adjunkte) werden einbezogen (vgl. Lönneker 2003: 69). Eine Frame-Analyse von solch einem Set an potenziellen Leerstellen aus vorzunehmen, statt die Leerstellen lediglich an den konkreten Sprachbelegen festzumachen, hat den Vorteil, auch im Diskurs marginalisierte Wissensaspekte feststellen zu können.

Weiterhin sei „der sprachliche Zugang zu konzeptgebundenem Wissen über in einer Sprachgemeinschaft gebräuchliche Prädikationen möglich“ (Fraas 1996: 5). Es können ,sprachliche Spuren konzeptuellen Wissens ausfindig [gemacht werden] indem die Prädizierungen der zu untersuchenden Konzepte [...] erfa[ss]t werden“ (ebd.). Die extrahierten Prädikationen werden daraufhin den Leerstellen zugeordnet. Frames sind also nicht nur kognitive Repräsentationsformate, sondern dienen auch als Instrument zur Erschließung und Darstellung für „zeichenbezogenes semantisches (bzw. konzeptuelles) Wissen“ (Busse 2012: 511).

Extrahierte Prädikationen müssen nicht zwingend als syntaktische Strukturen im engeren Sinne verstanden werden. Fraas zeigt dies nach Busse (ebd.) dadurch, dass sie nicht nur unmittelbare sprachliche Umgebungen einbezieht, sondern auch „Teile und semantische Aspekte von Sätzen [...] die syntaktisch üblicherweise 
nicht als direkte Prädikate zum Ziel-Nomen gelten“. Fraas vertritt demzufolge „ein abstrakteres, eher kognitiv-semantisches Verständnis von Prädikation, das über ein rein syntaktisches Verständnis von Prädikat weit hinausgeht" (ders.: 511 f.). Ziem (2008: 370) versteht Prädikationen ,als sprachliche Realisierungen des konzeptuellen Gehalts eines Ausdrucks, so dass auf der Basis der Menge an (quasi-)expliziten Prädikationen auf die kognitive Präsenz und Prominenz verstehensrelevanter Wissensaspekte zurück geschlossen werden kann“. Er grenzt zusätzlich explizite von impliziten Prädikationen ab und weist darauf hin, dass bei der Analyse Präsuppositionen, Implikaturen oder sonstiges inferiertes Wissen keine Rolle spielen dürfen, um ,,maximale Objektivität' zu erzielen“ (ders.: 411). Anders als Fraas bezieht er - zumindest in seinen Beispielfällen - bei der Aufstellung der Prädikationen zudem lediglich die direkte sprachliche Umgebung des frame-evozierenden Ausdrucks im Satz mit ein.

In der vorliegenden Arbeit wird mit Ziem auf implizite Prädikationen verzichtet, obgleich mit Fraas Prädikat als über die Satzgrenzen potentiell hinausreichend verstanden wird; denn sowohl hinsichtlich politischer Reden als auch Pressetexte liegt nahe, dass auch im vorherigen Text gegebene Information einen frame-evozierenden Ausdruck, der an der ,aktuellen“ Textstelle zur Bezeichnung der Personen(gruppe) gebraucht wird, prädizieren kann. Gleichwohl die Orientierung an den Valenzstellen bzw. semantischen Rollen eine Gemeinsamkeit mit der Herangehensweise nach Fillmore und FrameNet darstellt, wird, wie in Kap. 2 bereits angedeutet, bei der Analyse nicht auf Frames aus dem FrameNet-Repositorium zurückgegriffen, sondern sich an der auf nominale Lexeme zielenden Frame-Konzeption nach Barsalou orientiert. Der durch den jeweiligen sprachlichen Ausdruck evozierte Frame trägt denselben Namen wie der Ausdruck selbst, wird jedoch zur Unterscheidung von diesem in Majuskeln verschriftlicht (z. B. Flüchtlinge $\rightarrow$ FLÜCHTLINGE). Als Frame, der von den Ausdrücken Flüchtling und Geflüchtete_r evoziert wird, kommt nach dem FrameNet des Deutschen Flüchten in Frage, für Migrant_in allenfalls der abstraktere Frame Eigenbewegung. Um die diskurssemantischen Unterschiede der Lexeme erarbeiten zu können, müssen jedoch die (Namen der) evozierten Frames trennscharf auseinandergehalten werden, $d$. h. es wird auf die Zuhilfenahme der FrameNet-Frames verzichtet, denn: (a) Für FrameNet-Frames sind keine Leerstellen bzw. keine Meta-Frame-Elemente wie „Sprecher_inneneinstellung zum Referenzobjekt" vorgesehen; diese dürften jedoch unter dem Aspekt der politischen Korrektheit von Geflüchtete_r $r$ auch bei der frame-semantischen Analyse noch relevant werden. (b) Außerdem lassen FrameNet-Frames keine Einspeisung sprachsystematischer Aspekte in den Frame - wie sie auch Busse vorschlägt (s. o.) - zu. Dass in Geflüchteter eine Substantivierung bzw. Agentivierung auf 
Basis des Partizip Perfekts vorliegt, muss jedoch im kognitiven Modell auch eine Rolle spielen. (c) Zudem können die beiden genannten Frames dem Umstand des diffusen Gebrauchs, ergo der diffusen Bedeutung von Migrant_in nicht gerecht werden. (d) Für die genannten FrameNet-Frames dienen primär Verben als frame-evozierende lexikalische Einheiten, weshalb sich die Frage stellt, ob Personenbezeichnungen bzgl. der genannten Frames überhaupt als frame-evozierende Einheiten zulässig sind.

Im folgenden ersten Teil der Frame-Analyse sollen zwei Reden hoher politischer Amtsträger der Bundesrepublik Deutschland untersucht werden, die als mündlich realisierte Texte in Schriftform verstanden werden können. ${ }^{4}$ Dabei werden, ohne eine vollständige, über den Zweck dieser Arbeit weit hinausgehende Text- oder Argumentationsanalyse vornehmen zu können, exemplarisch einige Aspekte herausgegriffen, um zu zeigen, wie Frames perspektiviert und fokussiert werden können und ein und dieselbe Wortform unterschiedliche Frames evozieren kann. Bei den Frames handelt es sich demnach, wie auch im anschließenden zweiten Teil der Frame-Analyse, um instantiierte, in einen Kontext eingebettete Frames. „Einbettung“ soll dabei die Faktoren Kontext (außersprachliche/situative Einbettung) und Kotext (sprachliche Einbettung) meinen: In welchem Rahmen wird die Rede gehalten und wie beeinflusst dieser die Frame-Konstruktionen? Wodurch zeichnet sich die sprachliche Umgebung des frame-evozierenden Ausdrucks aus und wie trägt diese zur Frame-Konstruktion bei? Frame-semantische Überlegungen werden dabei mit textphorischen und pragmalinguistischen Aspekten angereichert.

\footnotetext{
${ }^{4}$ Die Kommunikationsform ist nach dem Modell von Koch/Oesterreicher (1985) also konzeptionell schriftlich und medial mündlich. Genaugenommen muss hier zwischen mindestens drei unterschiedlichen Texten differenziert werden, nämlich (a) dem Text, der dem Sprecher in schriftlicher Form vorliegt, also dem vorzutragenden Text, (b) dem Text, der vom Sprecher vorgetragen wird, in lautlicher Form, also dem vorgetragenen Text (mit Sprechpausen etc.), und (c) dem veröffentlichten Transkript des (medial-) mündlichen Vortrags; letzteres bildet den Untersuchungsgegenstand in Abschnitt 4.3. - Es musste hinsichtlich beider Reden auf eine Analyse von Aspekten der gesprochenen Sprache wie der Intonation o.ä. verzichtet werden, denn es ist zwar für die Rede von Joachim Gauck nahezu ungeschnittenes bildvisuelles Datenmaterial verfügbar, für die Rede von Heiko Maas liegen jedoch lediglich wenig-minütige bildvisuelle Ausschnitte vor.
} 


\subsection{Der Flüchtlings-Frame in politischen Reden}

\subsubsection{Joachim Gauck (Bundespräsident, 20.06.2015)}

Der damalige Bundespräsident Joachim Gauck (parteilos) hielt im Juni 2015 eine Rede anlässlich des ersten „Gedenktags für die Opfer von Flucht und Vertreibung“ in Berlin. ${ }^{5}$ Der Gedenktag wurde eingeführt, um ,jener Millionen von Deutschen, die am Ende des Zweiten Weltkriegs ihre Heimat verloren“ (S. 1) ${ }^{6}$, zu gedenken. Gleichzeitig beging die Bundesrepublik Deutschland an diesem Datum zum ersten Mal den Internationalen Weltflüchtlingstag, der im Jahr 2000 von den Vereinten Nationen beschlossen wurde. So heißt es zu Beginn weiter: „Auf eine ganz existenzielle Weise gehören sie nämlich zusammen - die Schicksale von damals und die Schicksale von heute $[\ldots]^{\text {“ }}$ (ebd.).

Gauck intendiert folglich eine Verbindung zu ziehen zwischen den „Heimatvertriebenen“ nach 1945 und den Flüchtenden und Geflüchteten, die im Zuge des sog. Sommers der Migration 2015 anhaltend Gegenstand der politischen wie gesellschaftlichen Debatte wurden. Dies ist zum einen auf sprachlicher Ebene zu beobachten: Eine Form des Partizips vertrieben (Substantivbildungen einbezogen) tritt in der rund 30-minütigen Rede 29 Mal auf; dabei benutzt er fünf Mal die Kollokation Flüchtlinge und Vertriebene. Zum anderen wird der Ausdruck Flüchtlinge hier bereits durch die außersprachliche Situation, dem Anlass der Rede, perspektiviert: Der durch ihn bei den Rezipient_innen evozierte Frame muss Leerstellen und/oder Füllwerte mit dem Frame teilen, den Vertriebene evoziert, denn die Referenzen beider frame-evozierenden Ausdrücke werden im Anlass genannt und verbunden: „die Opfer von Flucht und Vertreibung“.

Gauck wünscht sich, ,die Erinnerung an die geflüchteten und vertriebenen Menschen von damals könnte unser Verständnis für geflüchtete und vertriebene Menschen von heute vertiefen. Und umgekehrt: Die Auseinandersetzung mit den Entwurzelten von heute könnte unsere Empathie mit den Entwurzelten von damals fördern." (S. 1 f.). Es handelt sich hierbei demnach um eine Praxis strategischen Framings, das auf Wissen im weiten, auch Einstellungen einschließenden Sinne zielt (Klein 2018: 292). Zudem wird bereits an dieser Textstelle deutlich, dass in der frameanalytischen Darstellung Emotionen als integraler Bestandteil der evozierten Frames begriffen werden müssen. Sie fungieren

\footnotetext{
5 <https://www.bundespraesident.de/SharedDocs/Reden/DE/Joachim-Gauck/Reden/2015/ 06/150620-Gedenktag-Flucht-Vertreibung.html>(06.12.2021).

${ }^{6}$ Die Seitenangaben beziehen sich auf die Seitenzahlen des PDF-Dokuments, das unter dem in Anm. 5 angegebenen Link zum Download verfügbar ist (Stand: 06.12.2021).
} 
als Meta-Leerstellen, da es sich bei ihnen um Empfindungen über Sachverhalte handelt (ders.: 304).

Der Sprecher referiert hier mittels drei verschiedener Ausdrücke (geflüchtete Menschen, vertriebene Menschen, Entwurzelte) auf ein außersprachliches Objekt: die Gruppe derjenigen, nicht an einen bestimmten historischen Zeitabschnitt gebundenen Personen, die zwangsweise ihre Heimat verlassen mussten. Die Wortwahl reflektiert die Intention, die Gemeinsamkeiten nicht nur in historischer Sicht unterschiedlichster Menschen aufzuzeigen. Zugleich stellt dieser Wunsch das Ziel der Rede dar; ,,ich wünschte“ (S. 1) scheint dabei zwar zunächst einen expressiven Sprechakt einzuleiten, jedoch zielt die nachfolgende Äußerung durchaus auf die Realisierung dessen ab, wovon der Sprecher lediglich ausdrückt, dass er sich wünschte, es würde getan. Es liegt hier demnach vielmehr ein direktiver Sprechakt vor. ${ }^{7}$

Ein und derselbe Ausdruck (Flüchtling bzw. Flüchtlinge) evoziert im Verlauf der Rede unterschiedliche Frames. Man betrachte zunächst (09):

(09) $[\ldots]$ der Schriftsteller Jean Améry, Flüchtling vor Nazi-Deutschland und Überlebender von Bergen-Belsen [...] (S. 1)

Explizite Prädikationen:

- Der Flüchtling ist Schriftsteller

- Der Flüchtling heißt Jean Améry

- Der Flüchtling flüchtete vor Nazi-Deutschland

- Der Flüchtling ist Überlebender von Bergen-Belsen

Eine Leerstelle mag hier „Wovor ist die Person geflüchtet?“, d. h. die „Fluchtursache", sein. Sie wird durch die (mittels Präfigierung eines freien Morphems spezifizierte) Bezeichnung eines Landes gefüllt. Der semantische Gehalt des sprachlichen Zeichens Nazi-Deutschland, das in der semantischen Rolle des Verursachers (,causer') auftritt, besteht aus all dem, wofür Deutschland zwischen den Jahren 1933 und 1945 steht: das politische wie gesellschaftliche System und sämtliche damit verbundene Konsequenzen wie Unterdrückung, Ausgrenzung, Verfolgung und Ermordung politischer Gegner_innen und als minderwertig Erachteter. Zugleich bezeichnet der Ausdruck das Land, aus dem die Person, auf

\footnotetext{
${ }^{7}$ Diese Annahme wird von der Art und Weise unterstützt, wie die Medien Gaucks Rede wahrnahmen und auf diese reagierten: So sprechen z. B. Die ZEIT bzw. die Süddeutsche Zeitung von einer „Aufforderung“ (<https://www.zeit.de/politik/deutschland/2015-06/joachimgauck-bundespraesident-fluechtlinge > (06.12.2021)) bzw. einem „Aufruf“ (<https://www. sueddeutsche.de/politik/gauck-rede-zu-flucht-und-vertreibung-denken-wir-heute-nicht-zuklein-von-uns-1.2530253>(06.12.2021)).
} 
die referiert wird, geflüchtet ist: eine explizite Prädikation gibt hier somit Informationen über zwei Leerstellen und deren Füllwerte. Ferner liegt hier keinerlei Inferenz oder andere implizite Wissensvergegenwärtigung vor, vielmehr tritt der Ausdruck Nazi-Deutschland mit diesen zwei Bedeutungen zugleich auf - anders als in „klassischen“ Metonymien wie in Berlin verhandelt mit Ankara (eigenes Beispiel), in denen lediglich eine Entität bezeichnet wird (die deutsche bzw. türkische Regierung).

Im Frame, den Flüchtling hier evoziert, sind zudem die Leerstellen „Beruf“ und „Name“ mit Werten ausgefüllt, da es sich hier um ein bestimmtes Zitat einer bestimmten geflüchteten Person handelt. Dass es um eine konkrete Instanz des Frames Flüchtling geht, liegt aber schon allein aufgrund der Singularform nahe, wird mit der Pluralform doch die gesamte Personengruppe bezeichnet.

Die Konstruktionen Flüchtling vor Nazi-Deutschland und Überlebender von Bergen-Belsen dienen, verbunden durch den Konnektor und, als Apposition zur Nominalphrase der Schriftsteller Jean Améry. Der Ort Bergen-Belsen steht dabei für das von den Deutschen dort errichtete und betriebene Konzentrationslager. ${ }^{8}$ Dass in beiden Konstruktionen der Nullartikel bzw. kein indefiniter Artikel steht, reflektiert eine gewisse Anerkanntheit dieser permanenten sozialen „Rollen“. Wie bei ,Er ist Flüchtling mit eingeschränktem - sogenanntem subsidiären Schutzstatus' gilt: Es liegt zwar eine attributive Erweiterung vor (welche der Konstruktion mit Nullartikel ja grundsätzlich abgesprochen werden kann, vgl. 3.1.3), jedoch sind die Form-Inhalts-Paare mitsamt Attribut enorm konventionalisiert. Es gibt zahlreiche Personen, auf die Flüchtling vor Nazi-Deutschland zutrifft. Es wird keinerlei Verhältnis zwischen dem Träger der Lebensrolle und der Lebensrolle selbst bezeichnet, sondern die Lebensrolle an sich.

Der Frame FLÜCHTLING trägt hier, bedingt durch den semantischen Gehalt des Kookkurrenzpartners (Überlebender) des frame-evozierenden Ausdrucks, noch eine weitere Information: Die Flucht ist nicht ,gelungen“. Zwischen der

\footnotetext{
${ }^{8}$ In Kombination mit $\ddot{U}$ berlebende_r $r$ ist dies bspw. auch bei Auschwitz der Fall. Ein Hinweis auf den Grad der kognitiven Verfestigung mag dabei auch die Frage sein, ob durchgekoppelte Determinativkomposita bestehen. Auschwitz-Überlebender lieferte bei einer simplen Google-Suche zahlreiche Treffer, während Bergen-Belsen-Überlebender keinen einzigen Treffer ergab (Stand: 01.07.2020). Man muss hier gewiss bedenken, dass das Konzentrationslager in Bergen-Belsen oftmals als Aufenthaltslager bezeichnet wird, im Gegensatz zum - daneben viel größeren, eigentlich einen ganzen Lagerkomplex beinhaltenden - Konzentrationslager in Auschwitz, das oftmals nach der Funktion eines Lagers des Lagerkomplexes als Vernichtungslager bezeichnet wird. Vielleicht auch gerade deshalb steht Auschwitz in anderen Kotexten symbolisch für den Holocaust und nationalsozialistischen industriellen Massenmord. Vgl. hierzu Eitz/Stötzel 2007: 76 ff., 342 ff.
} 
Flucht und dem Überleben muss die Verhaftung und Internierung in das Konzentrationslager liegen. Diese Annahme muss im Verstehensprozess eine Rolle spielen, anderweitig kann die Äußerung nicht korrekt verstanden werden. Aber nicht jedes Element im Verstehensprozess, jede Information, die dem evozierten Frame innewohnt, muss von ideologischer Relevanz sein: Damit ist gemeint, dass insbesondere hinsichtlich politischer Sprache eine Trennung naheliegt zwischen Frame-Elementen bzw. Verstehensprozessen, die für das generelle Verständnis (politik-)sprachlicher Äußerungen zwar wichtig sind, denen jedoch keinerlei dezidierte Ideologie oder Intention der Sprecher_innen innewohnt, und solchen, für die Letzteres durchaus gilt. In diesem Ausschnitt ist unter der Berücksichtigung des Kontextes der Rede allein die Tatsache, dass es sich hier um eine zur Zeit des Nationalsozialismus geflüchtete Person handelt, von Belang. In solchen Fällen kann von vordergründigen und hintergründigen Frame-Elementen gesprochen werden.

Gegeben seien nun folgende Textstellen, an denen der Sprecher auf die Krise der europäischen Flüchtlings- und Migrationspolitik referiert (die Auszüge (10) bis (12) folgen im Redefluss unmittelbar einander):

(10) $\left(\left.{ }_{10}\right|_{11}\right)$ Wir haben die Seenotrettung im Mittelmeer zwar wieder verstärkt, aber viele andere Fragen immer noch nicht geklärt: Wie bekämpfen wir die Banden krimineller Schlepper? Wie sehen neue, sichere Formen der Anerkennung von Flüchtlingen aus? Wie werden die Flüchtlinge in Europa gerechter verteilt, wie wird in allen Mitgliedstaaten ein Asylsystem mit ähnlichen Standards aufgebaut? Wie gehen wir menschlich mit abgelehnten $\left(\left.{ }_{11}\right|_{12}\right)$ Asylbewerbern um? Und, nicht unwichtig: Wie regeln wir Einwanderung neben dem Asyl?

Explizite Prädikationen:

- Flüchtlinge werden anerkannt

- Flüchtlinge werden in Europa gerechter verteilt ${ }^{9}$

Flüchtlinge wird als Oberbegriff für sämtliche geflüchtete Menschen (seit dem sog. Sommer der Migration 2015 bzw. der Krise der europäischen Flüchtlingsund Migrationspolitik) verwendet, unabhängig davon, ob rechtlich ein „Flüchtlingsstatus" vorliegt (vgl. *,Wie sehen neue, sichere Formen der Anerkennung von anerkannten Flüchtlingen aus?'). Es werden Personen zu einem Zeitpunkt bezeichnet, an dem sie schon in Deutschland und Europa angekommen

\footnotetext{
${ }^{9}$ An dieser Stelle sei betont: Die expliziten Prädikationen bezeichnen keine Sachverhalte, sondern zeigen an, wie das sprachliche Zeichen in diesem Ausschnitt sprachlich prädiziert wird. Nur weil die Frage nach einer gerechteren Verteilung der Referenzobjekte in Europa gestellt wird, bedeutet dies keineswegs, dass diese gerechtere Verteilung bereits stattfindet.
} 
sind. Es geht um den Umgang mit diesen, die Ausdrücke tragen also jeweils die semantische Rolle des Patiens. (Dem ersten Text-Zeichen mag aufgrund von Anerkennung konkreter auch die Rolle des Benefiziär zugeordnet werden können.)

In (11) schließt das Personalpronomen wir neben dem Sprecher sämtliche Rezipient_innen ein, die potenziell politisch handlungsfähig sind (nicht nur die geladenen Zuhörer_innen), wobei diese Gruppe nicht auf Parlamentarier_innen beschränkt sein muss:

(11) Kurzum: Wie stellen wir sicher, dass wir, bedingt durch die Dimension des Problems, mehr tun? Und zwar mehr von allem: mehr aufnehmen und mehr helfen, zugleich aber besser steuern, schneller entscheiden, und ja, auch konsequenter abweisen - damit wir aufnahmefähig bleiben für diejenigen, zu deren unbedingtem Schutz wir uns verpflichtet haben und die unserer Hilfe stärker bedürfen als andere. (S. 12)

Der Sprecher appelliert in der offenen Frage an das wir, wobei der semantische Gehalt des Verbs tun im Anschluss expliziert wird mittels der Verben aufnehmen und helfen sowie der klimaktisch aufgebauten Staffelung ,besser steuern, schneller entscheiden, und ja, auch konsequenter abweisen': Steuern bezieht sich auf einen Zeitpunkt, zu dem sich die geflüchteten Personen noch nicht zwingend bereits in Deutschland befinden, sondern noch in andere Länder ,verteilt“ werden können. Das Verb drückt hier also den Wunsch des Sprechers nach Kontrolle über die Menschen aus. Entscheiden bezieht sich auf einen Zeitpunkt, zu dem sich die Menschen bereits in Deutschland aufhalten und darüber entschieden werden soll, ob sie bleiben dürfen (vgl. 3.1.1). Abweisen nimmt schließlich Bezug auf die Abschiebung der geflüchteten Menschen aus Deutschland. In und ja liegt eine Verbindung einer Konjunktion (und), die das im Folgenden zu Äußernde an das zuvor Geäußerte rückbindet, und einem Satzäquivalent (ja) vor, das die nachfolgende Äußerung bzw. deren Proposition bekräftigt. Es werden zwei Satzteile verbunden, wobei der zweite den ersten inhaltlich überbietet, denn: Es folgt unmittelbar eine Rechtfertigung in Form der Darlegung des Zwecks (,causa finalis') der Abweisung, die im Diskurs durchaus als umstrittenes Thema gelten kann. Die Aussage dieser Rechtfertigungsäußerung lässt sich grob wie folgt paraphrasieren: ,Wir können gar nicht anders handeln, uns sind die Hände gebunden. Wir haben diese Verpflichtung und der müssen wir nachkommen'. Sie basiert auf der Einstellung, dem Narrativ, dass ein Land oder Staat eine fixierte, numerisch messbare Kapazität hat, zu der es oder er geflüchtete und flüchtende Menschen aufnehmen kann (zu dieser konzeptuellen Container-Metapher vgl. Stefanowitsch 
2019). Die Implikatur dieser Äußerung ist folglich: a), Wenn wir nicht konsequent abweisen, können wir unsere Schutzfunktion, unsere Pflicht, nicht erfüllen. b) ,Wir müssen abweisen, um unsere Pflicht zu erfüllen. ' c), Wir müssen Menschen abweisen, um Menschen aufnehmen zu können.' Dies geht zudem einher mit der expliziten Äußerung, dass es Menschen gibt „die unserer Hilfe stärker bedürfen als andere"; es wird also zwischen unterschiedlichen Graden von Hilfsbedürftigkeit unterschieden, wodurch zugleich bestimmte (nicht genannte) Fluchtgründe für triftiger als andere Gründe befunden werden. Dadurch dass der Fokus auf die geflüchteten Menschen gelenkt wird, wird eine Auseinandersetzung mit dem moralisch schwierigen Thema der Abweisung umgangen. Dies ist deshalb bedeutend, da (11) die Beschaffenheit des Frames, den Flüchtlinge in (12) evoziert, vorbereitet:

(12) In jüngster Zeit ist nämlich erneut die Frage zu hören: Wie viele Flüchtlinge kann unsere Gesellschaft überhaupt verkraften? Eine Nation lebt ja vom Zusammengehörigkeitsgefühl, vom Vertrauen, der Kooperation und vom Mitgefühl unter ihren Bürgern. Flüchtlinge und Zuwanderer erhöhen einerseits die soziale und kulturelle Vielfalt und vergrößern die Innovationskraft der Gesellschaft. Deshalb sprechen wir in diesen Fällen auch von Bereicherung. Andererseits wissen wir aus jüngsten wissenschaftlichen Untersuchungen, dass gegenseitige Rücksichtnahme und die Bereitschaft zur Solidarität innerhalb einer Gesellschaft auch zurückgehen können, wenn etwa die Zahl der Flüchtlinge und Zuwanderer in Ballungsräumen zu schnell und zu stark steigt oder die kulturelle Distanz zu groß erscheint. (S. 12)

Explizite Prädikationen:

- Flüchtlinge werden von einer Gesellschaft verkraftet

- Flüchtlinge erhöhen die soziale Vielfalt

- Flüchtling erhöhen die kulturelle Vielfalt

- Flüchtlinge vergrößern die Innovationskraft der Gesellschaft

Durch das Adverb nämlich wird der nun folgende Teil der Rede inhaltlich an den unmittelbar vorherigen Teil angeschlossen. Die unbeantwortet gelassene Frage ,Wie viele Flüchtlinge kann unsere Gesellschaft überhaupt verkraften?` knüpft dabei inhaltlich an das bereits im vorangehenden Teil der Rede vom Sprecher herangezogene Narrativ der beschränkten Kapazität eines Staates oder Landes für „fremde“ Menschen an. Die Referenzgruppe wird dadurch als Bedrohung oder Last konzeptualisiert: Etwas muss verkraftet werden, wenn es subjektiv als negativ, als etwas zu Bewältigendes empfunden wird. In der Rede sind insgesamt drei Textstellen zu finden, an denen dieses Narrativ bemüht wird. So heißt es bereits vor den in (11) und (12) gegebenen Auszügen: 
(13) Wir wissen, dass weder Deutschland noch Europa insgesamt allen, die dies wünschen, eine Zuflucht und eine Zukunft bieten können. (S. 11)

Das faktive Verb wissen löst die faktive Präsupposition, Weder Deutschland noch Europa können insgesamt allen, die dies wünschen, eine Zuflucht und eine Zukunft bieten' aus. Eine Meinung oder Einstellung zu einem Sachverhalt wird als nüchterner, „objektiver“ Fakt dargestellt, dessen Veräußerung keine weitere Begründung erfordert. Die Hörer_innen bzw. Leser_innen dieser Rede greifen in dem Moment, wenn der Frame evoziert wird und seine Leerstellen zunächst konstruiert als auch daraufhin (zumindest teilweise) mit Werten gefüllt werden müssen, auf bereits vorher im Text angetroffene Informationen zurück. Solche später erneut für das Verstehen relevant werdende Informationen sind in den geschilderten Textstellen u. a. solche, die sich aus dem erwähnten Narrativ bilden.

Der Ausdruck Flüchtlinge steht jedoch nicht nur im referentiellen Zusammenhang mit der Krise der europäischen Flüchtlings- und Migrationspolitik und dem nationalsozialistischen Deutschland. Von den 27 im Fokus der Analyse stehenden Textzeichen, d. h. Flüchtling in sämtlichen deklinierten Formen, konnten zwölf ersterem, eines letzterem Kontext zugeordnet werden; sechs bezeichnen die „Heimatvertriebenen“, d. h. jene Deutsche in den ehemaligen Ostgebieten des Deutschen Reichs und Deutschsprachige aus Ost- und Südosteuropa, die nach 1945 ihre Heimat verlassen mussten (vgl. § 2 BVFG (Bundesvertriebenengesetz)). In der Regel ergibt sich diese Bedeutung durch die Kollokationsbildung mit Vertriebene (vgl. 14). Doch es treten ebenso Fälle auf, in denen Flüchtlinge allein steht und die oben unter Heimatvertriebene beschriebene Personengruppe meint. Beispiele für solche Fälle sind (15) und (16):

(14) Endlich ein tieferes Verständnis der Nachgeborenen für das Trauma ihrer vertriebenen Mütter und Väter, endlich ein tieferes Verständnis von Einheimischen für ihre Nachbarn und Freunde, die einst als Flüchtlinge und Vertriebene gekommen sind (S. 6)

(15) Unbehagen gegenüber den Fremden gab es zu allen Zeiten. Wir erleben es heute, wir erlebten es nach 1945, obwohl es sich bei den Flüchtlingen um Landsleute handelte, die in derselben Kultur verankert waren und zum Teil in derselben nationalen Geschichte. (S. 8)

(16) Vor siebzig Jahren hat ein armes und zerstörtes Deutschland Millionen von Flüchtlingen zu integrieren vermocht. (S. 12)

Explizite Prädikationen:

- Nachbarn kamen als Flüchtlinge 
- Freunde kamen als Flüchtlinge ${ }^{10}$

- Bei Flüchtlingen handelt es sich um Landsleute

- Flüchtlinge werden von Deutschland integriert ${ }^{11}$

Bei der Gegenüberstellung dieser Exzerpte fällt auf, dass der Sprecher dann Flüchtlinge allein zu verwenden scheint, wenn der Kontext ein solcher ist, der auch heute (d. h. im Rahmen der Krise der europäischen Flüchtlings- und Migrationspolitik) noch relevant ist: Für (15) sind dies Vorbehalte der Einheimischen gegenüber dem Fremden, für (16) Integration als Herausforderung, während (14) dagegen von generationenübergreifender, innerdeutscher Empathie handelt. Dadurch dass der Sprecher Flüchtlinge verwendet, aber die für gewöhnlich mittels Heimatvertriebene bezeichnete Personengruppe meint, versucht er, die Parallelen zwischen damals und heute aufzuzeigen, ganz im Sinne seiner zu Beginn der Rede angekündigten Intention. Ein etwas abweichender Fall ist (17), bei dem Flüchtlinge und Vertriebene nicht ausschließlich die „Heimatvertriebenen“ meint:

(17) Deutschland hat also viel Erfahrung mit Flüchtlingen und Vertriebenen, eine positive Erfahrung, auf die wir im öffentlichen Diskurs viel zu selten zurückgreifen. (S. 9)

Die Bedeutung des Wortes Flüchtlingen ergibt sich hier nicht durch die Kollokation mit Vertriebenen, der Ausdruck bezieht sich vielmehr auf sämtliche bis zu dieser Stelle im Text angesprochene geflüchtete Menschen: die „Heimatvertriebenen“, „Flüchtlinge aus der DDR“ (S. 8), ,aus kommunistischen Staaten Ostund Mitteleuropas“ (S. 8 f.) und „Flüchtlinge[...] aus Bürgerkriegsgebieten, Militärdiktaturen und zerfallenden Staaten, [wie] Griechenland [...] Türkei, Iran oder Jugoslawien“ (S. 9). Es liegt somit eine Text-emergente Bedeutungsstruktur dieses Ausdrucks vor. Demzufolge ist für (18) festzuhalten, dass hier ebenso nicht

\footnotetext{
${ }^{10}$ Dem möglichen Einwand, dass in (14) nicht eher etwas über die Nachbarn bzw. Freunde ausgesagt werde als über die Flüchtlinge, kann so begegnet werden: als zeigt, dass mittels Flüchtlinge auf eine soziale oder besser: von der Gesellschaft wahrgenommene Rolle verwiesen wird. Einst und die Verwendung des Perfekts (vgl. gekommen sind) zeigen, dass diese Rolle nur temporär getragen wurde und mittlerweile (vor dem Moment der Sprecheräußerung) abgelegt wurde. Die beiden Prädikationen erlauben somit durchaus eine Aussage über die Referenzobjekte, nämlich zu deren zeitweise „Identität“.

${ }^{11}$ Zum Zwecke der strukturellen Vereinheitlichung wird sich bemüht, dass der frameevozierende Ausdruck nur in der syntaktischen Funktion des Subjekts auftritt. In wenigen Fällen ist dies jedoch nicht möglich, möchte man sich möglichst nahe am sprachlichen Datenmaterial halten.
} 
ausschließlich die „Heimatvertriebenen“ bezeichnet werden, sondern dieselben Personengruppen wie in (17):

(18) Wir müssen uns immer wieder daran erinnern, welch großen Anteil Flüchtlinge und Vertriebene am erfolgreichen Aufbau Deutschlands hatten. (S. 12)

Der Ausdruck Flüchtlinge kann also zahlreiche unterschiedliche Frames evozieren. „Unterschiedlich“ meint dabei nicht nur die Differenzen auf der frame-typologisch höheren Ebene des Zeitbezugs (etwa flüchtlinge.ns_zeit vs. flüchtlinge.ddr_zeit vs. flüchtlinge.seit_sommer_2015), sondern auch innerhalb dieser Typen (z. B.: Geht es bzgl. flüchtlinge.seit_sommer_2015 um die Fluchtursachen oder um die möglichen Konsequenzen für die Aufnahmegesellschaft?). Die Beschaffenheit der Leerstellen und/oder die Standard- und Füllwerte über die evozierten Frames hinweg fallen sodann auf beiden (und weiteren) Ebenen unterschiedlich aus. Für den Großteil der expliziten Prädikationen gilt, dass sich diese der Leerstelle „Eigenschaften“ zuschreiben lassen. Die erläuterten Bezeichnungspraxen gehen dabei qua Eigenschaftsattribuierung mit einer strategisch-geplanten Frame-Konstruktion einher.

\subsubsection{Heiko Maas (Bundesaußenminister, 17.12.2019)}

Der Bundesminister des Auswärtigen Heiko Maas (SPD) hielt im Dezember 2019 eine Rede zur Eröffnung des Globalen Flüchtlingsforums in Genf. ${ }^{12}$ Diese handelt von der finanziellen Unterstützung anderer Aufnahmeländer und dem Beitrag zur Entwicklungshilfe durch die Bundesrepublik Deutschland sowie von Investitionen und Beiträgen Deutschlands zur Förderung von geflüchteten Menschen in Deutschland selbst.

Hinsichtlich der inhaltlichen Argumentationsführung des Sprechers kann die Rede in drei Teile gegliedert werden: Nachdem der Sprecher im ersten Teil das Problem darstellt und im zweiten Teil Lösungsmöglichkeiten postuliert, kommt er im dritten Teil der Rede darauf zu sprechen, wie Deutschland bereits zur Problemlösung beiträgt, indem er die Unterstützung erläutert, die Deutschland hinsichtlich der weltweiten politischen Herausforderungen mit flüchtenden und geflüchteten Menschen leistet: Finanzielle Hilfe für die Türkei, Erhöhung

\footnotetext{
$12<$ https://www.bundesregierung.de/breg-de/service/bulletin/bulletin-2010-bis-2019/rededes-bun desministers-des-auswaertigen-heiko-maas--1709078> (06.12.2021).
} 
der Resettlement-Plätze ${ }^{13}$ und der Gelder für humanitäre Hilfe und Fortsetzung der Entwicklungshilfe (S. 2 f.). ${ }^{14}$ Der zweite Teil der Aufzählung handelt von der Förderung geflüchteter Menschen im Bildungsbereich: der Unterstützung von deutschen Stipendiengebern und Stiftungsinitiativen, der Schaffung von Arbeitsplätzen im Nahen Osten und der Förderung der Bildung vor Ort und in Deutschland selbst (S. 4 f.). Übergeordnetes Ziel der Rede ist somit, Deutschlands wichtige Rolle in dieser Thematik darzustellen und zudem zu begründen, warum und wie es diese Rolle aus- und seine Pflicht erfüllt. Im Folgenden wird anhand einiger Beispiele gezeigt, wie der Ausdruck Flüchtlinge in der vorliegenden Rede verwendet wird, wobei die oben aufgeführten Themen wieder aufgegriffen werden. $\mathrm{Zu}$ Beginn der Rede heißt es:

(19) Nein, es gibt keine Flüchtlingskrise. Denn die Zahl von Flüchtlingen weltweit ist in Wirklichkeit nur das Symptom einer ganz anderen Krise: einer tiefen Krise der internationalen Zusammenarbeit. (S. 1)

Es liegt nahe, dass der Sprecher hier den Ausdruck Flüchtlingskrise kritisiert. ${ }^{15}$ Dieser Ausdruck trägt in sich die Behauptung, eine bestimmte Personengruppe (die Flüchtlinge) befände sich in einer Krise; tatsächlich scheint in diesem Fall die Bezeichnung dem bezeichneten Sachverhalt nicht gerecht zu werden. Denn dieser besteht aus den politischen und gesellschaftlichen Reaktionen und Verhaltensweisen weltweit im Umgang mit den Herausforderungen, die eine erhöhte Zahl an flüchtenden und geflüchteten Menschen mit sich bringt. Diese Art und Weise des Umgangs stellt die eigentliche Krise dar. Der Sprecher erläutert seine These, dass sich die „internationale Zusammenarbeit“ in „einer tiefen Krise“ befindet, durch eine anschließende Explikation dessen, was genau er unter dieser Krise versteht:

\footnotetext{
${ }^{13}$ Das Bundesinnenministerium gibt hierzu folgende Definition: „Resettlement stellt ein international anerkanntes flüchtlingspolitisches Instrument dar und bedeutet die Neuansiedlung von durch UNHCR [United Nations High Commissioner for Refugees; d. Verf.] anerkannten, besonders schutzbedürftigen Flüchtlingen in einem anderen Staat als dem Erstaufnahmestaat. Ziel des Resettlement ist es, eine dauerhafte Lösung und Perspektive für geflüchtete Menschen zu schaffen, die langfristig weder eine Perspektive auf Rückkehr in ihr Herkunftsland noch auf Integration im Erstaufnahmeland haben. Resettlement ermöglicht damit besonders schutzbedürftigen Personen die legale und sichere Einreise in einen aufnahmebereiten Drittstaat.“ (<https://www.bmi.bund.de/DE/themen/migration/asyl-fluech tlingsschutz/humanitaere-aufnahmeprogramme/humanitaere-aufnahmeprogramme-node. html> (06.12.2021)).

${ }^{14}$ Die Seitenangaben beziehen sich auf die Seitenzahlen des PDF-Dokuments, das unter dem in Anm. 12 angegebenen Link zum Download verfügbar ist (Stand: 06.12.2021).

${ }^{15}$ Nach dem Kenntnisstand des Verfassers ist dies das erste Mal, dass ein_e Träger_in eines politischen Amtes in Regierungsfunktion diesen Ausdruck kritisiert.
} 
(20) Immer mehr Menschen fliehen, weil wir, die internationale Gemeinschaft, keine Lösungen finden für die Dauerkrisen und Konflikte wie in Syrien, Afghanistan oder Somalia, um nur einige zu nennen [...] Gerade einmal 20 Prozent der 193 Staaten beteiligen sich in nennenswerter Weise bei der Versorgung der über 70 Millionen Menschen, die weltweit auf der Flucht sind. Und dies, obwohl die Genfer Flüchtlingskonvention für uns alle gilt. (S. 1)

Was zunächst nach Selbstkritik klingen mag, dient jedoch der inhaltlichen Vorbereitung dessen, was im restlichen Verlauf der Rede gesagt wird - zur Kohärenzbildung. Im Anschluss an die Problembenennung intendiert der Sprecher, ein positives Bild der Bundesrepublik Deutschland in ihrer Rolle als Geldgeberin und Unterstützerin der internationalen Staatengemeinschaft zu zeichnen. Dass der Sprecher Deutschland als Vorreiter stilisiert, wird in (21) deutlich:

(21) Die Botschaft, die von diesem globalen Treffen ausgehen muss, lautet: Wir wollen mehr Solidarität im Umgang mit Flüchtlingen! Mehr internationale Zusammenarbeit mit den Aufnahmeländern! Mehr Multilateralismus! (S. 2)

Das Personalpronomen wir wird in inklusiver Bedeutung verwendet: Es schließt neben dem Sprecher selbst die direkt im Publikum Anwesenden ein, d. h. sämtliche an diesem "globalen Treffen" teilnehmenden Personen bzw. die durch sie vertretenen Staaten. Obgleich sie als „Botschaften“ bezeichnet werden, kommen die Exklamativsätze Forderungen gleich. Siehe hierzu zudem (22):

(22) [...] blicken wir auf das, was wir ändern müssen. Erstens: Wir müssen die Lasten auf mehr und auf breitere Schultern verteilen. Und zweitens: Wir müssen Flüchtlingen Perspektiven bieten für ein selbstbestimmtes Leben, ein Leben in Würde. (Kursiv im Original; PN; S. 2)

Wir in blicken wir weist eine inklusive Funktion im Sinne des oben erwähnten wir auf, wir in wir ändern und wir müssen schließt jedoch neben dem Sprecher selbst nicht nur das anwesende Publikum ein, sondern auch sämtliche Träger_innen eines politischen Amtes in Regierungsfunktion (zu denen der Sprecher gehört). Die Adressat_innen dieser Forderungen gehen, auch wenn dieses mitangesprochen wird, über das physisch präsente Publikum vor Ort hinaus.

In (23) bilden den inhaltlichen Kontext des ersten bzw. zweiten zu untersuchenden sprachlichen Zeichens innenpolitische Maßnahmen bezüglich der Personen, auf die referiert wird, bzw. ihrer politischen Wahrnehmung durch die Ankunftsgesellschaft. Der Ausdruck wir umfasst hier erneut neben dem Sprecher selbst seine Kolleg_innen in Deutschland sowie das anwesende, internationale Publikum. Deshalb erscheint plausibel, dass der Ausdruck Flüchtlinge 
hier sämtliche geflüchtete Menschen bezeichnet, nicht nur diejenigen, die sich in Deutschland befinden:

(23) Lasst uns Flüchtlingen bessere Perspektiven bieten. Das setzt voraus, dass wir unseren Blick auf Flüchtlinge ändern. Wir reden in der internationalen Zusammenarbeit ständig von Resilienz und wie wir sie stärken können. Warum fördern wir dann nicht gezielt diejenigen, die bereits ein riesiges Maß an Resilienz bewiesen haben? Menschen, die wissen, was es bedeutet, alles zu verlieren und wieder neu anfangen zu müssen? (S. 3)

Explizite Prädikationen:

- Flüchtlingen werden bessere Perspektiven geboten

- Flüchtlinge werden anders betrachtet

(23) ist ein gutes Beispiel für einen Frame, der zunächst mit einigen Standardwerten ,auskommen“ muss, da die Leerstellen nur marginal durch den Kontext mit spezifischen Werten gefüllt werden. Erst durch die Explizierungen des Sprechers , diejenigen, die bereits ein riesiges $\mathrm{Ma} ß$ an Resilienz bewiesen haben " und ,Menschen, die wissen, was es bedeutet, alles zu verlieren und wieder neu anfangen zu müssen' werden die Personen, auf die Bezug genommen wird, näher bestimmt oder: Leerstellen gefüllt. Als eine der Leerstellen lässt sich „Eigenschaften“ herausarbeiten. Diese Eigenschaften, diese „Lebensleistungen“, werden fokussiert, um das Verdienst der Studierenden und Akademiker_innen unter den geflüchteten Menschen, finanziell gefördert zu werden, zu untermauern.

Leerstellen eines Frames, die gewöhnlich selbst bei isolierter Erscheinung des den Frame evozierenden sprachlichen Zeichens gefüllt sein dürften, ${ }^{16}$ können jedoch mitunter selbst bei Einbettung in einen größeren Text unbesetzt bleiben: Weder in (23) selbst noch im vorangegangenen Text werden Informationen zu den Leerstellen „Herkunftsland“, „Aufenthaltsland“ oder „Fluchtursache“ gegeben, konkrete, sprachlich realisierte Füllwerte liegen nicht vor. Interessant ist hier aus frame-theoretischer Sicht, ob die Leerstellen zu diesem Zeitpunkt tatsächlich unbesetzt bleiben oder doch mit (Standard)Werten besetzt werden. Die „typischen“ Standardwerte (zumindest diejenigen der vorgeschlagenen Leerstellen) sind zu diesem Zeitpunkt der Rede nicht relevant, um die Intention des Sprechers nachvollziehen zu können, d. h. es ist für den Verstehensprozess z. B. nicht wichtig, wo genau sich die geflüchteten Menschen nun befinden. Für die beiden ersteren Leerstellen mag ,weltweit“ angenommen werden können, da der

\footnotetext{
${ }^{16}$ Wie etwa bei einem Assoziationsexperiment.
} 
Sprecher keine genauen Informationen gibt und es somit naheliegt, dass sämtliche flüchtende und geflüchtete Menschen weltweit bezeichnet werden. Solch eine Annahme mag zwar inhaltlich höchst vage sein und keinerlei individualitätsstiftende Informationen über die Personen, um die es gerade geht, zur Verfügung stellen, muss sie zu diesem Zeitpunkt des Verstehensprozesses jedoch auch nicht. Eine Information über ein Frame-Element, genauer: ein Füllwert, kann folglich aus frame-analytischer Sicht auch aus der Absenz sprachlich gegebener Informationen gewonnen werden. Der Sprecher setzt schließlich fort:

(24) Davon profitieren gerade auch die Aufnahmeländer. Wie sehr, das ist mir erst heute Morgen noch einmal deutlich geworden, als ich mit einigen jungen Flüchtlingen hier gesprochen habe, die in Deutschland leben. Einer von ihnen ist Muhammed Shikhani. Er musste 2013 vor dem Krieg in Syrien fliehen. (S. 314) In Damaskus hatte er Bauingenieurwesen studiert. Im Libanon aber, mit einer Million weiterer syrischen Flüchtlingen, fand er allenfalls Gelegenheitsjobs und lebte zudem in ständiger Angst davor, nach Syrien zurückkehren zu müssen.

Bei dem Adverb davon handelt es sich um eine Anapher im linguistischen Sinne: Es wird ein Rückbezug zur Förderung geflüchteter Menschen in (23) hergestellt. Mit der Ellipse (vollständig: ,Wie sehr die Aufnahmeländer davon profitieren") und der Schilderung einer subjektiven Erfahrung sowie persönlichen Begegnung im nachfolgenden Satz verleiht der Sprecher seiner Forderung Nachdruck. Die Leerstellen des Frames zu Flüchtlinge werden sukzessive gefüllt bzw. die Eigenschaften derjenigen Personen, von denen der aktuale Teil der Rede handelt, näher beschrieben. Dies geschieht durch das Heranziehen quasi-konkreter Exemplare, die stellvertretend für die gemeinten Personen fungieren: Die Leerstelle „Altersschicht“ wird mit dem Wert ,jung“ gefüllt, die Leerstelle „Aufenthaltsland“ mit dem Wert „Deutschland“. Mittels einer weiteren (linguistischen) Anapher in diesem Redeteil, nämlich einer von ihnen, liefert der Sprecher ein konkretes Exemplar dieses Frames, wobei die Leerstelle „Bildungsschicht“ mit dem Wert „Studierender" gefüllt wird. Der Sprecher nennt bzgl. des Exemplars den Namen, das Jahr der Flucht, die Fluchtursache, das Herkunftsland, das Studienfach, den Ort der Universität, das zwischenzeitliche Aufenthaltsland und sozioökonomische bzw. psychologische Probleme, um darauf hin zu weisen, dass aus seiner Sicht Aufnahmeländer durchaus von „Flüchtlingen“, „profitieren“ können. Für den Frame, auf den der Sprecher hinausmöchte, ist insbesondere die sich auf die Ausbildung beziehende Information „Studierender“ wichtig.

Abb. 4.1 verdeutlicht, wie der intendierte Frame, d. h. die spezifische Gruppe geflüchteter Menschen, auf die sich der Sprecher beziehen möchte, im Verlaufe 
dieser Textstelle sprachlich konstruiert wird - wie gesehen mittels intersententialer Anaphorik. In diesem emergenten Prozess gelangt der_die Verstehende von einem überaus vagen Begriff der bezeichneten Personen(gruppe) (vgl. „weltweit") durch die strukturelle und inhaltliche Anreicherung des Frames zu einem spezifischen Begriff der bezeichneten Personen(gruppe), der aus der Summe der einzelnen sprachlichen Näherbestimmungen besteht. Dabei können nebenher andere Frames zum selben, jedoch in einer anderen syntaktischen Umgebung eingebetteten, sprachlichen Zeichen abgerufen werden. Ein Beispiel stellt derjenige mit den Leerstellen „Herkunft“ (Füllwert: „Syrien“), „Aufenthaltsland“ (,Libanon“) und „Anzahl“ (,eine Million“) dar (vgl. „Im Libanon aber, mit einer Million weiterer syrischen Flüchtlingen [...]") (vgl. (24)).

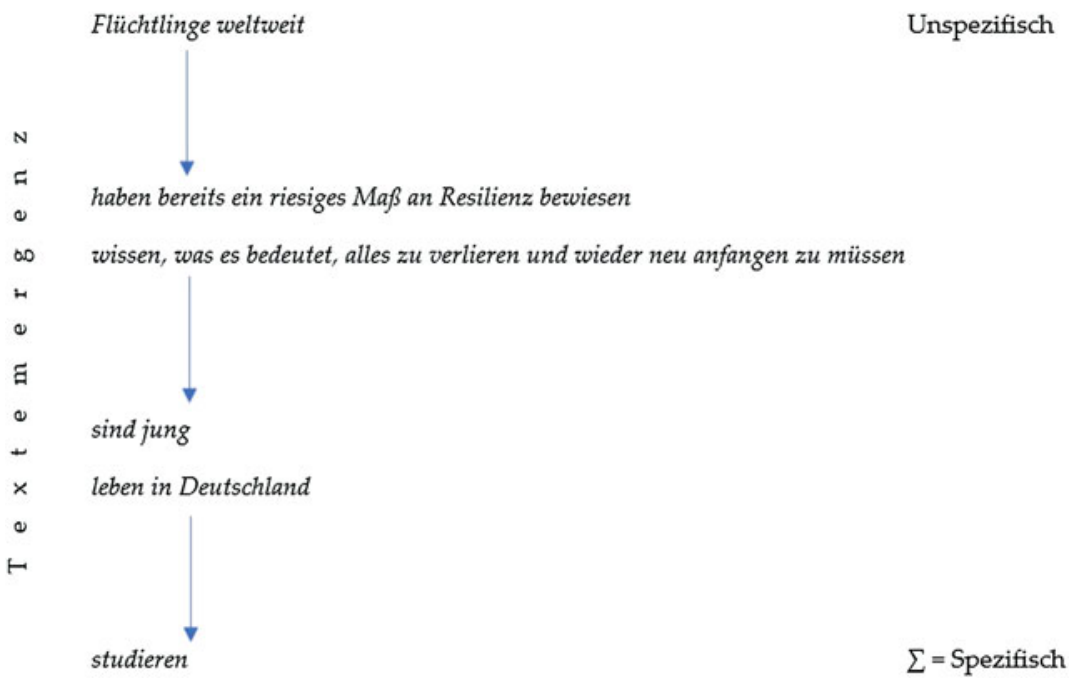

Abb.4.1 Sukzessiver Aufbau eines intendierten Frames zu Flüchtlinge in der Rede von Heiko Maas. Den Kern der Darstellung bilden die extrahierten Prädikationen. (Quelle: Eigene Darstellung)

Der Ausdruck Flüchtlinge wird in der vorliegenden Rede in zahlreichen unterschiedlichen inhaltlichen Kontexten verwendet. Folgende kontextuelle Codes wurden erarbeitet $(\mathrm{P}=$ Personen, auf die referiert wird $)$ :

- Menge (ausdrucksseitig: numerische Angabe) $(\times 4)$ 
- Aufnahme $(\times 3)$

- Generelle Hilfe für P $(\times 3)$ (Innenpolitische Maßnahmen $(\times 2)$, Unterstützung der P)

- (Akademische) Bildung $(\times 3)$

- Lage/Perspektiven der P $(\times 3)$

- Integration $(\times 2)$

- Genereller Umgang

- Politische Wahrnehmung

- Persönliche Begegnung des Sprechers

- Krise

An diesen Codes kann zweierlei abgelesen werden: Zum einen problematisiert der Sprecher nicht die flüchtenden und geflüchteten Menschen selbst, sondern den Umgang der globalen Staatengemeinschaft mit ihnen bzw. den Situationen, die Flucht verursachen. Zum anderen wirkt die Rede überaus konstruktiv, werden doch politische Handlungsfelder eröffnet und konkrete Handlungen in der Vergangenheit wie in der Zukunft benannt. Auch wenn diese Erkenntnisse ob des situativen Kontextes, in den die Rede eingebettet ist, nicht überraschend sein mögen, zeigen sie doch, wie das oftmals als konnotativ negativ dargestellte Wort Flüchtling neutral oder gar positiv verwendet werden kann.

\subsection{Die Frames im vorliegenden Textkorpus}

\subsubsection{Vorbemerkungen}

Nachdem im vorangehenden Abschnitt politische Reden analysiert wurden, sollen unter Erweiterung des methodischen Instrumentariums in den folgenden drei Unterabschnitten einige Presseausschnitte aus dem Korpus darauf untersucht werden, wie die Ausdrücke Flüchtling, Geflüchtete_r und Migrant_in eingebettet sind. „Einbettung“ meint zum einen den Sachkontext, d. h. die Situation, auf die der Text i.S. der Gesamtheit des Artikels, in dem die Textstelle mit dem zu untersuchenden Ausdruck auftritt, Bezug nimmt. Zum anderen meint sie zudem den Kotext, d. h. die Wörter in der Umgebung des Zielwortes. Es werden Prädikationen aufgestellt, mittels derer eine Charakterisierung der jeweiligen Elemente der durch die drei Ausdrücke evozierten Frames ermöglicht wird. Untersuchungsgegenstand ist demnach eine „politische Mediensprache“, die Sprache, die Medien gebrauchen, um über politisch relevante Sachverhalte zu berichten. 
Das Korpus für die Analyse der Presseausschnitte setzt sich aus vier Teilkorpora zusammen, wobei jedes Teilkorpus durch die Eingabe eines Suchbegriffs in die DWDS-Datenbank ${ }^{17}$ generiert wurde. Als auf den Seiten des DWDS zu durchsuchendes Korpus wurde das ZEIT-Korpus ausgewählt, da dieses unter sämtlichen verfügbaren Korpora am nächsten an den Zeitpunkt, an dem die Daten erhoben wurden, heranreichte. Der Untersuchungszeitraum wurde auf 2013 bis $2018^{18}$ festgelegt, dem Parameter Sortierung wurde die Einstellung zufällig zugewiesen. Die Teilkorpora 01 bis 03 bestehen jeweils sodann aus den ersten 100 zufällig sortierten Korpusbelegen zum Lemma Flüchtling bzw. Geflüchtete_r bzw. Migrant. Da die Suche nach letzterem Lemma lediglich die männlichen Formen anzeigte, wurde durch die Eingabe des Wortes Migrantin ein viertes Teilkorpus generiert. ${ }^{19}$

Ist bzgl. der politischen Reden eine strategisch-geplante Frame-Gestaltung durch den_die Sprachproduzent_in festzuhalten, gilt dies für die Presseartikel nicht pauschal. Denn kontemporäre Journalist_innen und Zeitungen werden von Nachrichtenagenturen mit Beiträgen beliefert, die sie ,integral verwerte[n] ohne sie zu kennzeichnen, ${ }^{20}$ oder [...] partiell um[schreiben], um sie als redaktionelle Eigenleistung erscheinen zu lassen“ (FPSM ${ }^{21}$ 2017: 150). Presse und Rundfunk berichten über das, was ihnen von den Agenturen zugespielt wird. Durch

\footnotetext{
${ }^{17}$ Digitales Wörterbuch der deutschen Sprache; <dwds.de $>$.

${ }^{18}$ Für das Jahr 2018 standen zum Erhebungszeitpunkt jedoch lediglich Korpusbelege für den Monat Januar zur Verfügung. Sollten allgemeine, d. h. über das vorliegende Korpus hinausgehende, quantitative Aussagen getroffen werden, wurde deshalb das Deutsche Referenzkorpus (abgerufen über Cosmas II (<cosmas2.ids-mannheim.de>)) herangezogen.

${ }^{19}$ Es wurden sowohl Singular- als auch Pluralformen angezeigt. Eine Suche nach Migrant* liefert zusätzlich Komposita und kam deshalb nicht in Frage.

${ }^{20}$ „Kennzeichnen“ meint hier , mit einem Kürzel versehen', hinter dem sich die Agentur verbirgt: $\mathrm{Zu}$ den global operierenden Agenturen gehören die Associated Press (AP) (USA), die Agence France-Presse (AFP) (Frankreich) und die Reuters (Vereinigtes Königreich, 2008 gekauft und fusioniert zu Thomson-Reuters mit Sitz in New York). Für den deutschsprachigen Raum sind die Deutsche Presse-Agentur (DPA), die Austria Presse Agentur (APA) und die Schweizerische Depeschenagentur (SDA) zu nennen (FPSM 148: 2017).

${ }^{21}$ Die durch den Verfasser vorgenommene Abkürzung FPSM steht für Forschungsgruppe zu Propaganda in Schweizer Medien. Als Seitenzahlen wurden die Seitenzahlen des PDFDokuments angegeben, da in der vorliegenden E-Book-Version keine Seitenzahlen vermerkt sind.
} 
diese Abhängigkeit entsteht ,,eine frappierende Gleichartigkeit in der internationalen Berichterstattung [.] Medien [berichten] oftmals über dieselben Themen und verwenden dabei sogar vielfach dieselben Formulierungen [...]“ (dies.: 152). ${ }^{22}$

Jedoch muss zwischen unterschiedlichen Arten von Presseartikeln differenziert werden: Das dieser Arbeit zugrundeliegende Korpus konstituiert sich neben einfachen Meldungen zudem u. a. aus Hintergrundberichten und Analysen, die in der Regel zwischen Langteaser und Datumsangabe durch den Namen des_der Autor_in gekennzeichnet werden. Für die einfachen Meldungen kann den (Mitarbeiter_innen der) Presse-Agenturen durchaus eine interessensgeleitete Frame-Konstruktion unterstellt werden, insofern als diese in diesem Zusammenhang gleichbedeutend mit der Bildung der öffentlichen Meinung ist. Den Sprachproduzent_innen, die die Beiträge zumeist schlicht übernehmen oder nur geringfügig ändern, dies in diesem Fall zu unterstellen, scheint jedoch nicht tragbar. Was Hintergrundberichte und Analysen anbelangt, liegt zwar nahe, dass die Informationen für solche Artikel wiederum ebenfalls aus Agenturen stammen müssen, jedoch wird in Artikeln solcher Art den Verfasser_innen weitaus mehr Gestaltungsfreiheit zuteil als in einfachen Meldungen, auch im Sinne der Wahl der sprachlichen Mittel. Je nachdem, wie groß jene Gestaltungsfreiheit dann ist, mag den Sprachproduzent_innen eine intentionale Frame-Konstruktion unterstellt werden können (die jedoch freilich wiederum auf unbewusste Prozesse zurückgehen mag). Gewiss übernehmen selbst ausgebildete Journalist_innen wie jedes menschliche Individuum häufig auch unbeabsichtigt bestimmte Frames und setzen sie in ihren Texten ein. Für gewöhnlich machen sie sich jedoch Gedanken darüber, in welchen Kontext sie einen Ausdruck stellen.

Aus kommunikationswissenschaftlicher Perspektive gilt: Je mehr positive bzw. negative Kognitionen (hier i.S. bewertender Wahrnehmung von bestimmten Sachverhalten) bestehen, desto positiver bzw. negativer ist die Einstellung der Rezipient_innen zum Einstellungsobjekt, in unserem Fall den Personen(gruppen), auf die sich bezogen wird (Scheufele 2003: 66). Ganz gleich, ob die ursprünglichen Verfasser_innen der Meldungen in den Agenturen oder die Journalist_innen selbst verantwortlich zeichnen: Medien wirken derart, dass sie ,bestimmte Sachverhalte hochspielen und sie für Rezipienten im ersten Schritt salienter machen.

\footnotetext{
${ }^{22}$ Von fremdsprachigen Agenturen stammende und ins Deutsche übersetzte Meldungen könnten darauf untersucht werden, in welchen Fällen ,refugees' als Flüchtlinge oder als Geflüchtete übersetzt wird und ob diesbezüglich Muster erkennbar sind.
} 
Im zweiten Schritt gleichen die Rezipienten ihre Einstellung diesen salienten Kognitionen an, um kognitiv-affektive Konsistenz herzustellen“ (ders.: 66 f.). ${ }^{23}$

\subsubsection{Frames zu Flüchtling}

Fraas (1996) bildet auf Basis des ihr vorliegenden Datenmaterials für ihre Analyse der Konzepte Deutsche und Identität zunächst Prädikationsmuster (die oberflächenstruktureller Natur sind), die sie sodann in Prädikationsklassen (die inhaltlicher Natur sind) einteilt, die wiederum bestimmten Leerstellen zugeordnet werden können. Dies soll zunächst exemplarisch im Folgenden auch auf das dieser Arbeit vorliegende Korpus angewendet werden. So lassen sich u. a. folgende (singuläre) Prädikationsmuster feststellen ( $X$ steht für das zu prädizierende Konzept (Flüchtlinge bzw. Flüchtling), $Y$ wird durch die Elemente bzw. das Element in der Liste festgelegt):
A. Y hat angeboten, ab einem noch zu bestimmenden Stichtag X zurückzunehmen die Türkei
B. Y würde X gewissermaßen durchreichen Tschechien
C. $\mathrm{Y}$ rechnet mit $\mathrm{X}$ die Bundesregierung
D. Y hat die Bundesregierung aufgefordert, $\mathrm{X}$ aufzunehmen die Bischöfin im Sprengel Hamburg und Lübeck, Kirsten Fehrs
E. Y hat mehr Deutschunterricht für X verlangt der SPD-Vorsitzende Sigmar Gabriel

F. Y rechnete schon im März mit einer neuen Rekordzahl von X in Europa der Chef der EU-Grenzschutzagentur Frontex, Fabrice Leggeri

\footnotetext{
${ }^{23}$ Scheufele (2003: 67) gibt im Anschluss ein Beispiel: „Indem Medien Abtreibung in einen ,Lebens-Frame“ stellen, vermitteln sie negative Kognitionen, die Rezipienten zu einer negativen Einstellung gegenüber $\$ 218$ bringt. Ein ,Selbstbestimmungs-Frame` vermittelt dagegen positive Kognitionen.“
} 
G. Y stellt Übernahmeersuchen mit der Bitte X zurückzunehmen Berlin

Die Muster bilden gemeinsam die Prädikationsklasse der Sprecher_innen, die als Akteur_innen im Umgang mit den Flüchtenden und Geflüchteten auftreten. Dabei geht es sowohl um politisches Handeln als auch die Vorbereitung dessen. Dass einzelne Prädikationen aus unterschiedlichen Prädikationsmustern eine Prädikationsklasse konstituieren können, zeigt sich zudem darin, dass die Prädikationsklasse „Angabe zum Herkunftsort“ aus Prädikationen der Prädikationsmuster $\mathrm{Y}=$ LINKSATTRIBUT $\mathrm{X}$ sowie $\mathrm{X}$ AUS $\mathrm{Y}$ besteht:

H. $\mathrm{Y}=$ LINKSATTRIBUT $\mathrm{X}$ (Auswahl)

tausende / jeden / weitere / syrisch $(2 \mathrm{x})$

I. X AUS Y

Syrien (2x) / Syrien und Irak / Ländern wie Afghanistan, Syrien, dem Sudan und dem Irak/Ländern des Westbalkan

Des Weiteren spiegeln die folgenden Prädikationsmuster den Gebrauch des frameevozierenden Ausdrucks als Attribut wider:

$\mathrm{X}$ als Genitivattribut:

J. Y DER X

Not / Herkunft / tägliches Leben / Problem / Unterbringung / Internierung / Gleichbehandlung (aller)

$\mathrm{X}$ als Präpositionalattribut:

K. Y VON $\mathrm{X}^{24}$

Verteilung / Versorgung (2x) / starker Andrang / Aufnahme und Unterbringung / Rückführung / sicherheitsrelevante Überprüfung / Registrierung / neue Rekordzahl / Integration / Abschiebung / mehr Rechte

L. Y FUR X

Schutzstatus / Hilfe / mehr Deutschunterricht / Schweigeminute / Sammelpunkt / Kosten / einheitlicher Ausweis

\footnotetext{
${ }^{24}$ Hier sei angemerkt, dass K ,im semantischen Sinne“ ebenso als Genitivattribut angesehen werden kann, da der Gebrauch der Präposition von allein der Tatsache geschuldet ist, dass der Ausdruck von einem unbestimmten Artikel im Plural (,Nullartikel“) begleitet wird, vgl. Die Verteilung der Flüchtlinge vs. Die Verteilung von Flüchtlingen.
} 
M. Y ZU X

Kontakt

N. Y MIT X

Sonderzug / Bus / Frachter / Länder

Die bis zu diesem Punkt aufgestellten Prädikationsmuster sind strikt an der Oberflächenstruktur der sprachlichen Äußerungen, die den frame-evozierenden Ausdruck enthalten, orientiert, d. h. Die Verteilung von Flüchtlingen bspw. wird noch nicht in die Prädikation Flüchtlinge werden verteilt aufgelöst. Dies soll der besseren Vergleichbarkeit dienen und die Brücke zu den Kookkurrenzen schlagen, die das DWDS-Wortprofil zum Lemma Flüchtling zeigt: ${ }^{25}$

Die Bezugswörter Versorgung, Aufnahme, Rückführung und Abschiebung aus K. sind allesamt unter den ersten zehn Kookkurrenzpartnern in der Kategorie hat Genitivattribut vertreten, Aufnahme, Rückführung und Abschiebung zudem unter den ersten fünf Kookkurrenzpartnern in der Kategorie ist in Präpositionalgruppe. Des Weiteren vervollständigt ein Blick auf die Kategorie ist Akk./Dativ-Objekt von mit abschieben an erster, aufnehmen an dritter und versorgen an sechster Stelle das Bild, dass auf Basis des der Arbeit vorliegenden Korpus, das lediglich einen kleinen Ausschnitt des Diskurses abbildet, bereits einige diskurs-zentrale ${ }^{26}$ sprachliche Prädikatoren erörtert werden konnten. Gerade bezüglich der Werte Rückkehr und Rückführung sowie abschieben und zurückschicken, die jeweils die ersten beiden Plätze der betreffenden Kategorie einnehmen, ist davon auszugehen, dass diese mit dem Suchbegriff in einem überaus engen sprachlichen Verhältnis stehen, mit ihm eine Kollokation bilden. Die inhaltliche Natur der Kollokatoren spiegelt dabei wider, dass subjektive Belange der Personen(gruppe), über die gesprochen wird, nicht thematisiert werden, sondern der politische, abstrahierte, auf Exklusion zielende Umgang im Vordergrund steht.

Welche Aussagen können unter Einbezug derartiger Kollokationen oder Prädikationsmuster nun über die Leerstellen des Frames getroffen werden? Bzgl. der Prädikationsmuster ergibt sich zunächst noch ein analysetechnisches Problem:

\footnotetext{
${ }^{25}$ Stand: 22.07.2020.<https://www.dwds.de/wp?q=Fl\%C3\%BCchtling>.

${ }^{26}$ Dem DWDS-Wortprofil liegt ein ,knapp 3 Mrd. Tokens umfassendes Zeitungskorpus aus überregionalen Tages- und Wochenzeitungen“ zugrunde $(<\mathrm{https} / / / \mathrm{www} . d w d s . d e / \mathrm{d} / \mathrm{res}$ sources >; 06.12.2021). Deshalb kann davon ausgegangen werden, dass die darin festgehaltenen Kookkurrenzen repräsentativ für den Gesamtdiskurs fungieren.
} 
Hinsichtlich der Muster J. Y DER X und K. Y VON X können quasi-explizite ${ }^{27}$ Prädikationen in der Regel mittels einer Passivkonstruktion aufgestellt werden:

- Unterbringung der $\mathrm{x} \rightarrow$ Flüchtlinge werden untergebracht

- Internierung der $\mathrm{X} \rightarrow$ Flüchtlinge werden interniert

- Verteilung von $\mathrm{X} \rightarrow$ Flüchtlinge werden verteilt

- Versorgung von $\mathrm{X} \rightarrow$ Flüchtlinge werden versorgt

Doch bei den folgenden Fällen verhält es sich diffiziler:

- tägliches Leben der $\mathrm{x} \rightarrow$ Flüchtlinge haben (?) ein tägliches Leben (redundant?)

- mehr Rechte von $\mathrm{X} \rightarrow$ Flüchtlinge haben (?) mehr Rechte (entspricht nicht dem Textsinn)

$\mathrm{Ob}$ und wie beobachtete Kollokationen zu einer Prädikation umgeformt werden können, muss von Fall zu Fall entschieden werden. Nicht jedes Prädikationsmuster, nicht jede Kollokation ist für eine Aufstellung von Prädikationen brauchbar - auch vor dem Hintergrund, dass umständliche Formulierungen möglichst vermieden werden müssen, da der_die Forschende anderweitig Gefahr läuft, den ursprünglichen Sinn der Sprachdaten zu verfälschen, indem er_sie die Daten ,vorinterpretiert".

Nachdem die formalen Prädikationsmuster $\mathrm{J}$ mit $\mathrm{N}$, sofern möglich, in Prädikationen umgewandelt worden sind, ergeben sich folgende Prädikationsmuster:

O. X.SUBJ WERDEN Y

untergebracht / interniert / gleichbehandelt / verteilt / versorgt / aufgenommen / rückgeführt / überprüft / registriert / integriert / abgeschoben / geschützt

P. X.OBJ WIRD Y

Hilfe zuteil / mehr Deutschunterricht zuteil / einheitlicher Ausweis zugeteilt

Die Prädikationen bilden die Prädikationsklasse ,Wie gestaltet sich der konkrete politische Umgang mit den geflüchteten Menschen?“, die sich mit ebendiesem

${ }^{27}$ Ziem nennt quasi-explizit all jene Prädikationen, die auf Fälle zurückgehen, in denen ,ein Referenzobjekt auf eine bestimmte Art und Weise epistemisch näher bestimmt wird, nämlich entweder durch (i) ein Attribut (im weiten Sinne), (ii) eine Präpositionalphrase oder (iii) einen Relativsatz“ (2008: 332). 
epistemischen Inhalt als Leerstelle des Frames festhalten lässt, dessen Füllwerte wiederum die oben unter $\mathrm{O}$ und $\mathrm{P}$ aufgeführten Kontextualisierungen bilden. ${ }^{28}$

Man betrachte im Folgenden einige konkrete Einbettungen des Ausdrucks:

(25) Knapp 500 Flüchtlinge aus Birma sind nach einer zweiwöchigen Schiffsfahrt in Malaysia an Land geschwommen. (01.01.2013)

Es können folgende explizite Prädikationen extrahiert werden:

- Flüchtlinge kommen aus Birma

- Flüchtlinge sind in Malaysia an Land geschwommen

- Flüchtlinge sind zwei Wochen auf einem Schiff gefahren

- Die Anzahl der Flüchtlinge beträgt knapp 500

Das bedeutet hinsichtlich der Leerstellen (LS) und Füllwerte (FW) des Frames, den Flüchtlinge evoziert:

- LS „Herkunftsland“ mit FW „Birma“

- LS „Aufenthaltsland““ mit FW „Malaysia“; der_die Verstehende kann ohne zusätzliche Information nicht wissen, ob es sich bei „Malaysia“ um das Zielland handelt oder es nur eine (geplante oder ungeplante) Durchgangsstation auf dem Weg in das eigentliche Zielland darstellt.

- LS „Handlung“ mit FW ,schwimmen“

- LS „Art und Weise der Flucht“" (Wie?“) mit FW „Schiff“

- LS „Dauer“ („Wie lange?“) mit FW „,Zwei Wochen“; möglicherweise weist der gesamte Prozess der Flucht eine höhere Dauer auf; das Adjektiv zweiwöchig bestimmt das Nomen Schiffsfahrt näher, das möglicherweise (unter Umständen voreilig) im Verstehensprozess mit dem semantischen Gehalt des Nomens Flucht gleichgesetzt wird.

- LS „Anzahl“ mit FW „500“

Bei der Frame-Analyse geht es nicht nur um konkrete, d. h. perzipierbare, sprachliche Daten, sondern auch darum, vorausgesetztes, nicht an der Oberfläche realisiertes Wissen ,nach außen zu stülpen“. So fragte sich Fillmore (1977: 72), warum man eine Frau, die ihren Ehemann ermordet hat, nur zögerlich als Witwe bezeichnen dürfte. Dem Ausdruck Witwe muss scheinbar etwas zu eigen sein, das eine solche Verwendung ad absurdum führt. Eine mögliche Erklärung ist: Im Frame zu Witwe ist gespeichert, dass der Tod des Ehemannes ohne ein Zutun der Ehefrau eingetreten sein muss.

${ }^{28}$ Busse spricht deshalb auch von ,,epistemischen Prädikationen“ (2012: 688 f.). 
Um solche Bedeutungsaspekte oder frame-semantisch formuliert: FrameElemente nach außen zu kehren wird nun der Ausdruck Flüchtlinge in (25) durch den Ausdruck Touristen ersetzt (dieses Prozedere sei fortan Substitutionsprobe genannt):

(25') Knapp 500 Touristen aus Birma sind nach einer zweiwöchigen Schiffsfahrt in Malaysia an Land geschwommen.

Während der Satz grammatikalisch einwandfrei ist, wirkt er nun semantisch betrachtet zwar nicht falsch, zumindest jedoch etwas schief, da ihm lediglich vor dem Hintergrund (situativen Frame) einer für besonders abenteuerlich gesinnte Tourist_innen organisierten Urlaubsaktivität Sinn verliehen werden kann. Warum aber wirkt der Satz (25) ganz und gar nicht schief? Es muss an dem verwendeten Lexem liegen, dass der Gebrauch des Verbs schwimmen nicht sonderbar erscheint: Der Frame FLÜCHTLINGE muss in (25) eine weitere Information beinhalten, die nicht sprachlich realisiert, jedoch beim Verstehensprozess aktiviert wird. Diese Information mag dem Wissen gleichkommen, dass Schiffe mit geflüchteten Menschen in aller Regel an Häfen oder Küsten nicht anlegen dürfen und somit die einzige Möglichkeit für die geflüchteten Menschen, das Festland zu erreichen, darin besteht, über Bord zu springen und die verbleibende Distanz zu schwimmen. An diese Information ist weiteres Wissen gebunden, wie Wissen um die Kriminalisierung von Nicht-Regierungs-Organisationen und der geflüchteten Menschen selbst. Dieses Wissen um die Notsituation, in der sich die geflüchteten Menschen befinden, macht nun das Verb schwimmen erwartbar. Nur durch die Aktivierung dieses Hintergrundwissens kann schwimmen und damit auch der gesamte Satz korrekt verstanden werden. Jede Abweichung von semantischen Erwartungen führt beim Verstehensprozess zu einem höheren kognitiven Arbeitsaufwand i.S. zusätzlicher Suchprozesse im Gedächtnis (vgl. Rösler 2011: 365). ${ }^{29}$

Man betrachte nun (26), in dem die Bezeichnung der Personengruppe als Genitivattribut gebraucht wird und neben dem Frame zu Flüchtlinge ein weiterer Frame interessant ist:

${ }^{29}$ Hieße es z. B. Knapp 500 Flüchtlinge aus Birma sind nach einer zweiwöchigen Schiffsfahrt in Malaysia an Land gesprintet wäre bei Verstehenden womöglich eine sog. N400Komponente zu erwarten, die bei neurolinguistischen Experimenten ,immer dann im EEG auftritt, wenn eine aus dem Kontext entwickelte semantische Erwartung durch die gerade wahrgenommene Information nicht erfüllt wird, [wobei] ,semantisch“ [...] sehr allgemein im Sinne einer Bedeutungszuweisung zu verstehen [ist], die mit dem Weltwissen vereinbar ist" (Rösler 2011: 365). 
(26) Der Libanon hat die internationale Gemeinschaft zur Unterstützung bei der Versorgung der Flüchtlinge aus Syrien aufgerufen. (04.01.2013)

Hier bildet nicht der Ausdruck selbst die Nominalphrase wie in (25), vielmehr fungiert die den Ausdruck inkludierende Nominalphrase der Flüchtlinge aus Syrien als Genitivattribut der Präpositionalphrase bei der Versorgung. Da sich Prädikatsausdrücke durch Substantive (hier: Versorgung) in Verbalphrasen ausdrücken lassen (Ziem 2008: 410), können folgende explizite Prädikationen extrahiert werden:

- Flüchtlinge kommen aus Syrien $\rightarrow$ LS „Herkunftsland“ mit FW „Syrien“

- Flüchtlinge werden versorgt $\rightarrow$ LS ,politischer Umgang“ (vorläufig so genannt) mit FW ,werden versorgt“

Daraus resultiert die Frage „Wer soll versorgen?“. Es muss zusätzlich der Frame VERSORGUNG betrachtet werden, den der Füllwert ,,versorgt“ der Leerstelle „Politischer Umgang“ des Frames FLÜCHTLINGE evoziert: Die Argumentstruktur zu versorgen (und damit einige Leerstellen des Frames VERSORGUNG) kann durch die Frage ,Wer versorgt wen womit wozu (,quam ad rem') warum (,cur')? beschrieben werden, wovon folgende realisiert (gefüllt) sind bzw. angenommen werden können:

- Wer? (Agens) $\rightarrow$ FW: „Der Libanon“

- Wen? (Benefiziär) $\rightarrow$ FW: „Flüchtlinge“

- Womit? (Thema) $\rightarrow$ mögliche Standardannahmen: „Lebensmittel“, „medizinische Hilfe"

Flüchtlinge ist sonach zur gleichen Zeit ein Füllwert der Leerstelle „Benefiziär“ des Frames VERSORGUNG. Hier wird deutlich, dass beim Textverstehen ganze Frame-Netze wirken und Frames einen rekursiven Charakter aufweisen, d. h., dass Frames selbst wieder aus Frames bestehen und in größere Frames eingebettet sein können (vgl. die graphische Darstellung des Frames in Anhang 4 im elektronischen Zusatzmaterial).

Eine weitere mögliche Leerstelle ist diejenige des momentanen Aufenthaltslandes der Flüchtlinge. Problematisch ist jedoch, dass deren Füllwert („Libanon“) nicht unmittelbar (wie z. B. mittels der Präposition in) sprachlich realisiert (syntaktisch eingebettet) wird und mithin zu diesem Zeitpunkt aus dem gegebenen 
sprachlichen Material inferiert werden bzw. aus zuvor angeeignetem Wissen stammen muss. Es handelte sich also um eine implizite Prädikation. Im weiteren Text heißt es:

(27) Das Kabinett teilte nach einer Sitzung am Donnerstagabend mit, sie wolle die Arabische Liga und internationale Organisationen zu einem Dringlichkeitstreffen auffordern, um ihnen die Lage der Flüchtlinge zu erklären. (04.01.2013)

Es liegt nahe, dass die Regierung eines Landes lediglich dann berechtigt ist, Regierungen anderer Länder ,zu einem Dringlichkeitstreffen aufzufordern“ (s. o.) und ,die Lage der Flüchtlinge zu erklären“ (s. o.), wenn dieses Land unmittelbar betroffen ist. Die (26) betreffende Inferenz kann durch (27) bestätigt werden, notwendig ist dieser zusätzliche Kontext jedoch nicht. Dass (26) auch ohne weitere sprachliche Information verstanden werden kann, liegt am durch Erfahrung gebildeten und akkumulierten Wissensspeicher der Verstehenden. Dieser Speicher könnte z. B. folgende Information enthalten: „Der Libanon ist ein Nachbarland Syriens“. Oder: „Im Libanon halten sich überaus zahlreiche aus Syrien geflüchtete Menschen auf“. (Die zweite Proposition mag eine logische Folgerung der ersten Proposition darstellen, ihr Gehalt kann jedoch auch ,gewusst“ werden, ohne den Gehalt der ersten Proposition zu ,wissen“.) Hier handelt es sich um ,diskursspezifisch produziertes und im Diskurs vorausgesetztes Wissen“ (Ziem 2008: 411), das bei der Analyse ignoriert werden muss, um „Objektivität“ sicherzustellen, auch wenn es für den Verstehensprozess Voraussetzung sein dürfte (ebd.).

Man betrachte nun folgendes Exzerpt:

(28) Versteckt in einem Transporter sind in Angola 16 [...] Flüchtlinge aus der Demokratischen Republik Kongo ums Leben gekommen. (06.01.2013)

Daraus ergeben sich die expliziten Prädikationen und Frame-Elemente:

- Flüchtlinge kommen ums Leben

- Flüchtlinge kommen aus der Demokratischen Republik Kongo

- Flüchtlinge befinden sich in Angola

- Flüchtlinge verstecken sich in einem Transporter

- Die Anzahl der Flüchtlinge beträgt 16

- LS „Eigenschaften“ mit FW ,gestorben“

- LS „Herkunftsland“ mit FW „Demokratische Republik Kongo“

- LS ,(Zwischenzeitliches) Aufenthaltsland“ mit FW „Angola“

- LS „Handlungen“ (ggf. gleichzusetzen mit „Art und Weise der Flucht“) mit FW „,sich verstecken in Transporter“ 
- LS ,Anzahl“ mit FW „16“

Bei der Substitutionsprobe wird erneut deutlich, dass im Frame zu Flüchtlinge noch ein weiterer Aspekt enthalten sein muss:

(28') Versteckt in einem Transporter sind in Angola 16 Touristen aus der Demokratischen Republik Kongo ums Leben gekommen.

Beim Versuch, Satz (28') zu verstehen, kommt womöglich eine Frage auf, die sich in (28) nicht zwingend stellt: Warum sollten sich die Menschen, auf die sich bezogen wird, in einem Transporter verstecken? Da es sich um eine Nachrichtenmeldung handelt, ${ }^{30}$ ist von Folgendem auszugehen: Wer sich versteckt, möchte nicht gefunden werden, da er_sie eine Handlung ausführt/ausführte, die falsch oder sogar illegal ist/war. Wird der_diejenige entdeckt, wird der_diejenige sicherlich einer Strafe begegnen müssen. Durch das Verstecken wird somit der Versuch unternommen, der Bestrafung zu entgehen. ${ }^{31} \mathrm{Um}$ die Verwendung des Verbs verstecken in (28) verstehen zu können, müssen die Verstehenden sonach den Grund für das Verstecken wissen, nämlich dass die Flucht etwas Falsches, Illegales ist und kriminalisiert wird. Um dem Ort des Verstecks (ausgedrückt durch das sprachliche Zeichen Transporter) Sinn zu verleihen, müssen die Verstehenden zudem wissen, dass sich flüchtende und geflüchtete Menschen an Personen wenden, die ihnen bei einem Teil ihrer Flucht helfen, indem sie sie ,transportieren“. Tatsächlich wurde (28) durch den Verfasser manipuliert. Im Original heißt es nämlich:

\footnotetext{
${ }^{30}$ Der Satz und der Gesamtartikel, in dem der Satz steht, sind selbst in einen übergeordneten Frame, den ,Nachrichten-Frame“ (vgl. van Dijk 1988), eingeordnet. Dadurch können die Verstehenden von jeder Meldung annehmen, dass diese ausreichend Relevanz besitzt, um in den Nachrichten zu erscheinen, und deshalb auf irgendeine Art und Weise ,wichtig“ ist. Noch konkreter wird dieses Hintergrundwissen der Verstehenden beim Blick auf das Stichwort, unter dem die Meldung erscheint (etwa Politik oder Flüchtlinge). So werden andere Bedeutungen von verstecken ausgeschlossen und die oben im Fließtext geschilderten Annahmen werden aktiviert. (Denn grundsätzlich ist, wenn von Verstecken gesprochen wird, auch denkbar, dass eine Kurzgeschichte vorliegt, in der Kinder Verstecken spielen.)

${ }^{31}$ Dass sich verstecken nicht zwingend bedeuten muss, dass der_die sich Versteckende nicht gesehen werden kann, zeigt der Fall Edward Snowden. Snowden kann von überall gut gesehen werden, auch von den USA. Diese können ihn jedoch strafrechtlich nicht belangen. Es geht also generell beim Verstecken nicht primär um das Nicht-Gesehen-Werden-Können, sondern - metaphorisch gesprochen - um das Nicht-Angefasst-Werden-Können, obgleich in (28) Ersteres gewiss gleichbedeutend mit Zweiterem ist.
} 
(28”) Versteckt in einem Transporter sind in Angola 16 illegale Flüchtlinge aus der Demokratischen Republik Kongo ums Leben gekommen. (06.01.2013)

Wie gezeigt, ist die sprachliche, ausdrucksseitige Information ob der Illegalität (die sich auf den illegalen Grenzübertritt bezieht) jedoch nicht notwendig, um den Satz verstehen zu können. Dies zeigt, dass der erläuterte Aspekt der Kriminalisierung flüchtender und geflüchteter Menschen Teil des Frames FLÜCHTLINGE ist; er ist erwartbar. So fungiert er auch im Diskurs zur Krise der europäischen Flüchtlings- und Migrationspolitik als Standardwert des type-Frames, da es schlichtweg nach der Schließung der Balkanroute keine legalen Fluchtwege mehr gibt und jede Flucht, jeder „Flüchtling“, aus EU-Sicht illegal ist. ${ }^{32}$

Neben dem Rückgriff auf Argumentstrukturen gibt es noch eine weitere Möglichkeit, die Leerstellen zu ermitteln, die ein Frame bündelt: Bei der lexikographischen Vorgehensweise der Hyperonymtypenreduktion (Konerding 1993) werden die Lexikoneinträge der jeweiligen Ausdrücke auf Hyperonyme untersucht und so lange verfolgt, bis das ,oberste“ Hyperonym angetroffen wird bzw. sich eine zirkuläre Verweisstruktur abzeichnet. Als Nachschlagewerk wurde die offizielle Webpräsenz des Duden (duden.de) ausgewählt:

a) Flüchtling $\rightarrow$,Person, die aus politischen, religiösen, wirtschaftlichen oder ethnischen Gründen aus ihrer Heimat geflohen ist ${ }^{* 33}$

b) Geflüchtete bzw. Geflüchteter $\rightarrow$,,weibliche“34 bzw. „männliche Person, die aus politischen, religiösen, wirtschaftlichen oder ethnischen Gründen aus ihrer Heimat geflohen ist" "35

c) Migrant bzw. Migrantin $\rightarrow$,jemand, der in ein anderes Land, in eine andere Gegend, an einen anderen Ort abwandert ${ }^{* 36}$; der Eintrag $\mathrm{zu}$ jemand verweist daraufhin erneut auf „Person“. 37

\footnotetext{
${ }^{32}$ Für eine graphische Darstellung des Frames siehe Anhang 4 im elektronischen Zusatzmaterial.

$33<$ https://www.duden.de/rechtschreibung/Fluechtling > (06.12.2021).

$34<$ https://www.duden.de/rechtschreibung/Gefluechtete>(06.12.2021).

$35<$ https://www.duden.de/rechtschreibung/Gefluechteter>(06.12.2021).

$36<$ https://www.duden.de/rechtschreibung/Migrant>(06.12.2021); unter Migrantin erscheint „weibliche Form zu Migrant“ (<https://www.duden.de/rechtschreibung/Mig rantin>; 06.12.2021)).

$37<$ https://www.duden.de/rechtschreibung/jemand>(06.12.2021).
} 
Jeder der drei zur Untersuchung stehenden frame-evozierenden Ausdrücke kann sonach qua Hyperonymtypenreduktion auf den Matrixframe PERSON (Konerding 1993: 322) zurückgeführt werden, der seine Leerstellen an die zugehörigen Sub-Frames vererbt. Ziem (2008: 406 ff.) zeigt am Beispiel des Ausdrucks Finanzinvestor, dass hier durchaus eine fruchtbare Methode zur Bestimmung der Leerstellen vorzuliegen scheint. Aus den über 20 Leerstellen des Matrixframes PERSON, genauer: „Person mit temporärer oder dauerhafter Eigenschaft/Disposition bzw. in besonderem Zustand" (denn Konerding unterscheidet diesen Frame von dem zu „Person in berufsbezogener Rolle) (1993: 324 ff.) seien einige ausgewählt:

Tab.4.1 Eine Auswahl der möglichen Leerstellen der Frames, die die zu untersuchenden Ausdrücke aufrufen

\begin{tabular}{l|l}
\hline$\#$ & Leerstelle des Matrix-Frames \\
\hline$(1)$ & Wie ergeht es der Person mit dieser Eigenschaft? \\
\hline$(2)$ & $\begin{array}{l}\text { Welche besonderen Dispositionen weist die Person aufgrund dieser Eigenschaft } \\
\text { auf? }\end{array}$ \\
\hline$(3)$ & $\begin{array}{l}\text { In welchen Handlungen - oder für die Person wichtigen funktionalen } \\
\text { Zusammenhängen - spielt die Eigenschaft der Person eine bestimmte Rolle? }\end{array}$ \\
\hline$(5)$ & $\begin{array}{l}\text { In welchen funktionalen Zusammenhängen haben die Eigenschaften der Person } \\
\text { ihren Ursprung? }\end{array}$ \\
\hline$(6)$ & $\begin{array}{l}\text { Was hat (hatte) das Auftreten der Eigenschaften zur Voraussetzung? } \\
\text { Eigenschaften bei der Person? }\end{array}$ \\
\hline
\end{tabular}

Die „temporäre oder dauerhafte Eigenschaft“ kann bzgl. Flüchtling mit „geflüchtet sein/flüchtend" beschrieben werden. An das vorliegende Konzept angepasst, werden die Leerstellen des Matrixframes (4), (5) und (6) zur Leerstelle „Fluchtursache“ zusammengefasst. Es seien sodann die folgenden Ausschnitte betrachtet:

(29) Keiner der Asylsuchenden aus den Balkan-Staaten wurde im vergangenen Jahr als Flüchtling anerkannt. (15.01.2013)

(30) Er kam als Flüchtling nach Holland. (14.01.2013)

In (29) repräsentiert der Ausdruck eine beständige, formale Kategorie, die durch juristisch-politische Arbeit erschaffen wurde und auf Basis derer Recht gesprochen wird. Es wird sich auf den inhaltsseitigen Aspekt des rechtlichen Status 
bezogen, dieser Bezug wird über die Anerkennung bzw. das Anerkannt-Sein vorgenommen. Anerkennung als und anerkennen als bilden im DWDS-Wortprofil zum Lemma Flüchtling in der Kategorie ist in vergl. Wortgruppe die beiden typischsten Werte (logDice 9.8 bzw. 9.6). ${ }^{38}$ Zudem nimmt anerkannt im Wortschatz der Universität Leipzig, dem ein ,deutsches Nachrichten-Korpus basierend auf Texten gecrawlt 2018 mit 46.843.422 Sätzen“39 zugrunde liegt, für das Eingabewort Flüchtling in der Liste der 60 häufigsten rechten Nachbarn den zweiten Platz ein. Dies zeigt, dass der Ausdruck Flüchtling durchaus eine typische Verwendung in seiner Bedeutung der juristisch-politischen Kategorie erfährt (vgl. hierzu auch Stefanowitsch 2019). Es ist von entscheidender Bedeutung für das Leben der geflüchteten Menschen, ob sie zu dieser Kategorie gehören, in diesem Fall also das Recht haben, Asyl zu beantragen. Unter dieser Betrachtung drückt die Kategorie einen Vorteil gegenüber anderen, nämlich denjenigen, die nicht anerkannt werden, aus. Eine solche Kategorienbedeutung des Ausdrucks ist in einer anderen Sphäre lokalisiert als eine alltäglich-gesellschaftliche, nämlich der juristisch-politischen. Denn für den Gebrauch in der Alltagssprache ist - wie bereits erwähnt - meist unerheblich, ob den Personen, auf die referiert wird, tatsächlich der „Flüchtlingsstatus“ nach der GFK zugesprochen wird.

Nun kann die Frage gestellt werden, inwiefern hier dem instantiierten Frame ein eigener (d. h. juristisch-politisch zu verstehender) type-Frame zugrunde liegt. Die Bedeutung eines Wortes darf jedoch keineswegs mit dem durch dieses Wort evozierten Frame gleichgesetzt werden. Unterschiedliche Wörter können denselben Frame evozieren, sodann jeweils aus verschiedener Perspektive thematisieren (vgl. buy, sell, pay und den durch sie evozierten Frame ,commercial

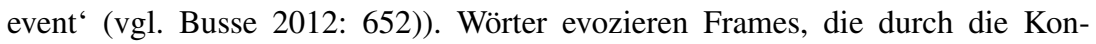
textualisierung durch andere Wörter (Einbettung) hinsichtlich ihrer möglichen Leerstellen und Füllwerte eingeschränkt werden; bestimmte (Gruppen von) Leerstellen und Füllwerte werden fokussiert. Heißt es also ,Er wurde als Flüchtling anerkannt', perspektiviert der Kotext den evozierten Frame insofern, dass die Leerstelle (3) des Matrix-Frames „In welchen für die Person wichtigen funktionalen Zusammenhängen spielt die Eigenschaft der Person eine bestimmte Rolle?“ mit dem Wert „rechtliche Anerkennung" gefüllt wird, andere Leerstellen, wie „Herkunftsland“ oder „Art und Weise der Flucht“, aber frei bleiben. Die Verstehenden müssen sonst mit Standardannahmen und Inferenzen auskommen. Wissen sie um die Kriterien, die eine Person erfüllen muss, um nach der GFK den

\footnotetext{
${ }^{38}$ Stand: $22.07 .2020 .<$ https://www.dwds.de/wp?q=Fl\%C3\%BCchtling >

$39<$ https://corpora.uni-leipzig.de/de?corpus Id=deu_newscrawl-public_2018 $>$ (06.12.2021).
} 
„Flüchtlingsstatus“ zu erhalten, können sie u. a. die den obengenannten Leerstellen zuzuordnenden Werte inferieren; die inferierten Werte bleiben jedoch bis zu dem Zeitpunkt, an dem konkrete Daten verfügbar, d. h. perzipierbar, sind, Standardwerte i.S.v. „Mutmaßungen“.

Wie in (29) wird in (30) der Nullartikel gebraucht. Flüchtling gilt demnach unter Berücksichtigung der Ergebnisse in Unterabschnitt 3.1.3 und kraft der Funktion des Wortes als, das Bezugswort näher zu erläutern, in beiden Fällen als Lebensrolle. Trotz aller sozialen Konsequenzen, die mit dem „Flüchtlingsstatus“ verbunden sind, ist diese Rolle in (29) jedoch zuallererst eine juristische, die der bezeichneten Person durch eine übergeordnete Staatsgewalt attribuiert wurde. In (30) dagegen liegt eine soziale Rolle im eigentlichen Sinne vor. Es wird der gesellschaftlich relevante Zustand einer Person beschrieben, in dem sie sich vorübergehend befand. Die Person, auf die referiert wird, hat diesen Zustand vor dem Äußerungsakt erworben, indem sie die grundlegenden Eigenschaften erfüllte, um von Bürger_innen der Aufnahmegesellschaft als Flüchtling fremdbezeichnet und wahrgenommen werden zu können (wozu indes nicht unbedingt eine rechtliche Anerkennung vorliegen muss).

Die Äußerung in (30) impliziert, dass die Person im Moment der Äußerung kein Flüchtling mehr ist und diese Rolle nur temporär trug, d. h. die Voraussetzungen, um als Flüchtling kategorisiert zu werden, (zumindest bis zu einem gewissen Grad) in der Zwischenzeit ablegte. Im Frame wird die Leerstelle „Zielland“ mit dem Wert „Holland“ gefüllt. Aus dem gesamten Text, in den der Satz eingebettet ist, ${ }^{40}$ geht hervor, dass ,Zielland“ mit „Aufenthaltsland“ gleichzusetzen ist, die Person, auf die referiert wird, sich demgemäß nach wie vor in diesem Land befindet.

Wie kann im Frame die Information enthalten sein, dass hinsichtlich des mit dem Wort ausgedrückten Konzepts eine Lebensrolle vorliegt? Eine Möglichkeit: Die Leerstelle (3) des Matrix-Frames ist Teil des type-Frames und deren Standardwert heißt: ,in jedem Zusammenhang“. Dieser mag sodann durch Kontextualisierung verworfen werden und ein konkreter(er) Wert wie ,im rechtlichen Zusammenhang" tritt als Füllwert an seine Stelle. Oder etwas anders argumentiert: Allein an der Tatsache, dass der Ausdruck als Lebensrolle gebraucht wird bzw. gebraucht werden kann (Er ist Flüchtling und Er kam als Flüchtling) wird deutlich, dass diese Eigenschaft der bezeichneten Person für den_die Sprecher_in im Moment der Äußerung von Bedeutung ist.

\footnotetext{
${ }^{40}$ W. $\quad$ Duk: $<$ https://www.zeit.de/wissen/2013-01/minenraeumer-mine-kafon-has sani> (06.12.2021).
} 
Durch den Matrix-Frame konnte eine Leerstelle ermittelt werden, die weder an den erweiterten Argumentstrukturen erkennbar noch mittels der ,forensischen Topoi“ feststellbar ist. Wie es sich mit den zu erwartenden Leerstellen „Herkunftsland“ (,woher?“) und „Zielland“ (,wohin?“) verhält, wird im Folgenden untersucht:

(31) Die Türkei hat angeboten, ab einem noch zu bestimmenden Stichtag jeden Flüchtling, der über die Türkei nach Griechenland kommt, zurückzunehmen, wenn ihr dafür die gleiche Zahl von syrischen Flüchtlingen abgenommen wird, die bereits in der Türkei leben. (17.03.2016)

(32) Dorthin würde auch Tschechien Flüchtlinge gewissermaßen durchreichen, sofern Berlin zustimmt. (01.09.2015)

Mit „Herkunftsland“ sei das Land gemeint, aus dem die Personen, auf die referiert wird, stammen und/oder in dem sie bis zur Flucht lebten. In manchen Fällen kann sich dieses von dem Geburtsland oder Land, in dem sie aufwuchsen, unterscheiden; dieses Land sei mit „Heimatland“ bezeichnet. In der Regel entsprechen „Herkunftsland“ und „Heimatland“ jedoch einander. Das „Zielland“ sei sodann das Land, in das sich die Personen selbstständig bewegen (wollen/werden) oder nach politischem Beschluss bewegen (sollen). Zuletzt sei das „Aufenthaltsland“ das Land, in dem sich die Personen zum Zeitpunkt bzw. im Kontext der sprachlichen Äußerung befinden, unabhängig davon, ob sie dort bleiben werden. Das „Aufenthaltsland“ kann sonach das ehemalige „Zielland“ sein, wenn Hoffnungen der betroffenen Subjekte erfüllt werden.

Der Frame FLÜCHTLING in (31), einem Konditionalgefüge, gestaltet sich daraufhin durchaus komplex. Betrachtet werden muss der gesamte Hauptsatz ,Die Türkei $_{a}$ hat angeboten, ab einem noch zu bestimmenden Stichtag jeden Flüchtling, der über die Türkei ${ }_{b}$ nach Griechenland kommt, zurückzunehmen.' Türkei $i_{a}$ bezeichnet die türkische Regierung, Türkei $i_{b}$ die geopolitische Region. Dann kann Folgendes für den Frame festgehalten werden:

- LS „Aufenthaltsland“ mit FW „Griechenland“ (vgl. nach Griechenland)

- LS „Durchgangsland/Zwischenzeitliches Aufenthaltsland“ mit FW „Türkei“ (vgl. über die Türkei)

- LS „Zielland“ mit FW „Türkei“ (vgl. Die Türkei hat angeboten ... zurückzunehmen)

Die Füllwerte der Leerstellen „Zwischenzeitliches Aufenthaltsland“ und „Zielland" entsprechen demzufolge einander, kraft der Semantik des Präfix des Verbs zurücknehmen. 
Für den Frame FLÜCHTLINGE im Bedingungssatz kann konstatiert werden:

- LS „Herkunftsland“ mit FW „Syrien“

- LS „Aufenthaltsland“ mit FW „Türkei“

In (32) fungiert wie in (31) ein Land (ausdrucksseitig) bzw. eine Regierung eines Landes (inhaltsseitig) als Akteur und die Flüchtenden und Geflüchteten als Behandelte. Aus dieser Rolle des über eine Handlung Kontrolle Ausübenden ergibt sich, dass das Aufenthaltsland der Personen, auf die Bezug genommen wird, Tschechien sein muss. Für den Frame FLÜCHTLINGE gilt somit:

- LS „Aufenthaltsland“ mit FW „Tschechien“; das sprachliche Zeichen Tschechien ist dabei bisemantisch: die Regierung bzw. die geopolitische Region werden bezeichnet.

Strenggenommen handelt es sich bei dem Füllwert der Leerstelle „Aufenthaltsland" um eine Inferenz, die der_die Verstehende kognitiv bewerkstelligt, da die sprachlichen Daten ein Aufenthaltsland nicht konkret benennen. Tschechien wird als die tschechische Regierung verarbeitet. Das Verb durchreichen fordert einen Start- und einen Zielpunkt sowie eine Strecke (vgl. das Präfix durch-). Der Name des Startpunktes Tschechien ergibt sich durch den Umstand, dass die tschechische Regierung als Akteurin auftritt, und ist äquivalent zum momentanen Aufenthaltsland der Personen, auf die der Ausdruck referiert. Bedingt durch die Semantik des Verbs durchreichen liegt nahe, dass dieser Aufenthalt von verhältnismäBig kurzer Dauer sein dürfte. Der Zielpunkt ergibt sich (anaphorisch) aus dem vorangehenden Textausschnitt, s. (32'):

(32') Doch Tausende sind schon da, warten am Ostbahnhof von Budapest auf die Weiterreise, bevorzugt nach Deutschland und in andere westeuropäische Staaten. Dorthin würde auch Tschechien Flüchtlinge gewissermaßen durchreichen, sofern Berlin zustimmt. (eigene Hervorhebung (PN); 01.09.2015)

- LS „Zielland“ mit FW „Deutschland und andere westeuropäische Staaten“

Das Lokaladverb dorthin wird hier anaphorisch gebraucht und verweist auf nach Deutschland und in andere westeuropäische Staaten. Dass sich das Adverb nur auf nach Deutschland bezieht, ist allein aus Gründen der Sprachverarbeitung unplausibel. Zudem besteht die Erfordernis einer Zustimmung der Deutschen 
Bundesregierung (vgl. metonymischer Ausdruck Berlin) auch falls die bezeichneten Subjekte in andere Staaten Westeuropas gebracht werden sollen, da der kürzeste Weg aus Tschechien nach Westeuropa über Deutschland führt. (Es wäre wohl enorm unpraktisch, etwa eine Route über Österreich und die Schweiz zu wählen.)

Für sämtliche instantiierten Frames in (31) und (32) gilt zudem, dass die Leerstelle (3) des Matrixframes PERSON ,In welchen für die Person wichtigen funktionalen Zusammenhängen spielt die Eigenschaft der Person eine bestimmte Rolle?“ - wie in (29) - mit dem Füllwert ,rechtlicher Zusammenhang“ besetzt wird. Diese analytische Erkenntnis basiert jedoch nicht auf einer expliziten Prädikation: Während in (29) noch der direkt perzipierbare Wert anerkannt gegeben ist, der als Konkretisierung des rechtlichen Rahmens gelten kann, muss aus dem Textzusammenhang im Artikelausschnitt inferiert werden, dass es sich um einen rechtlichen Zusammenhang handelt.

Man betrachte nun einen weiteren Fall:

(33) Jetzt donnert Strache: „Von den Flüchtlingen hat keiner einen Pass, aber jeder hat ein Handy. Und damit rufen sie an in der Heimat und es spricht sich rum, dass man hier nicht arbeiten muss.“(14.10.2017)

Explizite Prädikationen:

- Flüchtlinge haben keinen Pass

- Flüchtlinge haben ein Handy

- Flüchtlinge rufen mit dem Handy in der Heimat an

Die ersten beiden Prädikationen geben Füllwerte der Leerstelle „Eigenschaften“, letztere den Füllwert der Leerstelle „Handlungen“. In diesem instantiierten Frame FLÜCHTLINGE muss jedoch eine weitere Leerstelle enthalten sein: „Einstellung der Sprecher_in zum Referenzobjekt“. Diese muss durch die Interpretationsarbeit des_der Untersuchenden gefüllt werden, da konkrete Füllwerte diesbezüglich nur in den seltensten Fällen explizit sprachlich realisiert werden und es sich um ein Meta-Frame-Element handelt. Wie im frame-theoretischen Teil dieser Arbeit erörtert, trägt dieses Element Meta-Informationen, die wirkungsvoll andere Informationen des Frames prägen. Es wird eine spezifische Leerstelle aus der Gesamtheit der Leerstellen des Muster-Frames aktiviert, nämlich die der „Eigenschaften“. Von welcher Beschaffenheit die Füllwerte sind, die die Leerstelle annimmt, wird durch die Sprecher_inneneinstellung beeinflusst. Es 
liegt eine durch die Intention des Sprechers gesteuerte Perspektivierungshandlung vor. Der Sprecher, der österreichische Politiker Hans Christian Strache der rechtspopulistischen Freiheitliche Partei Österreichs (FPÖ), konzeptualisiert mit dieser Aussage die bezeichneten Personen als arbeitsunwillig und böswillig, steht diesen also ablehnend gegenüber. Durch diese Einstellung wird für die Füllwerte der Leerstelle die Bedingung gesetzt, dass diese pejorativen Gehalt haben. Ist in einem Frame ein Meta-Frame-Element wie die Sprecher_inneneinstellung auszumachen, geht dies in der Regel mit einer inhaltlichen Evaluation der Referenzobjekte bzw. Personen, auf die Bezug genommen wird, einher, eine „neutrale“ Sprecher_inneneinstellung zeigt sich per definitionem ja nicht. Flüchtende und Geflüchtete werden dann zumeist zur selben Zeit als etwas Negatives konzeptualisiert, wie auch in folgendem Exzerpt:

(34) Die EU-Kommission hat Kritik an dem Flüchtlingsabkommen mit der Türkei zurückgewiesen. Die Vereinbarung sei „der einzige Weg vorwärts, um das Problem zu lösen“, sagte Kommissionsvizepräsident Frans Timmermans im Europaparlament. „Hätten wir nichts getan, hätten wir Griechenland dazu verdammt, ein riesiges Flüchtlingslager mit hunderttausenden Flüchtlingen $z u$ werden. " Athen unternehme schon jetzt ,unglaubliche Anstrengungen“, um die Lage in den Griff zu bekommen. (eigene Hervorhebung (PN); ntv.de; 28.04.2016) $)^{41}$

Einzige explizite Prädikation ist:

- Die Anzahl der Flüchtlinge beträgt mehrere Hunderttausend

Lediglich implizite Prädikationen sind:

- Flüchtlinge bilden ein riesiges Flüchtlingslager

- Flüchtlinge halten sich in Griechenland auf

Dass die bezeichneten Personen als Bedrohung konzeptualisiert werden, zeigt sich an Ausdrücken wie verdammen, riesig und hunderttausenden. Unter solch einer Wortwahl sollte das Meta-Frame-Element der Einstellung des_der Sprecher_in zum Referenzobjekt als in dem evozierten Frame inbegriffen verstanden werden, soll ein Frame epistemisch vollständig beschrieben werden.

In den gezeigten Beispielkontexten werden (a) die Flucht an sich $(25,28)$ und (b) der politische Aktionsrahmen und Handlungskonsequenzen der involvierten Staaten $(26,29,31,32,34)$ thematisiert sowie (c) Zuschreibungen vorgenommen $(30,33)$. In lediglich 14 von 100 Fällen aus dem Die Zeit-Korpus tritt das

\footnotetext{
41 <https://www.n-tv.de/ticker/EU-Kommission-verteidigt-Fluechtlingsdeal-mit-der-Tue rkei-article17576796.html $>(06.12 .2021)$.
} 
Zielwort als Agens des Satzes auf. ${ }^{42}$ Dabei fällt auf, dass sich sämtliche Menschen, auf die Bezug genommen wird, im Kontext der sprachlichen Äußerung auf europäischem Boden befinden: Entweder offensichtlich, da dieser Umstand bereits für den Zeitpunkt der sprachlichen Äußerung gilt, oder implizit, falls sich die Äußerung auf einen Zeitpunkt in der Zukunft bezieht, zu dem sich die Menschen auf europäischem Boden befinden werden. Es wird deutlich, dass allein durch das Auftreten des Ausdrucks als Agens im Satz nicht zwangsläufig darauf geschlossen werden kann, dass den Personen eine Rolle als handelnde Individuen zukommt. So wird in sechs Fällen (inklusive zweier Fälle, die inhaltlich volitiver Natur sind) ihre kollektive, physische Bewegung thematisiert. Des Weiteren ist in lediglich zwei Fällen festzustellen, dass den Flüchtenden und Geflüchteten eine Stimme verliehen wird: Sie klagen (i.S.v. vor Gericht klagen) und sie fordern und bestehen somit auf ihre Rechte. Da auch dies auf sprachlicher Ebene im Kollektiv geschieht (dann sogar auch höhere Chancen auf Erfolg hat), ist nicht die Konzeptualisierung der Individuen als Kollektiv an sich das Kritikwürdige. Vielmehr muss die Perspektivierung des Ausdrucks und die damit einhergehende Fokussierung auf eine sich stumm fortbewegende Masse problematisiert werden. Für den Muster-Frame bedeutet das: In ihm als kognitive gebrauchsbasierte Entität ist auch eine gewisse Passivität der durch den frame-evozierenden Ausdruck Bezeichneten gespeichert. An diese Passivität ist zugleich eine gewisse Abstraktheit geknüpft, treten die bezeichneten Personen doch nur in den seltensten Fällen als sich artikulierendes Kollektiv oder gar Individuen auf - vielmehr werden sie in der Regel als anonyme, stumme Masse konzeptualisiert.

Um zu untersuchen, ob die Personen, auf die der Ausdruck referiert, bei Gebrauch des Lemmas Flüchtling als aus Eigenantrieb Handelnde auftreten, und das Verhältnis zu den Lemmata Geflüchtete_r $r$ und Migrant_in zu überprüfen, reicht deshalb eine quantitative Herangehensweise nicht aus. Vielmehr müssen die „Verwendungskontexte“ in diesem Zusammenhang detailliert und qualitativ untersucht werden.

\subsubsection{Frames zu Geflüchtete_r}

Durch Anwendung des im vorangehenden Abschnitt vorgestellten Verfahrens wurden für Geflüchtete_r die folgenden Prädikationsmuster aufgestellt und diese

\footnotetext{
${ }^{42}$ Für eine tabellarische Übersicht über diese Fälle siehe Anhang 3 im elektronischen Zusatzmaterial.
} 
sogleich, insofern möglich, unter Betrachtung des Gesamtartikels, in den der Ausdruck jeweils eingebettet wurde, in Prädikationsklassen eingeteilt:

A. X.SUBJ WERDEN Y (zu attributiven Fällen, die nicht umformuliert werden konnten, s. u.)

politisch-institutioneller Umgang mit den Personen, auf die referiert wird $(=\mathrm{P})$ registriert (x3) / aufgenommen (x2) / abgeliefert / gescannt / abgeschoben / nicht gemäß der Menschenrechtscharta der EU behandelt / behandelt wie eine ansteckende Krankheit, die man sich vom Hals halten will gesellschaftliche Einstellungen gegenüber $\mathrm{P}$

pauschal abgelehnt / darauf reduziert, Kosten zu verursachen

gesamtgesellschaftliche Integration von $\mathrm{P}$

ausgebildet / eingeladen / auf Arabisch durch verschiedene Sammlungen der Hauptstadt geführt

sonstige

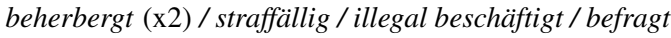

B. X.OBJ WIRD Y

gesamtgesellschaftliche Integration von $\mathrm{P}$

die Chance gegeben, möglichst früh den Arbeitsalltag in der Bundesrepublik zu erleben / das Gefühl gegeben, wirklich angekommen zu sein / eine Perspektive geboten / ein diskriminierungsfreier Zugang zu ärztlicher Versorgung geboten sonstige

der Rücken zugedreht / X.um die Geflüchteten Y.sich gekümmert /

X.auf die Geflüchteten Y.ein anderer Blick geworfen I

X.allen Geflüchteten und Vertriebenen Y.nicht Schutz, gewährt

C. Y VON X

Integration / Rückkehr / Zuwanderung / aktuelle Präsenz /

Y.Probleme X.Geflüchteten und Einheimischen /

Y.wachsende Zahl X.Arbeitsmigranten und Geflüchteten

D. Y DER $\mathrm{X}^{43}$

Situation / Rückkehr / Grad der wirtschaftlichen Integration /

Y.akademische Integration X.der nach Deutschland Geflüchteten

${ }^{43}$ Die Mengenangaben wurden getilgt (15 Prozent, 58 Prozent, ein Drittel, Mehrheit, einige). 
Die vorliegenden Daten deuten darauf hin, dass das Konzept ${ }^{44}$ Integration ein zentraler Begleiter des Ausdrucks Geflüchtete_r $r$ ist. Dies wird unterstützt durch eine Betrachtung der weiteren sprachlichen Umgebung des Ausdrucks in einem größeren Korpus: Der Ausdruck Integration steht für die Eingabewörter Geflüchteter und Geflüchteten in der Liste der 60 häufigsten Satzkookkurrenzen im Wortschatz der Universität Leipzig jeweils an erster Stelle, ${ }^{45}$ tritt also in diesem Korpus von allen Wörtern am häufigsten mit dem jeweiligen Eingabewort auf. Anders für die Eingabewörter Flüchtlinge bzw. Flüchtlingen: Integration nimmt nach Ausdrücken wie aufnehmen, Migranten, Syrien und Mittelmeer erst den siebzehnten bzw. nach Ausdrücken wie Unterbringung und Aufnahme erst den vierten Platz in der Liste der Satzkookkurrenzen ein. ${ }^{46}$ Demnach gilt: Wenn der Ausdruck Geflüchtete_ $r$ gebraucht wird, ist Integration in aller Regel ein zentrales Thema der sprachlichen Äußerung, während bei Gebrauch des Ausdrucks Flüchtlinge eher andere Themen fokussiert werden.

Im Folgenden werden einige aus dem Korpus herausgegriffene Beispielkontexte analysiert. (35) zeigt zunächst, wie Leerstellen instantiierter Frames - im Gegensatz zu Muster-Frames - durch mehrere unterschiedliche Werte zur selben Zeit gefüllt sein können:

(35) Heute leben in der kleinen Stadt, in der auch ich wohne, 1.200 Geflüchtete, vor allem aus Syrien, Eritrea und dem Maghreb. (13.02.2017)

Explizite Prädikationen:

- Geflüchtete leben in einer kleinen Stadt

- Geflüchtete leben in derselben Stadt wie der_die Sprecher_in

- Die Anzahl der Geflüchteten beträgt 1200

- Geflüchtete kommen aus Syrien

- Geflüchtete kommen aus Eritrea

\footnotetext{
${ }^{44}$ Wenn vom Konzept Integration die Rede ist, soll dies auch solche sprachlichen Ausdrücke wie ausbilden oder eine Perspektive bieten einschließen, nicht nur integrieren und Integration.

${ }^{45}$ Für Geflüchteter: $<$ https://corpora.uni-leipzig.de/de/res?corpusId=deu_newscrawl-pub lic_2018\&word=Gefl\%C3\%BCchteter $>$; für Geflüchteten $:<$ https://corpora.uni-leipzig. de/de/res?corpusId=deu_newscrawl-public_2018\&word=Gefl\%C3\%BCchteten $>$ (beide 23.08.2020). Das DWDS-Wortprofil erweist sich für den Ausdruck Geflüchtete_r (in sämtlichen deklinierten Formen) als nicht hilfreich.

${ }^{46}$ Für Flüchtlinge: $<$ https://corpora.uni-leipzig.de/de/res?corpusId=deu_newscrawl-pub lic_2018\&word=Fl\%C3\%BCchtlinge $>$; für Flüchtlingen: $<$ https://corpora.uni-leipzig. de/de/res?corpusId=deu_newscrawl-public_2018\&word=Fl\%C3\%BCchtlingen $>$ (beide 23.08.2020).
} 
- Geflüchtete kommen aus dem Maghreb

Die Leerstelle „Herkunftsland“ wird durch die Werte „Syrien“, „Eritrea“ und „Maghreb“47 gefüllt. Die sich aus dem gesamten Artikel ergebende Leerstelle „Aufenthaltsland“ mit dem Füllwert „Deutschland“ erfährt im Exzerpt eine Spezifizierung zu „Aufenthaltsort“ mit dem Füllwert „die Stadt, in der der_die Sprecher_in lebt“".

Betrachtet man (36), wird die Leerstelle (3) des Matrixframes PERSON „In welchen für die Person wichtigen funktionalen Zusammenhängen spielt die Eigenschaft der Person eine bestimmte Rolle?“ relevant:

(36) Erstens haben registrierte Geflüchtete in der Türkei keinen Flüchtlingsstatus nach internationalem Recht. Die Türkei heißt die Flüchtlinge ${ }^{48}$ zwar als „Gäste" willkommen, kann sie aber nach nationalem Recht jederzeit abschieben, wenn die politische Lage es vorgibt. (10.04.2017)

Explizite Prädikationen:

- Geflüchtete sind registriert

- Geflüchtete sind in der Türkei

- Geflüchtete haben keinen Flüchtlingsstatus nach internationalem Recht

Der Satz handelt von den rechtlichen Bedingungen, denen die Personen, auf die sich bezogen wird, ausgesetzt sind. Der konkrete Füllwert lautet hier demnach „rechtlicher Zusammenhang“. Der dadurch evozierte Frame strukturiert und organisiert weiteres Wissen: Das Recht als integrativer Bestandteil der Gesellschaft beeinflusst die Möglichkeiten eines Individuums oder - wie hier - eines Kollektivs, sich in anderen Bereichen der Gesellschaft zu verwirklichen, enorm; gerade dann, wenn Rechte (hier in Form des „Flüchtlingsstatus“) verwehrt werden: Ihre „temporäre oder dauerhafte“ Eigenschaft determiniert Grundrechte wie Recht auf Asyl, Recht auf Arbeit und Aufenthaltsrecht. Insbesondere die Integration in den Arbeitsmarkt wird im öffentlichen Diskurs vielfach als Schlüssel zur Integration $^{49}$ geflüchteter Menschen in die Gesellschaft konzeptualisiert. An

\footnotetext{
${ }^{47}$ Herkunftsland soll auch Entitäten bezeichnen, die im eigentlichen Sinne keine Länder oder Staaten, sondern Regionen o.ä. darstellen.

${ }^{48}$ Auf die Fälle, in denen zwei oder gar alle drei der zur Untersuchung stehenden Ausdrücke im selben oder darauffolgenden Satz verwendet werden, wird zu einem späteren Zeitpunkt eingegangen.

${ }^{49}$ Vgl. zu dieser Metapher Stefanowitsch 2020.
} 
das Verwehren des „Flüchtlingsstatus“ sind demnach rechtliche Konsequenzen gebunden, an die wiederum weitreichende soziale Konsequenzen anschließen, die zugleich an den rechtlichen Status rückgebunden bleiben (vgl. z. B. die Frage nach der Krankenversicherung bei einer ärztlichen Behandlung).

Das bedeutet indes nicht, dass mit dem „Flüchtlingsstatus“ einer sozialen Integration nichts mehr im Wege stünde: Die „Eigenschaft“, das GeflüchtetSein, mag sodann auf mikrosozialer Ebene in jeder Lage im sozialen Alltag (ob bspw. im Bildungsbereich oder bei medizinischer Versorgung) für die Betroffenen dafür von Bedeutung sein, wie mit ihnen interagiert wird - insofern als die stereotypisierte Wahrnehmung der Betroffenen durch die Angehörigen der Ankunftsgesellschaft durch diese (zugeschriebene) Eigenschaft bestimmt wird und nicht dadurch, ob er_sie einen „Flüchtlingsstatus“ innehat.

Wie verhält es sich mit Leerstelle (1) des Matrixframes „Wie ergeht es der Person mit dieser Eigenschaft?“ des Matrixframes? Man betrachte die Exzerpte (37) bis (39):

(37) Einfach ist es für sie nicht, eine neue Existenz aufzubauen. Denn die Geflüchteten haben Traumata erlebt, die sich die meisten von uns kaum vorstellen können. Sie wissen, wie verheerend Bombenanschläge sind, wie es ist, in ständiger Angst vor Anschlägen zu leben, wie es sich anfühlt, wenn der Mann vom syrischen Regime gefoltert, der Bruder von Al-Nusra-Kämpfern entführt, die Schwester vom IS verschleppt wurde. (11.10.2016; eigene Hervorhebung)

Explizite Prädikationen:

- Geflüchtete bauen sich nicht einfach eine neue Existenz auf

- Geflüchtete haben Traumata erlebt

- Geflüchtete wissen, wie verheerend Bombenanschläge sind

- Geflüchtete wissen, wie es ist, in ständiger Angst vor Anschlägen zu leben

- Geflüchtete wissen, wie es sich anfühlt, wenn der Mann vom syrischen Regime gefoltert wird

- Geflüchtete wissen, wie es sich anfühlt, wenn der Bruder von Al-Nusra-Kämpfern entführt wird

- Geflüchtete wissen, wie es sich anfühlt, wenn die Schwester vom IS verschleppt wurde

(38) ZEIT ONLINE: Sie bieten auch Kurse für Geflüchtete an, viele sind über das Wasser nach Europa gekommen und haben traumatische Erinnerungen. (09.06.2017; es handelt sich hierbei um ein Interview) 
Explizite Prädikationen:

- Geflüchteten werden Kurse angeboten

- Geflüchtete sind über das Wasser nach Europa gekommen

- Geflüchtete haben traumatische Erinnerungen

(39) Die Wartezeiten seien Gift für die Geflüchteten, die oft durch die Erfahrungen des Krieges und der Flucht traumatisiert seien. (18.08.2016)

Explizite Prädikationen:

- Geflüchtete warten

- Geflüchtete wurden durch die Erfahrungen des Krieges traumatisiert

- Geflüchtete wurden durch die Erfahrungen der Flucht traumatisiert

Bei einem Blick auf die Prädikationen wird deutlich: Für alle drei frameevozierenden Ausdrücke in den obigen Ausschnitten wird die Leerstelle (1) des Matrixframes gefüllt. Das Zustandekommen der Eigenschaft ist äquivalent zum Zustandekommen des Traumatisiert-Seins: Die Person ist aufgrund der Prozesse, die dazu geführt haben, dass sie geflüchtet ist, also dass ihr die Eigenschaft des Geflüchtet-Seins überhaupt erst zugesprochen werden kann, traumatisiert. Dazu passt Konerdings Prädikatorenklasse der „Prädikatoren zur Charakterisierung des subjektiven Befindens der Person aufgrund dieser Eigenschaft/dieses Zustands“ (1993: 275; Hervorhebung aufgehoben).

Bei jedem der Ausschnitte kommen die Personen, auf die referiert wird, zwar nicht selbst zu Wort und sie treten als kollektive, anonyme Gruppe auf, jedoch wird auf deren subjektives Empfinden und deren subjektive Erfahrungen eingegangen. Die Füllwerte der Leerstelle konstituieren selbst ebenso Frames, wie z. B. in (37) deutlich wird: Wird die Leerstelle (2) des Matrixframes „Welche besonderen Dispositionen weist die Person aufgrund dieser Eigenschaft auf?" so ausgelegt, dass „Dispositionen“ auch Wissen umfassen kann („Welches besondere Wissen weist die Person aufgrund dieser Eigenschaft auf?"), fungiert etwa das Wissen um die Tragweite von Bombenanschlägen als Füllwert dieser Leerstelle; das Wissen um Bombenanschläge per se ist dann erneut als Frame organisiert, für den gemäß dem Attack-Frame die Leerstellen „Angreifer“, „Opfer“ 
oder ,Zweck“ naheliegen, ${ }^{50}$ usw. (Für eine graphische Darstellung des Frames, die auch dieser Überlegung Rechnung trägt, siehe Anhang 4 im elektronischen Zusatzmaterial.)

Man betrachte nun zwei weitere Fälle:

(40) Die Geflüchteten von Calais dürfen das Camp verlassen und wählen, in welche Region Frankreichs sie gebracht werden. (24.10.2016)

(41) Geflüchtete sollen bei der Einreise ihr gesamtes Bargeld und ihre Handys abgeben. (18.12.2017)

Syntaktisch betrachtet treten die bezeichneten Personen hier als Handelnde auf. Der Gebrauch der Modalverben dürfen und sollen zeigt jedoch: In (40) wird den Personen eine Erlaubnis zuteil, in (41) wird eine Forderung an sie verlautbart. In beiden Fällen werden sie durch die Handlung (des Erlaubens, des Forderns) eines nicht näher genannten Akteurs affiziert. Demnach nehmen die Ausdrucksformen im Satz die semantische Rolle des Patiens ein (vorausgesetzt, sie profitieren vom Verlassen des Lagers, in (39) möglicherweise die des Benefiziär). Der Frame, den der Ausdruck hier evoziert, beinhaltet somit auch die Information, dass die Personen, auf die der Ausdruck Bezug nimmt, nicht aus Eigenantrieb handeln. Bei der Analyse der Sätze sollen Proposition und die Modalitätskonstituente nicht getrennt werden, denn für die Wissensanalyse spielt es durchaus eine Rolle, ob in der Prädikation eine Möglichkeit (dürfen) bzw. Notwendigkeit (sollen) ausgedrückt wird oder nicht (vgl. Lönneker 2003: 67). Die expliziten Prädikationen lauten demnach für (40)

- Geflüchtete befinden sich in Calais

- Geflüchtete dürfen das Lager verlassen

- Geflüchtete dürfen wählen, in welche Region Frankreichs sie gebracht werden

und für (41)

- Geflüchtete reisen ein

- Geflüchtete sollen ihr gesamtes Bargeld abgeben

- Geflüchtete sollen ihre Handys abgeben

(42) illustriert einen weiteren Aspekt, der bei der inhaltlichen Analyse beachtet werden muss:

$50<$ https://framenet2.icsi.berkeley.edu/fnReports/data/frameIndex.xml?frame= Attack>(06.12.2021). 
(42) Berechnungen des Bundesamts für Migration und Flüchtlinge aus dem Jahr 2015 zufolge sind beispielsweise etwa ein Drittel der Geflüchteten aus Syrien kurdischer Abstammung. (07.04.2017)

Daraus ergeben sich die expliziten Prädikationen und Frame-Elemente:

- Geflüchtete kommen aus Syrien $\rightarrow$ LS „Herkunftsland“ mit FW „Syrien“

- Geflüchtete sind kurdischer Abstammung $\rightarrow$ LS „Abstammung“ mit FW „kurdisch“

Die explizite sprachliche Markierung der Abstammung der bezeichneten Personen zeigt, dass bei Phrasen wie syrische Geflüchtete, aber auch syrische Flüchtlinge davon abzusehen ist, das durch ein Adjektiv angegebene Herkunftsland mit der Volkszugehörigkeit oder Abstammung gleichzusetzen, handelt es sich bei den Herkunftsländern doch zumeist um multiethnische Staaten. Syrische Geflüchtete wie syrische Flüchtlinge erscheinen aus analytischer Sicht sonach als ungenaue Angaben, können damit doch ebenso Flüchtende und Geflüchtete aus kurdischen Gebieten mitgemeint sein. Das Wissen, das hier untersucht wird, ist jedoch nicht in Kategorien wie „ungenau“, ,falsch“ oder ,wahr“ einzuteilen; in einem Frame ist Wissen an sich gespeichert, auf das Humana zurückgreifen, um der Welt Sinn zu verleihen. Mit anderen Worten: Wenn Rezipient_innen syrische $X$ so verstehen, dass die Personen, um die es geht, Syrer_innen sind (und womöglich gar nicht wissen, dass Kurd_innen auch Syrer_innen sein können), bildet dies deren Realität und ist somit auch ,wahr“.

Wie in Unterabschnitt 3.2.2 als Argument für (den Gebrauch von) Geflüchtete_r erläutert, erlaubt dieser Ausdruck im Gegensatz zu Flüchtling eine unmittelbare Markierung der Fluchtursache mittels adverbialer Bestimmung. Generell weist er ein höheres attributives Potential auf:

(08) Dabei geht es nicht nur um das Schicksal der aus ihren Ländern vor Krieg und Verfolgung Geflüchteten, sondern vor allem um die Europäer. (02.05.2015)

(43) Die Türkei sagte derweil den vor den Kämpfen in Nordsyrien Geflüchteten Hilfe zu. (06.02.2016)

(44) Die Hochschulrektorenkonferenz (HRK) befürchtet, so Präsident Horst Hippler, dass die ,akademische Integration“ der nach Deutschland Geflüchteten nicht gelingen könne ohne ,spürbare finanzielle Unterstützung durch die Politik“. (28.12.2015)

Im ZEIT-Korpus tritt Geflüchtete_r mit einer solchen syntaktischen Einbettung (d. h. in Kombination mit vor/aus/nach) im Untersuchungszeitraum von 2013 bis 
2018 jedoch lediglich neun Mal auf. ${ }^{51}$ Das attributive Potenzial wird demnach im Diskurs bzw. im Sprachgebrauch keineswegs ausgeschöpft. In den meisten dieser Fälle wird das Herkunftsland mittels der Präposition aus markiert (was in anderer syntaktischer Stellung auch mit Flüchtling möglich ist):

(45) Mit dem Geld soll die Türkei unter anderem gegen Schleuser an der Mittelmeerküste vorgehen und aus Syrien Geflüchtete von Griechenland zurücknehmen. (07.03.2016)

(46) Vor allem die schwer traumatisiert aus Kriegsgebieten Geflüchteten litten unter der rauen Stimmung und Enge im Slum. (24.10.2016)

Im Zusammenhang mit den obigen Exzerpten drängt sich aus frame-analytischer Sicht jedoch eine Frage auf: Aus (46) ist die explizite Prädikation ,Geflüchtete kommen aus Kriegsgebieten“ extrahierbar. Die Angabe zu dem Land, aus dem die Menschen, auf die Bezug genommen wird, flüchteten, ist semantisch äquivalent zum Herkunftsland. Rein formal handelt es sich um die Leerstelle „Herkunftsland“, die mit „Kriegsgebiet“ gefüllt wird. Doch dieser Füllwert indiziert zugleich die Fluchtursache, nämlich Krieg. Es liegt nahe, dass im Frame, der bei Verstehenden beim Verstehensprozess evoziert wird, beide Leerstellen gefüllt werden. Bei der Analyse sollte eine Prädizierung also nicht mit einer Leerstelle bzw. einem Füllwert gleichgesetzt werden.

Ähnlich in (43): Die Leerstelle „Fluchtursache“ wird mit dem Wert „Kämpfe in Nordsyrien“ gefüllt. Daraus kann abgeleitet werden, dass die Leerstelle „Zwischenzeitliches Aufenthaltsland“ mit dem Wert „Nordsyrien“ besetzt ist. Es ist hier davon abzusehen, diesen Wert der Leerstelle „Herkunftsland“ zuzuordnen, denn: Es ist naheliegend, dass sich in Nordsyrien bspw. auch irakische Geflüchtete aufhalten, die über die Türkei und Griechenland nach West-, Mittel- oder Nordeuropa gelangen möchten.

Zwar kann ein Unterschied zwischen Geflüchtete aus Syrien/aus Syrien Geflüchtete (auch Flüchtlinge aus Syrien) und syrische Geflüchtete (auch syrische Flüchtlinge) gezogen werden, d. h. die Markierungen mittels Attribut und Adjektiv mögen nicht zwingend dieselbe Bedeutung tragen: Letzteres mag „exklusiver“ auf die Herkunft i.S. einer Staatsangehörigkeit, Nationalität o.ä. verweisen; bei Gebrauch des Attributs wird dagegen eher auf ein Land, in dem sich die Menschen zuvor befanden, verwiesen. Doch im Zuge des Verstehensprozesses wird wohl das Land, aus dem die betroffenen Subjekte geflüchtet sind, zumeist mit dem Land, dessen Staatsangehörigkeit sie besitzen, gleichgesetzt.

${ }^{51}$ Genaue Zusammensetzung: vor $1 \mathrm{x}$, aus $5 \mathrm{x}$, nach $3 \mathrm{x}$. 
Etwas diffiziler verhält es sich in (45): Hier ist die explizite Prädikation ,Geflüchtete kommen aus Syrien' extrahierbar, auch hier wird die Leerstelle „Herkunftsland“ gefüllt. Obwohl im Gegensatz zu obigem Satz keine sprachliche Realisierung bspw. mittels eines Determinans (Kriegsgebiet) vorliegt, kann davon ausgegangen werden, dass die Leerstelle „Fluchtursache“ ebenfalls gefüllt wird. Füllwerte von Leerstellen können Füllwerte anderer Leerstellen beeinflussen: Fungiert das Konzept Syrien als Füllwert von „Herkunftsland“, fungiert mit hoher Wahrscheinlichkeit das Konzept Bürgerkrieg als Wert der Leerstelle „Fluchtursache“. Barsalou (1992: 39) spricht bezüglich solcher einschränkender Phänomene von ,contextual value constraints'. Es ist in diesem Fall nicht von einem Füllwert im Sinne eines am konkreten sprachlichen Material ,,abzulesenden“ Konzepts zu sprechen, sondern von einer Annahme oder einem inferierten Wert.

Wie verhält es sich mit Fällen, in denen sowohl Geflüchtete_r als auch Flüchtling auftritt? Man betrachte zunächst (47) bis (49):

(47) So unterschiedlich die in Deutschland lebenden Geflüchteten auch sind, so teilen die meisten dennoch die gleichen Werte: Freiheit, Sicherheit, Familie und Arbeit sind für die meisten Flüchtlinge neuen Studien zufolge am wichtigsten. (13.08.2016)

Explizite Prädikationen:

- Geflüchtete sind unterschiedlich

- Geflüchtete leben in Deutschland

- Geflüchtete teilen die Werte Freiheit, Sicherheit, Familie und Arbeit

- Flüchtlingen sind Freiheit, Sicherheit, Familie und Arbeit am wichtigsten

(48) Wird Flüchtlingen in Deutschland kein Asyl zugesprochen, müssen die jeweiligen Bundesländer dafür sorgen, dass die Geflüchteten in ihre Herkunftsländer zurückkehren. (14.12.2016)

Explizite Prädikationen:

- Flüchtlinge bekommen in Deutschland kein Asyl

- Geflüchtete kehren in ihre Herkunftsländer zurück 
(49) Während im gesamten Land auf ungefähr jeden vierten Einwohner ein Flüchtling kommt - sechs Millionen Libanesen beherbergen etwa 1,5 Millionen Geflüchtete - ist die Quote in Bar Elias noch höher: auf jeden libanesischen Bürger kommen vier Bürgerkriegsflüchtlinge aus Syrien. (26.12.2017)

Explizite Prädikationen:

- Ein Flüchtling kommt auf ungefähr jeden vierten Einwohner

- 1,5 Millionen Geflüchtete werden von sechs Millionen Libanesen beherbergt

Wie die expliziten Prädikationen zeigen, liegt in diesen Fällen ein alternierender Gebrauch der beiden Ausdrücke vor, ohne dass ein Unterschied bzgl. der betreffenden, bezeichneten Personen erkennbar ist: Der Ausdruck, der im Satz dem anderen Ausdruck nachfolgt, bezieht sich anaphorisch auf den zuerst genannten Ausdruck. In (49) beispielsweise handelt es sich bei dem Einschub lediglich um eine Konkretisierung dessen, was im vorangehenden Teilsatz bereits ausgesagt wurde. Anders verhält es sich dagegen in (50):

(50) Gleichzeitig suchten Flüchtlinge ihren Weg vor allem in Staaten wie Schweden oder Deutschland, die auch besonders viele Geflüchtete aufgenommen haben. (04.05.2016)

Explizite Prädikationen:

- Flüchtlinge suchen ihren Weg in Schweden

- Flüchtlinge suchen ihren Weg in Deutschland

- Geflüchtete wurden von Schweden aufgenommen

- Geflüchtete wurden von Deutschland aufgenommen

Die Personen, auf die Flüchtlinge Bezug nimmt, sind in Bewegung, befinden sich noch auf der Flucht (vgl. suchten ihren Weg), während für die Personen, auf die mit dem Ausdruck Geflüchtete referiert wird, eine gewisse Statik festgestellt werden kann (vgl. aufgenommen). Tatsächlich wird bei einem Blick in den gesamten Artikel, in den der obere Ausschnitt eingebettet ist, deutlich, dass sämtliche Verwendungen des Ausdrucks Flüchtlinge mit dieser Bedeutung einhergehen. In (51) und (52) werden die durch den Ausdruck bezeichneten Personen ,,verteilt“, in (53) „weichen“ sie ,,auf andere Wege aus“:

(51) Die EU erlaubt Grenzkontrollen und plant ein neues Asylsystem: Ist ein Land mit Flüchtlingen überfordert, werden diese verteilt. Wer sich weigert, muss Strafe zahlen. 
(52) Auch wegen des Abkommens mit der Türkei will die Kommission Flüchtlinge in Europa gerechter verteilen.

(53) Die Situation dort [an der EU-Außengrenze in Griechenland] habe sich zwar gegenwärtig beruhigt, dennoch bleibe die Lage ,äußerst unbeständig“. Zudem könnten Flüchtlinge auf andere Wege ausweichen, etwa auf die „Route über das zentrale Mittelmeer", also über Libyen und Italien.

Um die Frage, ob sich hier ein Muster abzeichnet, beantworten zu können, wurde das gesamte vorliegende Korpus untersucht: Zunächst wurden alle Fälle, in denen Flüchtlinge als Thema benannt wird ${ }^{52}$ oder Teil der Behördenbezeichnung Bundesamt für Migration und Flüchtlinge ist, aus dem 100 Fälle umfassenden Teilkorpus 01 getilgt. In einem zweiten Schritt wurden irrelevante Fälle (anderer zeitlicher Bezug, Doppeltreffer) aus dem ebenso 100 Fälle umfassenden Teilkorpus $02 \mathrm{zu}$ Geflüchtete_ $r$ getilgt. Im letzten Schritt wurden Fragekriterien entwickelt, um die Codes in Bewegung (B) / nicht mehr in Bewegung (nB) vergeben zu können, die unter Zuhilfenahme des gesamten Artikels, in dem der Satz auftritt, beantwortet wurden:

- Wo, in welchem Land befindet sich die Person(engruppe), auf die mit dem Ausdruck referiert wird?

- Inwiefern stellt das derzeitige Aufenthaltsland auch das Zielland dar?

- Wurde die bezeichnete Person(engruppe) bereits von dem Land aufgenommen, in dem sie sich aufhält?

- Befindet sich das derzeitige Aufenthaltsland auf der Skala des subjektiven Verlaufs der Fluchtbewegung an einem mittleren Punkt? Dies bedeutete, es ist lediglich ein „Übergangsland“, um in ein anderes Land zu gelangen.

in Bewegung (B) meint demnach: Die Menschen, auf die Bezug genommen wird, sind noch nicht im Zielland angekommen oder wurden von diesem aufgenommen. Dabei bezieht sich Bewegung auf die Fluchtbewegung; so werden z. $B$. Flüchtende und Geflüchtete, die sich auf den griechischen Inseln aufhalten, als $B$ kodiert, da sie in aller Regel nicht beabsichtigen, dort zu bleiben, sondern sich weiter nach Nord-, West- und Mitteleuropa bewegen wollen (vgl. UNHCR Global Trends 2019: 39 f.). Falls sich die Menschen bereits auf europäischem Boden befinden (was, wie im vorangehenden Abschnitt gezeigt, für sämtliche Fälle des Teil-Korpus 01 gilt, in denen Flüchtlinge als Agens im Satz auftritt), ist dies also nicht mit nicht mehr in Bewegung gleichzusetzen. Nicht mehr in Bewegung meint vielmehr: Die Menschen sind im Zielland angekommen bzw. befinden sich

52 z. B.: Lesen Sie hier mehr zu den Themen „Migration“ und „Flüchtlinge“. 
in dem Land, in dem sie auch bleiben (ein Gesuch um Asyl stellen) möchten. Typische öffentlich ausgehandelte Themen sind in diesem Fall Integration und Rückkehr bzw. Abschiebung.

Exemplarisch seien folgende Fälle und der jeweilige vergebene Code genannt:

(54) „Der faktische Wegfall der Vorrangprüfung baut bürokratische Hemmnisse bei der Integration von Geflüchteten in den Arbeitsmarkt ab“, sagt Senatorin Melanie Leonhard. (08.08.2016)

$\boldsymbol{n B}$ (in Deutschland)

(55) Das, was gern von Geflüchteten verlangt wird - das Erlernen der Sprache und die Teilhabe an gesellschaftlichem Zusammenleben -, wurde von den Identitären mit Gewalt sabotiert. (22.04.2016)

$\boldsymbol{n B}$ (in Österreich)

(56) Auf dem Mittelmeer ist erneut ein Boot voller Geflüchteter in Seenot geraten (26.05.2016)

$\boldsymbol{B}$ (auf dem Mittelmeer)

(57) In Berlin wurde am Sonntag ein Sonderzug mit rund 600 Flüchtlingen aus München erwartet. (13.09.2015)

$\boldsymbol{n B}$ (in Deutschland)

(58) Der starke Andrang von Flüchtlingen stellt die Bundespolizei vor beispiellose Probleme. (12.07.2015)

$\boldsymbol{B}$ (in der österreichisch-bayrischen Grenzregion)

Die Analyse lieferte folgende Ergebnisse:

- In $54 \%$ aller Fälle (44 von 81), die den Ausdruck Flüchtling enthalten, sind die Menschen, auf die Bezug genommen wird, nicht mehr in Bewegung (Code $n B)$, werden also in solch einen Kontext gestellt, dass sie sich im Zielland befinden oder bereits aufgenommen wurden. Zudem ist in $47 \%$ der Fälle (38 von 81) Deutschland als Aufenthaltsland festzustellen.

- In $78 \%$ aller Fälle (75 von 96), die den Ausdruck Geflüchtete_r enthalten, sind die Menschen, auf die Bezug genommen wird, nicht mehr in Bewegung (Code $n B$ ). Zudem ist in $69 \%$ der Fälle (66 von 96) Deutschland als Aufenthaltsland festzustellen. 
Diese Ergebnisse bestätigen das Muster. In den „Verwendungskontexten“ des vorliegenden Korpus wird der Ausdruck Geflüchtete_r weitaus häufiger gebraucht als der Ausdruck Flüchtlinge, wenn sich die bezeichnete Person(engruppe) auf der Skala der Fluchtbewegung relativ weit oben befindet. ${ }^{53}$ An dieser Position befinden sich die Personen näher an der Lebenswelt der Sprachproduzent_innen als auch der Adressat_innen; in den meisten Fällen: in Deutschland. Dies bedeutet zugleich, dass die Fluchtbewegung bei Gebrauch des Ausdrucks Geflüchtete_r eher in die Vergangenheit transponiert wird, als dies bei Gebrauch des Ausdrucks Flüchtling der Fall ist. (Was - wie gesehen - nicht heißt, dass der Ausdruck Geflüchtete_r nicht auch in Kontexten verwendet werden kann, in denen sich nicht auf näher an der Lebenswelt befindliche Personen(gruppen) bezogen wird.) Dieses Argument pro Geflüchtete_r im diskursiven Streit, das zumeist lediglich auf der morphosemantischen Beschaffenheit des Ausdrucks basiert, wird bzgl. der dieser Arbeit vorliegenden Sprachdaten also unterstützt.

Dies bedeutet, der type-Frame zu Geflüchtete_r integriert ein Meta-FrameElement, das das Wissen um die Lage der Fluchtbewegung in der Vergangenheit enthält. Da ein Lexem-bezogener Frame auch Informationen integriert, „die sich speziell auf sprachsystematische Aspekte des Lexems beziehen“" (Busse 2012: 619) - hier etwa substantivierte Partizip-Perfekt-Konstruktion - kann jenes MetaFrame-Element auch mit diesem Füllwert verbunden sein.

\subsubsection{Frames zu Migrant_in}

Für den Ausdruck Migrant_in können im vorliegenden Textkorpus vier unterschiedliche Referenzgruppen festgestellt werden: Einige Prädikationen beziehen sich auf / stehen in einem Kontext zur Krise der europäischen Flüchtlingsund Migrationspolitik; andere stellen einen Bezug zu Menschen auf der Flucht durch Mexiko in die USA her; eine Prädikation bezieht sich auf beruflichqualifizierte aus dem Ausland nach Deutschland Zuwandernde. Zudem wird auf Menschen referiert, die schon seit längerer Zeit in Deutschland leben und auf die die Bezeichnung mit Migrationshintergrund $(\mathrm{MH})$ zutreffen mag. Die Prädikationsmuster für den Ausdruck Migrant_in gestalten sich wie folgt:

\footnotetext{
${ }^{53}$ Wann und ob überhaupt eine Flucht ,zu Ende ' sein kann, wann generell von, erfolgreicher ‘ Integration gesprochen werden kann, sind Fragestellungen, deren Beantwortung nur interdisziplinär gegeben werden kann: Es bedarf hierzu umfangreicher empirischer soziologischer, migrationspolitischer, aber auch sozialpsychologischer und diskursanalytisch angelegter linguistischer Forschung, die die Stimmen der Betroffenen, der Flüchtenden und Geflüchteten einerseits und der Ankunftsgesellschaft andererseits, nicht vergisst.
} 
E. $\mathrm{x}$ (entspricht) $\mathrm{y}$

$\underline{\text { Krise der europäischen Flüchtlings- und Migrationspolitik }}$

X.Migranten bedeutet Y.Flüchtlinge / X.Migranten bedeutet Y.Bootsflüchtlinge / X.Migranten sind Y.Iraker

Menschen, die bereits seit längerer Zeit in Deutschland leben bzw. mit einem $\underline{\mathrm{MH}}$

X.Migranten sind Y.23,1 Prozent aller Personen, die in den letzten dreieinhalb Jahren ein Unternehmen gegründet haben / X.Migranten sind Y.Gründer ${ }^{54}$ / X.Migrant ist Y.der typische Einwohner in seinem [des Sprechers] Stadtteil

F. $\mathrm{x}$ werden $\mathrm{y}$

$\underline{\text { Krise der europäischen Flüchtlings- und Migrationspolitik }}$

in die Türkei zurückgeschickt $(\mathrm{x} 4)$ / in die Türkei zurückgebracht / zurückgenommen (x2) / abgeschoben (x2) / zur österreichischen Grenze gebracht / nicht aufgenommen / auf dem Weg nach Westeuropa aufgehalten / registriert / gezählt (x2) / erwartet/versorgt/untergebracht/aus einem Lastwagenanhänger gerettet / systematisch gerettet und nach Griechenland gebracht / aufgenommen / beraten / ausgebildet

$\underline{\text { Menschen auf der Flucht durch Mexiko in die USA }}$ erpresst auf dem Weg in die USA / in die Hände der Entführer geschickt beruflich-qualifizierte aus dem Ausland nach Deutschland Zuwandernde in den deutschen Arbeitsmarkt eingegliedert

Menschen, die bereits seit längerer Zeit in Deutschland leben bzw. mit einem $\underline{\mathrm{MH}}$

in ihren Themen und Positionen auf ihren Migrationsbezug festgenagelt / kaum gehört /verprügelt / gehasst und umgebracht / nach ihrer Zufriedenheit mit ihrem Leben im Allgemeinen gefragt / gefragt, wovor sie Angst haben

(59) und (60) stellen Beispiele für die letztgenannte Referenzgruppe der „Menschen, die bereits seit längerer Zeit in Deutschland leben bzw. mit einem $\mathrm{MH}^{\text {“ }}$ dar. Diese Gruppe ist im vorliegenden Teilkorpus lediglich bei $17 \%$ der Fälle (16 von 96) festzustellen.

\footnotetext{
${ }^{54}$ Diese Prädikation geht aus einem Satz hervor, der im entsprechenden Presseausschnitt der Prädikation Migranten sind 23,1 Prozent aller Personen, die in den letzten dreieinhalb Jahren ein Unternehmen gegründet haben direkt nachfolgt. Er zählt also nicht zu den Treffern im eigentlichen Sinne, wurde jedoch zur Illustration hier aufgeführt - da hier auch keine Aussagen über Verteilungen o.ä. getroffen werden.
} 
(59) Rund 30.000 Migranten aus Nicht-EU-Ländern und damit rund zehn Prozent der Mannheimer Bevölkerung sind ebenfalls betroffen und werden kaum gehört. (21.09.2013) $)^{55}$

(60) Fragt man Migranten jedoch nach ihrer Zufriedenheit mit ihrem Leben im Allgemeinen, sind sie nicht überdurchschnittlich unzufrieden. Im Gegenteil: Sie sind sogar etwas zufriedener als die Bevölkerung ohne Migrationshintergrund und blicken optimistischer in die Zukunft. (03.05.2016)

In einigen Fällen wird Migranten des Weiteren als Oberbegriff gebraucht. Exzerpt (61) stammt aus Teilkorpus 01, weswegen es bzgl. der obigen Prädikationsmuster nicht berücksichtigt wurde:

(61) Die Rückführung von Flüchtlingen und anderen Migranten von Griechenland in die Türkei sowie die Umsiedlung von Syrern aus der Türkei in die EU beginnt. (31.08.2016)

Die durch den Ausdruck Flüchtlingen bezeichneten Personen werden hier als eine Art derjenigen Personen dargestellt, die mit Migranten bezeichnet wird: Neben „Flüchtlingen“ gibt es demnach noch ,,andere Migranten“.

Ebenso verhält es sich in (62):

(62) Die Zuwanderung nach Deutschland ist 2012 auf dem höchsten Stand seit 1995. Laut Migrationsbericht, den die Bundesregierung am Mittwoch beschloss, kamen im Jahr 2012 1,08 Millionen Migranten nach Deutschland - 13 Prozent mehr als im Vorjahr. 2011 waren 960.000 Menschen nach Deutschland eingewandert. (15.01.2014)

Die durch den Ausdruck Migranten bezeichnete Personengruppe umfasst hier sowohl die mittels Zuwanderer als auch die mittels Einwanderer zu bezeichnenden Personen. Dabei kommen alle drei Formulierungen für sich genommen zudem Oberbegriffen gleich und schließen geflüchtete Menschen mit ein.

Ein weiterer anschaulicher Fall ist (63) (ebenfalls aus Teilkorpus 01):

(63) Tausende Flüchtlinge harren in Booten aus, weil sich die Zielländer bisher weigerten, sie aufzunehmen. Ein Großteil der Flüchtlinge sind Angehörige der muslimischen Minderheit der Rohingya, die in Myanmar politisch diskriminiert und verfolgt wird. Hinzu kommen Migranten aus Bangladesch, die versuchen, der Armut in ihrem übervölkerten Heimatland zu entkommen. (20.05.2015)

\footnotetext{
${ }^{55}$ Für eine graphische Darstellung des Frames siehe Anhang 4 im elektronischen Zusatzmaterial.
} 
Hier fungiert Flüchtlinge offenbar als Oberbegriff, der ,Angehörige der muslimischen Minderheit der Rohingya“ und „Migranten aus Bangladesch“ umfasst. Die mittels Migranten bezeichnete Personengruppe bildet einen Teil der mittels Flüchtlinge bezeichneten Personengruppe. Vom „Großteil der Flüchtlinge“ werden die Migranten jedoch wiederum abgegrenzt: auf der einen Seite die politisch Diskriminierten und Verfolgten, auf der anderen Seite die von Armut Betroffenen. ${ }^{56}$

Im Großteil der Fälle aus dem Korpus wird mittels Migrant_in jedoch auf dieselbe Gruppe referiert, wie es zumeist mittels Flüchtling der Fall ist: Die Referenzgruppe bilden in 57 \% (55 von 96) der Fälle diejenigen Personen, über die seit dem sog. Sommer der Migration 2015 in Gesellschaft und Politik intensiv diskutiert wird. (64) und (65) illustrieren dies:

(64) Derzeit legen die sogenannten Dublin-Regeln fest, dass dasjenige Land für Asylverfahren zuständig ist, in dem Migranten zum ersten Mal den Boden der EU betreten haben. (06.04.2016)

(65) Der Flüchtlingspakt sieht vor, dass die Türkei nach Griechenland übergesetzte Migranten zurücknimmt. (15.05.2016)

In beiden Beispielen befinden sich die Personen, auf die referiert wird, noch in Bewegung, d. h. noch nicht im eigentlichen Zielland. Dies gilt nach Anwendung des im vorherigen Unterabschnitt vorgestellten Verfahrens für $80 \%$ (44 von 55) der Fälle, in denen auf die Krise Europas im Umgang mit flüchtenden und geflüchteten Menschen referiert wird. Was diesen Aspekt betrifft, grenzt sich Migrant_in sonach eindeutig von Geflüchtete_r ab.

Des Weiteren werden in einigen Fällen die beiden Ausdrücke Migrant_in und Flüchtling ,simultan“ gebraucht - auch im Falle der expliziten Markierung weiblicher Personen, die dem instantiierten Frame zu Flüchtlinge dann sogar den Füllwert des weiblichen Geschlechts zukommen lässt, s. (68). In solchen Fällen liegt nahe, dem Frame zu Migranten die Leerstelle „Identität“ zu induzieren, die alsdann durch den Wert „Flüchtlinge“ gefüllt wird:

(66) Das berichteten ungarische Medien am späten Freitagabend. Die Busse sollen die Migranten zur österreichischen Grenze bringen, hieß es. Mindestens 800 Flüchtlinge waren zu Fuß aus Budapest aufgebrochen, nachdem sie dort erfolglos auf einen Weitertransport in Richtung Deutschland oder Österreich gewartet hatten. (04.09.2015)

\footnotetext{
56 Salopp formuliert: „Migranten“ werden in einen Topf mit „Flüchtlingen“ geworfen, aber auch zugleich von diesen unterschieden.
} 
(67) Lille (AFP) In der nordfranzösischen Hafenstadt Calais sind bei Zusammenstößen zwischen Flüchtlingen und Polizisten erneut elf Beamte verletzt worden. Rund 250 Migranten hätten in der Nacht zum Dienstag auf einer Zugangsstraße zum Hafen versucht, sich in Lastwagen zu verstecken, erklärte die örtliche Präfektur. Die Flüchtlinge hätten Gegenstände auf die Fahrbahn gelegt, um den Verkehr zum Verlangsamen zu zwingen. (10.11.2015)

(68) Sofia (AFP) Im Südosten von Bulgarien sind zwei Migrantinnen erfroren. Nach Angaben der Regierung sowie Ärzten zufolge wurden die beiden Flüchtlinge am Samstagabend in der Nähe der türkischen Grenze aufgefunden. (07.02.2016)

Der Blick auf die Satzkookkurrenzen für das Eingabewort Migranten $^{57}$ zeigt das grundlegende, da auch über ein größeres Korpus hinweg feststellbare, enge sprachliche Verhältnis zwischen diesen beiden Ausdrücken: Flüchtlinge steht an erster Stelle der häufigsten Satzkookkurrenzen. Doch nicht nur hinsichtlich der Häufigkeit, sondern auch hinsichtlich der Typizität ist Flüchtling ein enger Partner von Migrant: In der nach logDice sortierten Kategorie in Koordination mit des DWDS-Wortprofils zum Lemma Migrant ${ }^{58}$ stehen Flüchtling bzw. Flüchtlinge an zweiter bzw. vierter Stelle.

Werden in wenigen Ausnahmefällen doch unterschiedliche Personen(gruppen) bezeichnet, werden die Differenzen expliziert:

(69) Daneben hätte ein solches Gesetz [ein neues Einwanderungsgesetz, für das der Sprecher plädiert; PN] zwei große Aufgaben: Es muss weit mehr für die Integration getan und ausgegeben werden, nicht nur der Neuankömmlinge, sondern auch der hier schon lebenden Migranten. Das könnte auch viele Ängste in der Bevölkerung nehmen. (21.01.2015)

(70) Frauen, die fliehen mussten, seien häufig allein und schutzlos, und auch Migrantinnen, die schon lange in Österreich leben, fehlt oft ein Netzwerk außerhalb des engsten Familienkreises, in dem die Gewalt stattfindet. (02.09.2017)

(69) zeigt eine deutliche Abgrenzung: „Neuankömmlinge“ werden „Migranten“ gegenübergestellt, wobei Letzteres durch das phrasale Attribut hier schon lebend semantisch näher bestimmt wird. Neuankömmlinge kann in diesem Satz als ,noch nicht (lange) hier lebende Migranten“ gelesen werden. Ob Migranten in diesem Auszug solche Personen denotiert, die bereits seit einiger Zeit in Deutschland leben und für die ebenso die Bezeichnung mit Migrationshintergrund gebräuchlich ist, kann aus dem Kontext nicht festgestellt werden; naheliegend ist ein

\footnotetext{
$57<$ https://corpora.uni-leipzig.de/de/res?corpusId=deu_newscrawl-public_2018\&word= Migranten> (23.08.2020).

$58<$ https://www.dwds.de/wp?q=Migrant>(23.08.2020).
} 
Gebrauch des Ausdrucks als Oberbegriff. In (70) werden „Frauen, die fliehen mussten“, „Migrantinnen, die schon lange in Österreich leben“, gegenübergestellt. In (69) wie auch in (70) kann der Ausdruck je nach Intonation (,die schon LANge in Österreich leben“) als Oberbegriff verstanden werden, der die „Neuankömmlinge“ wie die „Frauen, die fliehen mussten“, miteinbezieht. Ganz gleich ob betont oder unbetont: Es wird stets zwischen Personen, die erst seit Kurzem in dem Land leben, und Personen, die bereits seit einiger Zeit im Land leben, unterschieden.

Generell bildet die Herkunft der Personen einen relevanten Aspekt in Verbund mit Migranten: Im DWDS-Wortprofil zum Lemma Migrant nimmt Herkunftsland in der Kategorie ist Genitivattribut von den ersten Platz der typischen Partner ein, während die Präposition aus den häufigsten rechten Nachbar des Eingabewortes Migranten im Leipziger Wortschatz darstellt. Wird in den dieser Arbeit vorliegenden Sprachdaten eine Herkunft mittels Präposition markiert, liegt zugleich Referenzobjektidentität mit Flüchtlinge vor. Die Exzerpte (71) bis (73), in denen die Leerstelle des Frames „Herkunftsland“ mit Werten wie „Syrien“, „Irak“ und „Afghanistan“ gefüllt werden, zeigen dies:

(71) Die überwiegend aus Syrien stammenden Menschen seien auf zwei Schiffe verteilt gewesen und vor Sizilien aufgegriffen worden, teilte ein Sprecher mit. Einige der Migranten seien Iraker. Von dem ersten Boot wurden 515 Menschen aufgegriffen, von dem zweiten rund 300. Genauere Zahlen sollen vorliegen, wenn die Flüchtlinge im sizilianischen Ort Augusta an Land gegangen sind. (12.05.2016)

Explizite Prädikationen:

- Migranten sind syrischer Herkunft

- Migranten sind irakischer Herkunft

- Flüchtlinge gehen im sizilianischen Ort Augusta an Land

(72) Dutzende Busse mit weiteren Migranten waren nach griechischen Medienberichten unterwegs von Piräus nach Idomeni. Nur Migranten aus Syrien, dem Irak und Afghanistan dürfen die Grenze passieren. (07.02.2016)

Explizite Prädikationen:

- Migranten bewegen sich von Piräus nach Idomeni

- Migranten sind syrischer Herkunft 
- Migranten sind irakischer Herkunft

- Migranten sind afghanischer Herkunft

(73) Der chinesische Künstler Ai Weiwei brachte ein Klavier in das Flüchtlingslager, um auf die Situation der Flüchtlinge aufmerksam zu machen. Damit wollte er unter anderem einer Migrantin aus Syrien helfen, die ihr Klavier vermisst. (13.03.2016)

Explizite Prädikationen:

- Migrantin ist syrischer Herkunft

- Migrantin vermisst ihr Klavier

Möchte man die u. a. in (73) auftretende, weiblich markierte Form des untersuchten Ausdrucks betrachten, sind für den gesamten Zeitraum von 2013 bis 2018, auf den die Suche im ZEIT-Korpus eingeschränkt wurde, lediglich 34 Formen zu finden, die explizit weibliche Personen bezeichnen (d. h. Migrantin und Migrantinnen) und nicht Teil gendergerechter Ausdrücke sind (d. h. Migrantinnen und Migranten und MigrantInnen). Die durch die Form Migrantin evozierten instantiierten Frames, aber auch der zugehörige type-Frame unterscheiden sich von der Form Migrant natürlich u. a. dadurch, dass der Person, auf die der Ausdruck referiert, das weibliche statt dem männlichen Geschlecht zugeordnet wird. Weiblichen Personen kommt im vorliegenden Kontext in der Sprache offenbar eine enorme Unterrepräsentanz zu, denn auch die Konstruktionen weibliche Geflüchtete und weibliche Flüchtlinge treten überaus selten auf: Für weibliche Geflüchtete sind im Untersuchungszeitraum (im ZEIT-Korpus) lediglich zwei Treffer festzustellen, während die Suche der Konstruktion weibliche Flüchtlinge nach Tilgung der Mehrfachnennungen 18 Treffer liefert. Im Großteil der Fälle erscheinen die Personen explizit im Kontext sexueller Gewalt; wird das Adjektiv weiblich gebraucht, werden die instantiierten Frames bis auf wenige Ausnahmen hinsichtlich einer besonders hohen Schutz- und Hilfsbedürftigkeit perspektiviert, die den Füllwert der Leerstelle „Eigenschaft“ bildet und die ohnehin durch das Geflüchtet-Sein stark ausgeprägte Vulnerabilität übersteigt.

Der Großteil der Menschen in Bewegung kann zwar dem männlichen Geschlecht zugeordnet werden, doch bei Betrachtung der statistischen Daten kann durchaus bezweifelt werden, ob der Grad der Unterrepräsentanz gerechtfertigt ist: Für die Jahre 2015, 2016 und 2017 beträgt der Anteil weiblicher Erstantragstellerinnen auf Asyl in Deutschland an der Gesamtzahl 31\%, $34 \%$ und 
$40 \% .{ }^{59}$ Der Gebrauch des männlich konnotierten Ausdrucks Flüchtling reflektiert (auch in Pluralform) so nicht nur das Narrativ eines ,,allein reisenden männlichen Flüchtlings" (vgl. Neuhauser et al. 2017: 177), sondern stimuliert dieses zugleich. Neuhauser et al. (2017: 184) konstatieren: „Die dominante öffentliche Debatte ist durch einen starken male bias geprägt, der Flucht unhinterfragt als männliches Phänomen thematisiert und die Gruppe der Geflüchteten homogenisiert und [...] problematisiert" (Hervorhebung im Original). Auch die Ergebnisse einer korpuslinguistischen Untersuchung in Stefanowitsch 2019 legen nahe, ,that the default interpretation of Flüchtling is, indeed, ,male“", wobei gezeigt wird, dass die männliche Konnotation nicht zwangsläufig auf das grammatische Geschlecht des Ausdrucks zurückzuführen ist, sondern in der Semantik typischer, mit dem Ausdruck gebrauchter Adjektive begründet gesehen werden kann.

Anders als bei Flüchtling und Geflüchtete_r scheint es bzgl. Migrant_in schwieriger, die „Eigenschaft“, die der Matrix-Frame PERSON fordert, zu benennen. Die den durch die anderen beiden Ausdrücke bezeichneten Personen zuschreibbaren Eigenschaften sind wohl nicht das „Flüchtling-Sein“ oder das „Geflüchtete_r-Sein“, sondern das „Geflüchtet-Sein“. Die ersten beiden Formulierungen bergen das Problem, definieren zu müssen, was es denn überhaupt bedeutet, „Flüchtling zu sein“ bzw. „Geflüchtete_r zu sein“. Die Formulierung „Migrant_in-Sein“ ist demnach zu verwerfen. Doch ist dann eine adäquate Formulierung der Eigenschaft bzgl. Migrant_in ,migriert sein“ oder ,,migrierend“? Was genau bedeutet dann ,migrieren“? Tritt der Ausdruck im Kontext der Krise der europäischen Flüchtlings- und Migrationspolitik anstelle von Flüchtling auf, steht er wohl für „flü̈chten“. In anderen Kontexten mag er generell „sich aus der Heimat fortbewegen, mit dem Ziel, dieser länger fernzubleiben“ bedeuten. Hinsichtlich instantiierter Frames muss deshalb aus analytischer Sicht abgewogen werden, welches Verständnis von „migrieren“ bei den Verstehenden erweckt wird. Die Werte der aus den Matrix-Leerstellen (4) bis (6) zusammengefassten Leerstelle „Beweggründe für die Fortbewegung aus der Heimat“ (möglichst allgemein formuliert, statt Fluchtursache), entsprechen im Gros der Fälle denjenigen der entsprechenden Leerstelle der Frames zu Flüchtlinge. Sie bleiben jedoch zumeist Standardwerte: Diese Leerstelle bzgl. Migrant_in wird in aller Regel nur konkret gefüllt, wenn Kompositabildungen vorliegen, die den (wohlgemerkt fremdzugeschriebenen) Grund markieren, wie in Arbeitsmigrant_in, Wirtschaftsmigrant_in. Diese Ausdrücke evozieren jedoch wiederum einen anderen type-Frame als der Ausdruck Flüchtlinge oder Migrant_in in einem „Flüchtlingskontext“.

$59<$ https://www.bpb.de/gesellschaft/migration/flucht/zahlen-zu-asyl/265710/demografie>; Bundeszentrale für politische Bildung (06.12.2021). 
Es ist an dieser Stelle festzuhalten: Hinsichtlich des Ausdrucks Migrant_in liegt ein überaus diffuser Gebrauch vor. Er wird als Oberbegriff verwendet, zur Bezeichnung bereits einige Zeit in Deutschland lebender Menschen sowie solcher mit einem sog. Migrationshintergrund. Zudem im Gros der Fälle zur Bezeichnung der flüchtenden und geflüchteten Menschen im Zuge des sog. Sommers der Migration, davon zumeist konkret derjenigen, die sich noch in der Fluchtbewegung befinden. Weitere im vorliegenden Korpus eher selten auftretende Verwendungsarten sind diejenigen zur Bezeichnung von Menschen in Bewegung auf dem amerikanischen Kontinent sowie von nach Deutschland zuwandernden Fachkräften. Beide mögen auch zur Verwendung als Oberbegriff gerechnet werden können.

Der festgestellte diffuse Gebrauch des Ausdrucks muss nicht zwangsläufig auf eine bewusste Entscheidung der Sprachproduzent_innen, genauer: der Journalist_innen, zurückgehen, diesen Ausdruck nun in diesen spezifischen Kontext zu setzen. Er kann auch das Produkt einer gewissen Motivation, nicht in einem Text wiederholt denselben Ausdruck zu gebrauchen, sondern ihn mit anderen Ausdrücken abzuwechseln, sein. Exemplarisch für ein solches Prozedere seien die folgenden Ausschnitte aus einem Artikel der ZEIT vom 17.03.2018 gegeben:

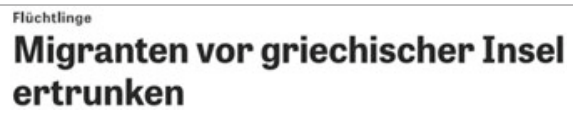

Dachzeile: Flüchtlinge. Überschrift: Migranten.

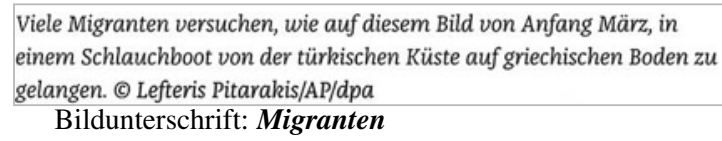

(76) Es wird angenommen, dass es sich bei den Passagieren um Geflüchtete handelt, die von der Türkei aus Richtung Europa gelangen wollten.

(77) Trotz des Abkommens zwischen der EU und der Türkei, mit dem der Zustrom von Geflüchteten und Migranten begrenzt worden ist, versuchen Dutzende und manchmal Hunderte [...]

(78) In den vergangenen Jahren seien dort [in der Ägäis] aber bereits rund 500 Flüchtlinge und Migranten ertrunken.

Flüchtlinge in der Dachzeile des Artikels fungiert als Stichwort und stellt das Thema des Artikels dar. Für die Referenzpersonen sämtlicher Ausdrücke kann der Code $B$ vergeben werden, was bzgl. Migranten und Flüchtlinge auch mit 
den Ergebnissen der qualitativen Korpusanalyse übereinstimmt, bzgl. Geflüchtete jedoch nicht - hier liegt im Korpus eher eine Person vor, die sich bereits näher an der Lebenswelt der Sprachproduzent_innen wie Rezipient_innen befindet. Auch die Kollokationsbildungen in Geflüchtete und Migranten sowie Flüchtlinge und Migranten weisen auf einen unmotivierten, keinerlei Muster folgenden Gebrauch hin. Da die Ergebnisse der Analyse des vorliegenden Korpus freilich keine Allgemeingültigkeit beanspruchen, erscheinen dergleichen Artikel nicht überraschend. Es sind jedoch in jedem Fall Artikel auszumachen, in denen die lexikalische Wahl motiviert zu sein scheint. So heißt es in einem (Hintergrund-)Artikel der ZEIT vom 05.08.2016:

\title{
Eben noch Flüchtling, jetzt Unternehmer
}

\author{
Überschrift: Flüchtling.
}

(80) „Bei uns lernen technisch versierte Geflüchtete das Programmieren“, sagt die Geschäftsführerin Anne Kjær Riechert.

(81) Let's Integrate ist ein Portal, das Treffen zwischen Einheimischen und Geflüchteten fördert.

(82) Der Syrer Khaled arbeitet mit drei anderen Geflüchteten an einer Plattform [...]

(83) „Wir dürfen die Geflüchteten nicht als Opfer sehen. Sie sind Überlebende, die fabelhaft ausgebildet sind. Das zeigen unsere Erfahrungen.“

Die Autorin gebraucht im Artikeltext selbst ausschließlich den Ausdruck Geflüchtete_r, nicht nur in der Wiedergabe der Worte der Geschäftsführerin, auch in eigenen Formulierungen. Dass das Thema, das der Artikel behandelt bzw. in dessen Rahmen die Personen die Bezeichnung Geflüchtete erfahren, Integration ist, passt zu einem der Ergebnisse der Analyse in Unterabschnitt 4.4.3. Lediglich in der Überschrift taucht der Ausdruck Flüchtling auf. Dies ist jedoch wie folgt erklärbar: Es werden zwei Lebensrollen gegenübergestellt: Er ist__Unternehmer ist genauso möglich wie Erist__Flüchtling. Flüchtling wird durch die temporalen Marker eben und noch als eine vergängliche Lebensrolle dargestellt. Nach Aussage der Überschrift, die Aufmerksamkeit generieren soll, fand ein Wechsel der Lebensrollen statt. Dabei zeigen die temporalen Marker nicht nur die potenzielle Vergänglichkeit der Lebensrolle Flüchtling an, sondern auch, dass zwischen den beiden Lebensrollen eigentlich ein sehr langer Weg liegt bzw. ein sehr großer Unterschied besteht. Dieser Unterschied ist so groß, dass beide Lebensrollen nicht zur selben Zeit getragen werden können - auch das deutet die Überschrift 
an. Ersetzt man Flüchtling mit Geflüchteter, lautet die Überschrift: ,Eben noch Geflüchteter, jetzt Unternehmer'. Abgesehen von der Frage, ob Geflüchtete_r eine Lebensrolle bezeichnen kann (d. h. ob z. B. Er ist_Geflüchteter produktiv ist), scheint die manipulierte Überschrift in geringerem Maße zu funktionieren wie die ursprüngliche. Ein möglicher Grund: Geflïchteter markiert - noch konkreter als Flüchtling - die der durch den Ausdruck bezeichneten Person zuschreibbare Eigenschaft des „Geflüchtet-Seins“. Gefü̈chtet ist der Bezeichnete immer noch, selbst wenn er zugleich Unternehmer ist. Geflüchteter und Unternehmer scheinen sich nicht im selben hohen Maße auszuschließen wie Flüchtling und Unternehmer. Diese „Unvereinbarkeit“" ist jedoch Voraussetzung dafür, dass die Überschrift ihre Wirkung entfaltet.

Für den Diskurs zur europäischen Krise im Umgang mit Flucht- und Migrationsbewegungen bedeuten die bis zu dieser Stelle ausgeführten Punkte: Die instantiierten Frames zu Migranten erfahren ihre Perspektivierung dadurch, dass sie überaus häufig und typischerweise aufgerufen werden, wenn im selben Satz oder Artikel „simultan“ von Flüchtlingen gesprochen, ein Frame zu Flüchtlingen aufgerufen wird. Letzter beeinflusst die instantiierten Frames (a) strukturell: gewisse Leerstellen, nämlich diejenigen, die die beiden type-Frames gemeinsam haben, werden aktiviert und Bedingungen für ebenderen Füllwerte festgelegt; (b) inhaltlich: gewisse für den type-Frame zu Flüchtlinge typische Werte treten als Füller der instantiierten Frames zu Migranten auf. Bei einer repetitiven gemeinsamen Kontextualisierung der Ausdrücke gelangen so Standardwerte des type-Frames zu Flüchtlinge in den type-Frame zu Migranten. Es liegt angesichts der starken Dominanz des Ausdrucks Flüchtling bzw. Flüchtlinge nahe, ${ }^{60}$ dass die Perspektivierung zum größten Teil in diese Richtung verläuft. Doch es bleibt stets eine Frage der kognitiven Arbeit der eine Sprachgemeinschaft bildenden Individuen, welche Frame-Elemente in diesem Prozess konkret wirken.

Eine stärkere Perspektivierung von der einen in die andere Richtung schließt dabei jedoch eine teilweise Perspektivierung in die entgegengesetzte Richtung nicht aus: Anknüpfend an die Theorie der mentalen Räume entsteht ein neuer

${ }^{60}$ Diese zeigt sich zum einen an den Trefferzahlen für die Lemmata im DWDS-Die ZEITKorpus: 59092 für Flüchtling, 608 für Geflüchtete_r, 6703 für Migrant_in. Zum anderen an der enorm hohen Produktivität, was die Bildung von Komposita anbelangt: Flüchtlingskrise, Flüchtlingsdebatte, Flüchtlingsunterkunft, Flüchtlingsrat, Flüchtlingshilfe, Flüchtlingsheim, Flüchtlingslager, Flüchtlingscamp, Flüchtlingspolitik, Flüchtlingsbekämpfung, Flüchtlingskonvention, Flüchtlingsstatus, Flüchtlingsabwehr, Flüchtlingswelle, Flüchtlingsstrom, Bootsflüchtlinge, Kriegsflüchtlinge, Wirtschaftsflüchtlinge, Klimaflüchtlinge, Binnenflüchtlinge, Kontingentflüchtlinge, Konventionsflüchtlinge uvm. Ein überaus rares „,Gegenbeispiel“" findet sich in Geflüchtetenunterkunft $<$ https://www.neues-deutschland.de/artikel/113 8257.freital-rechte-kante.html>(vom 24.06.2020; 06.12.2021). 
Raum außerhalb der beiden ,inputs', wobei dieser neue Raum alsdann durch den neuen - da nun strukturell und inhaltlich anders beschaffenen - type-Frame zu Migranten strukturiert wird. In jenem Frame kann daraufhin nach wie vor Information enthalten sein, die auch zuvor bereits enthalten war, wie eine gewisse Freiwilligkeit hinsichtlich des Verlassens des Heimatlandes; zudem ist rein formal der Aspekt der Flucht, demnach der Aspekt der Notlage, anders als in Flüchtling und Geflüchtete_r in Migrant_in nicht enthalten. Kurz: Werden geflüchtete und flüchtende Menschen als Migrant_innen bezeichnet, birgt dies das Potential, diesen ihre Notlage abzusprechen. Zwar ist auch denkbar, dass die Personen durch den Gebrauch des Ausdrucks bewusst nicht auf ihre Notlage reduziert werden sollen, jedoch kann dies auch zur Folge haben, dass der Aspekt der Hilfsbedürftigkeit verlorengeht.

Ein type-Frame vereint, wie im frame-theoretischen Teil der Arbeit gezeigt, prototypisches Wissen. Für den Untersuchungszeitraum kann aufgrund der in diesem Unterabschnitt gewonnenen Ergebnisse konstatiert werden: Der Prototyp eines „Migranten“ ist ein „Flüchtling“, die prototypischen „Referenzobjekte“ des Ausdrucks Migranten sind seit Sommer 2015 geflüchtete und flüchtende Menschen.

\subsubsection{Kognitive Verfestigung von Frame-Elementen}

In den vorangehenden Abschnitten wurden Leerstellen und Füllwerte (Wissensaspekte) der Frames zu den drei zur Untersuchung stehenden Ausdrücken erarbeitet. Vor dem Hintergrund, dass Wissensaspekte instantiierter Frames den type-Frame bilden, stellt sich die Frage, welche der Leerstellen besonders häufig mit Füllwerten besetzt werden und somit, welche Leerstellen der type-Frame aufweist. Dieser Frage nach der type-Frequenz steht die Frage nach der tokenFrequenz gegenüber: Wie oft fungiert ein bestimmter Wert als Füllwert einer bestimmten Leerstelle, die dem Frame angehört? Bei einer hohen token-Frequenz tritt also ein Wert weitaus häufiger auf als andere Werte. Sind konkrete Füllwerte so oft aufgetreten, dass Sprachproduzent_innen diese unterstellen können (diese nicht expliziert werden müssen), entstehen Standardwerte (Ziem 2008: 342 f.).

Der Frage nach der Organisation des Leerstellen-Gefüges (also nach der typeFrequenz) der jeweiligen Frames für Flüchtling, Geflüchtete_r und Migrant_in wird sich durch eine Untersuchung des vorliegenden Korpus darauf angenommen, welche Prädikationstypen (Leerstellen) wie oft mit Prädizierungen (Füllwerten) versehen werden. Die Menge aller Leerstellen, die mit Füllwerten besetzt werden, bildet schließlich das Kontextualisierungspotential (Fraas 1996: 5), d. h., 
was gesagt werden kann, in welchen Zusammenhang das Konzept gestellt werden kann. Anknüpfend an Ziem 2005 wird die hierarchische Leerstellen-Struktur in Radiusmodellen veranschaulicht. Die Ellipsen und ihre jeweiligen Zahlenwerte zeigen in absteigender Reihenfolge von außen nach innen an, wie oft eine bestimmte Leerstelle (Slot) im Untersuchungskorpus mit einem konkreten Wert gefüllt wird. Je näher sich also ein Slot in der Grafik am Zentrum befindet, desto häufiger wird dieser Slot gefüllt. Die Zahlenwerte wurden für Abb. 4.2 und 4.3 in 5er-Schritten, für Abb. 4.4 in 10er-Schritten gerundet.

Können dem Frame die Leerstellen „Politischer Umgang“ und „Umgang“ induziert werden, tritt der frame-evozierende Ausdruck im Verwendungskontext als Patiens des Satzes auf. „Umgang“ bezeichnet die Art und Weise, wie generell mit den bezeichneten Subjekten auf makro- und mikrosozialer Ebene umgegangen wird; Füllwerte sind etwa „werden gleichbehandelt“ und „,werden unterrichtet“. Im Gegensatz dazu wurden Füllwerte wie ,werden abgeschoben“ und „werden zurückgeführt" der Leerstelle des politischen Umgangs zugeschrieben, da die Handlungsausführenden hier dezidiert politische Instanzen sind. Tritt der Ausdruck im Satz als Agens auf, kann der zugehörige Frame die Leerstelle „Handlungen“ tragen; Füllwerte sind etwa „klagen“ und „,berichten“. Wie zu einem früheren Zeitpunkt der Arbeit erläutert, wird beim Gebrauch statischer Verben wie ,ausharren“ jedoch davon abgesehen, die Leerstelle „Handlungen“ zu induzieren; hier trifft eher die Leerstelle „Eigenschaften“ zu.

Im Zentrum des Frames zu Flüchtling steht der politische Umgang mit den Menschen, auf die mittels des frame-evozierenden Ausdrucks referiert wird. Zur Basis gehört zudem die Leerstelle „Aufenthaltsland“. „Zielland“ und „Herkunftsland" stehen in der Peripherie des Frames, werden also im vorliegenden Textkorpus kaum explizit thematisiert.

Das Zentrum des Frames zu Geflüchtete_r ist dichter besiedelt als das Zentrum des Frames zu Flüchtling, s. Abb. 4.3:

Die Leerstellen „Aufenthaltsland“ und „Politischer Umgang“ sind auch bzgl. dieses Frames von zentraler Bedeutung, doch die Leerstelle, die am häufigsten mit konkreten sprachlichen Elementen gefüllt wird, ist „Umgang“ - eine Leerstelle, die im Frame zu Flüchtling in der äußersten Peripherie liegt. Der Großteil der Füllwerte ist dabei inhaltlich der Domäne der Integration zuzuordnen, was eines der Ergebnisse der Frame-Analyse in Unterabschnitt 4.4.3 reflektiert.

Die Leerstelle „Aufenthaltsland“ spielt nicht nur bei allen drei Frames eine gewichtige Rolle, sie steht auch im Zentrum des Frames zu Migrant_in, s. Abb. 4.4:

Für diesen Frame gilt zudem genauso wie für die anderen beiden Frames: In den untersuchten Texten spielen das Herkunftsland und das Zielland auf 


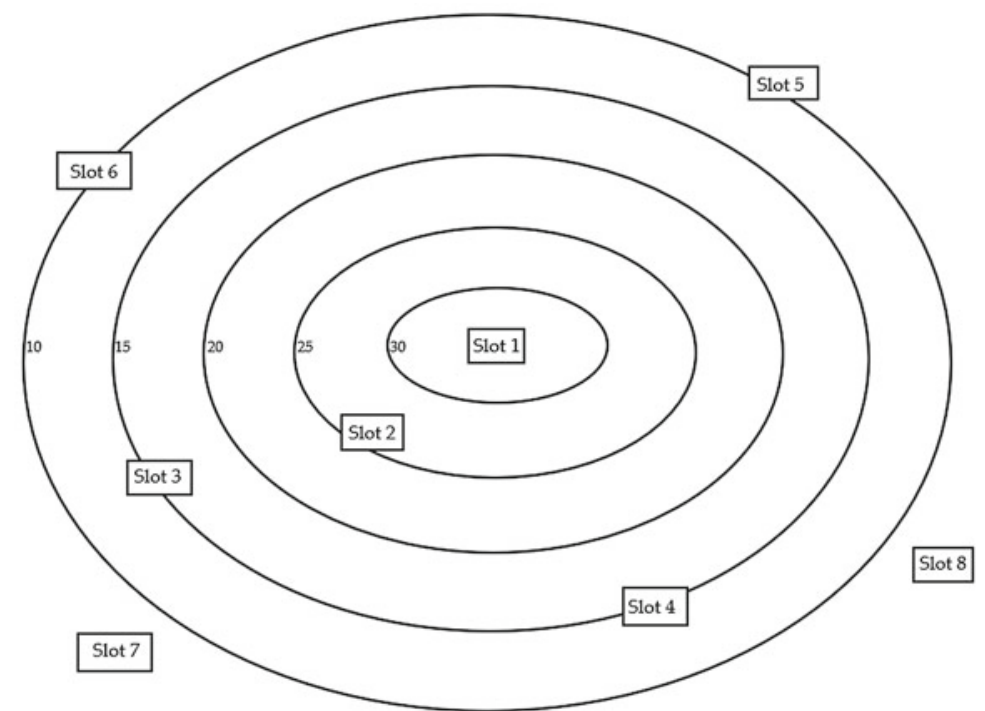

Legende: Slot 1 = Politischer Umgang, Slot 2 = Aufenthaltsland, Slot 3 = Anzahl, Slot 4 = Handlungen, Slot 5 = Eigenschaften, Slot $6=$ Zielland, Slot 7 = Herkunftsland, Slot 8 = Umgang

Abb.4.2 Radiusmodell zum Flüchtling-Frame im untersuchten Diskursausschnitt

sprachlicher Ebene lediglich eine marginale Rolle. Die Leerstelle „Aufenthaltsland" im Zentrum des Frames und die, wenn auch in der Peripherie liegende, Leerstelle „Fluchtart“61 zeigen zudem, dass im vorliegenden Textkorpus der Ausdruck Migrant_in häufig zur Bezeichnung flüchtender und geflüchteter Menschen gebraucht wird. Konnte die Leerstelle „Fluchtart“ im Korpus für den frame-evozierenden Ausdruck Flüchtling lediglich vier Mal mittels expliziter Prädikationen induziert werden und taucht sie deshalb im Radiusmodell nicht auf, erfährt die Art und Weise der Flucht in den Exzerpten mit Migrant_in mit sechs Explizierungen eine ähnlich marginale Thematisierung. Bzgl. Geflüchtete_r ist lediglich eine einzige Explizierung der Fluchtart festzustellen (vgl. 38). Die Füllwerte der Leerstelle können aus unterschiedlichen formalen Prädikationstypen

${ }^{61}$ Fluchtart soll dabei stets lediglich die Art und Weise eines Teils der Fluchtbewegung meinen. - Als Name für diese Leerstelle wurde bewusst ein genereller gewählt; die Leerstelle müsste genaugenommen noch gegliedert werden, etwa in Fortbewegungsmittel (z. B. Transporter, Boot) und Route nach Untergrund (z. B. Landroute, Seeroute), wobei erneut die von Barsalou konzipierten , constraints` zum Tragen kommen. 


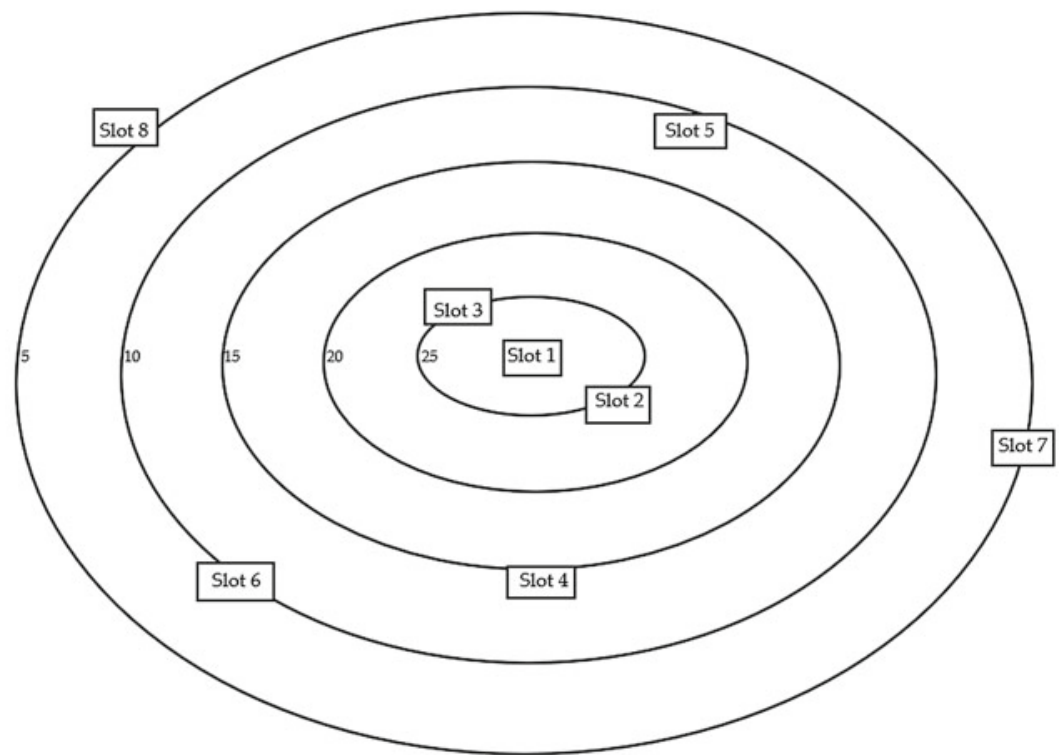

Legende: Slot 1 - Umgang, Slot 2 - Aufenthaltsland, Slot 3 - Politischer Umgang, Slot 4 - Anzahl, Slot 5 - Eigenschaften, Slot $6=$ Handlungen, Slot 7 - Herkunftsland, Slot $8=$ Zielland

Abb.4.3 Radiusmodell zum Geflüchtete_r-Frame im untersuchten Diskursausschnitt

hervorgehen: Das Prädikat trägt die Fluchtart selbst (84) oder wird attributiv erweitert $(85,38)$ :

(84) Der Flüchtlingspakt sieht vor, dass die Türkei nach Griechenland übergesetzte Migranten zurücknimmt. (15.05.2016)

Explizite Prädikation: Migranten setzen nach Griechenland über

(85) Der Migrant am Strand gab an, sie seien mit dem Boot von Dünkirchen aufgebrochen, um nach Großbritannien zu gelangen. (06.02.2016)

Explizite Prädikation: Migranten brechen mit dem Boot von Dünkirchen auf

(38) ZEIT ONLINE: Sie bieten auch Kurse für Geflüchtete an, viele sind über das Wasser nach Europa gekommen und haben traumatische Erinnerungen. (Es handelt sich hierbei um ein Interview (PN); 09.06.2017)

Explizite Prädikation: Geflüchtete kommen über das Wasser nach Europa 


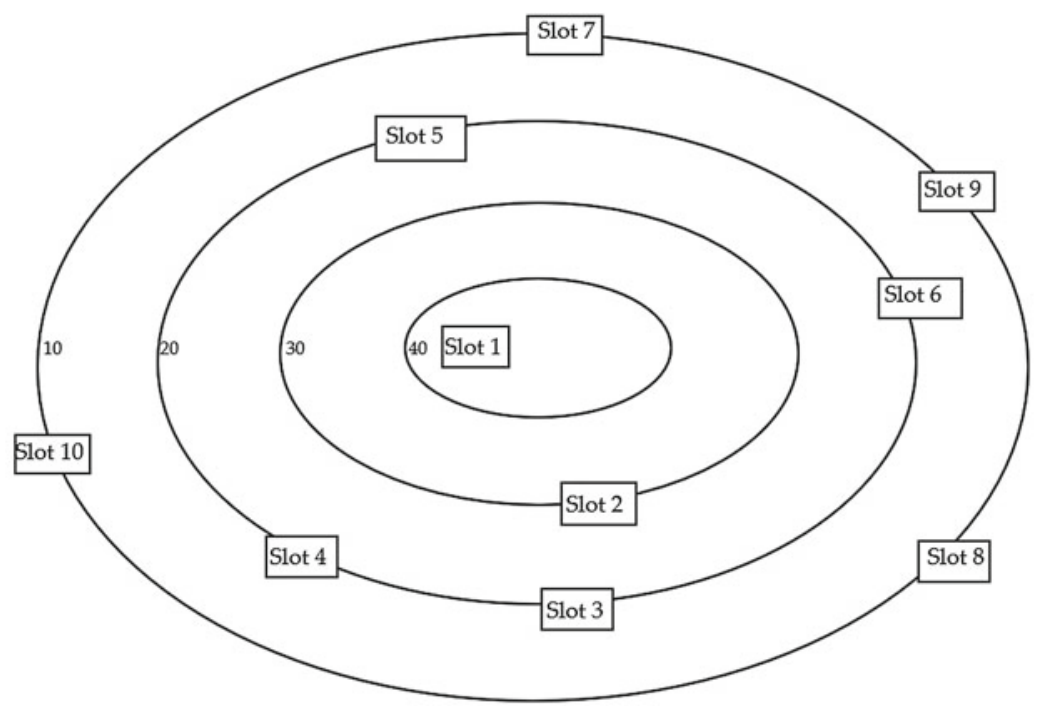

Legende: Slot 1 = Aufenthaltsland, Slot $2=$ Anzahl, Slot $3=$ Politischer Umgang, Slot $4=$ Handlungen, Slot $5=$ Eigenschaften, Slot $6=$ Umgang, Slot $7=$ Zwischenzeitliches Aufenthaltsland, Slot $8=$ Zielland, Slot $9=$ Herkunftsland, Slot $10=$ Fluchtart

Abb.4.4 Radiusmodell zum Migrant_in-Frame im untersuchten Diskursausschnitt. Slot 1 befindet sich leicht linksversetzt im Zentrum, um den Eindruck zu vermeiden, der Wert betrage 45 (genauer Wert: 42)

Etwas komplizierter verhält es sich aus frame-analytischer Sicht mit (86) und (87):

(86) Zugleich kämen immer neue Flüchtlinge auf den Inseln an. (28.09.2016)

(87) Ein Studiogast der Live-Talkshow „Günther Jauch“ erzwang am 19. April eine Schweigeminute für Hunderte im Mittelmeer ertrunkene Flüchtlinge. $(30.05 .2015)$

Anders als in den vorangehenden Exzerpten wird die Fluchtart (übersetzen, mit dem Boot, über das Wasser) nicht expliziert, sondern muss aus impliziter Information mithilfe generellen Weltwissens erschlossen werden: So kann eine Insel nur über Wasser- und Luftfahrzeuge erreicht werden; da letzteres im vorliegenden Kontext auszuschließen ist, müssen die Personen, auf die Bezug genommen wird, 
in (86) über das Wasser gekommen sein. ${ }^{62}$ Dass sich die ertrunkenen Menschen in (87) im Mittelmeer befunden haben müssen, um im Mittelmeer zu ertrinken, ist eine Präsupposition. Aufgrund ihres Inferenzstatus handelt es sich bei den möglichen Prädikationen also um implizite Prädikationen.

In der Peripherie liegende Leerstellen müssen nicht zwingend im type-Frame fehlen; die zentralen Leerstellen haben nur bessere Chancen, in den type-Frame „einzugehen“. Dass Werte nicht sprachlich realisiert werden (also Leerstellen in den Belegstellen für den_die Betrachter_in erst erkennbar sind), kann zweierlei Gründe haben: Zum einen kann es dem geschuldet sein, dass sich die Werte bereits kognitiv verfestigt haben und nicht mehr expliziert werden müssen. Zum anderen kann es ein Hinweis auf im Diskurs marginalisierte Wissensaspekte sein. So wird bspw. das Herkunftsland der Personen, von denen die Rede ist, im vorliegenden Textkorpus kaum explizit thematisiert. Es liegt jedoch nahe, dass das Konzept Syrien als Standardwert fungiert, da seine sprachlichen Realisierungen (syrisch, aus Syrien u. a.) wiederholt als Füllwerte auftraten, mittlerweile im Sprachgebrauch jedoch als implizit mitgedacht unterstellt werden können.

Um einen stark marginalisierten Wissensaspekt, der über sämtliche Frames hinweg festgestellt werden kann, handelt es sich wohl bei der persönlichen Identität der durch den Ausdruck bezeichneten Person, eine Leerstelle, die etwa durch Personennamen gefüllt werden kann. Dies ist allein an der sich fast ausschließlich auf Personengruppen beziehenden Referenz, die in Form von Pluralbildungen vorliegt, abzulesen. Im 300 Fälle umfassenden Textkorpus sind lediglich zwei Fälle zu erkennen, in denen ein Personenname genannt wird. Einen weiteren stark marginalisierten Wissensaspekt stellt das Lebensalter des Person(en), auf die sich bezogen wird, dar: für Flüchtling und Migrant_in liegen hierzu jeweils drei Fälle vor. Hier ist jedoch womöglich auch von einem standardisierten Wert auszugehen (s. u.).

Die Abbilldungen 4.5 bis 4.7 fassen, bezogen auf den jeweiligen sprachlichen, frame-evozierenden Ausdruck, die im Verlauf dieser Arbeit gewonnenen Ergebnisse $\mathrm{zu}$ einem prototypischen type-Frame zusammen und veranschaulichen diskurszentrale Wissensaspekte. Orientiert am Entrenchment-andconventionalization-model (Schmid 2020) speist sich die Prototypizität aus einer hohen type- und token-Frequenz (s. o.). Die Leerstellen heben sich von den Standardwerten durch einen blauen Untergrund ab.

\footnotetext{
${ }^{62}$ Konkret liegt in ,Die Flüchtlinge gelangen über das Wasser auf die Inseln“ wohl ein semantisches Entailment vor. In jedem Fall scheint es sich hier nicht um eine Präsupposition zu handeln, da das Kriterium der Konstanz unter Negation nicht erfüllt wird.
} 
Insbesondere an den Leerstellen „Lebensalter“ und „Zeit“ (der Fluchtbewegung) wird veranschaulicht, was im theoretischen Abschnitt dieser Arbeit erläutert wurde: Nicht nur Standardwerte und Füllwerte tragen in sich Informationen, sondern auch Leerstellen; insofern, dass diese selbst keineswegs leere Hülsen darstellen, sondern Bedingungen dafür festlegen, welche Werte überhaupt als Füllwerte in Frage kommen können. Dies geschieht in Verbindung mit dem Konzept ${ }^{63}$ und zeigt die relationale kognitive Bedeutung von Leerstellen: Die Leerstelle „Lebensalter“ setzt z. B. im Konzept-Frame zu Schüler_in andere Bedingungen als im Konzept-Frame zu Flüchtling. ${ }^{64}$

Eine weitere, mögliche Information, die der type-Frame enthalten mag, jedoch in obiger Darstellung ausgelassen wurde, ist das Wissen der Rezipient_innen, dass der Ausdruck unter Umständen abwertend verstanden wird. Insbesondere das brisante Potential von Sprache in politischen Zusammenhängen bedacht, darf eine Frame-Theorie den Aspekt nicht vergessen, dass Sprachproduzent_innen wie Verstehende bewertendes Wissen über die frame-evozierende Wortform (die Ausdrucksseite) repräsentiert haben, an das pragmatisches Gebrauchswissen geknüpft ist. Wissen kann dabei auch den „Tatsachen“ entgegengesetzt behalten werden (vgl. das Ergebnis, dass in linkspolitischen Sujets, die generell eher mit politisch korrekter Sprache in Verbindung stehen als konservative Kreise, der Ausdruck Flüchtlinge nach wie vor weit vor dem Ausdruck Geflüchtete dominiert). Jenes Wissen stellt als Wissen um die Konnotation möglicherweise ein Meta-Frame-Element dar. Dass solches Wissen Teil des Frames selbst sein muss, liegt nahe - wie genau es Teil des Frames ist, bedarf weiterer Forschung. Voraussetzung hierfür ist freilich ein weiter Wissensbegriff, nach dem Wissen nicht per se von Einstellungen getrennt wird.

Der Frame, den der Ausdruck Flüchtling evoziert, wenn er als Bezeichnung einer juristisch-politischen Kategorie gebraucht wird (vgl. ,Er wurde als Flüchtling anerkannt ${ }^{\circ}$ ), ist insofern anders beschaffen als in Abb. 4.5 abgebildet, als in seinem Zentrum Leerstelle 3 des Matrixframes PERSON ,In welchen für die Person wichtigen funktionalen Zusammenhängen spielt die Eigenschaft der Person eine bestimmte Rolle?“ mit dem (nahezu niemals zu verwerfenden) Standardwert „rechtlicher Zusammenhang“ steht. Lexikalische Einheiten wie anerkannt verleihen dem Frame also eine zusätzliche, inhaltliche (rechtliche) Dimension.

\footnotetext{
${ }^{63}$ Busse spricht hier von einer „Attribut-Referenzpunkt-Relation“ (2012: 594).

${ }^{64}$ Diese Bedingungen sind auch wandelbar - durch einen Wandel gesellschaftlicher Umstände und eine dadurch qualitativ und quantitativ andersartige, iterative sprachliche Kontextualisierung: Im Frame zu Hochzeit z. B. setzten die Leerstellen „Lebensalter der Braut“ und „Lebensalter des Bräutigams“ in der Gesellschaft der 1950er Jahre gewiss andere Bedingungen als in den 2010er Jahren.
} 


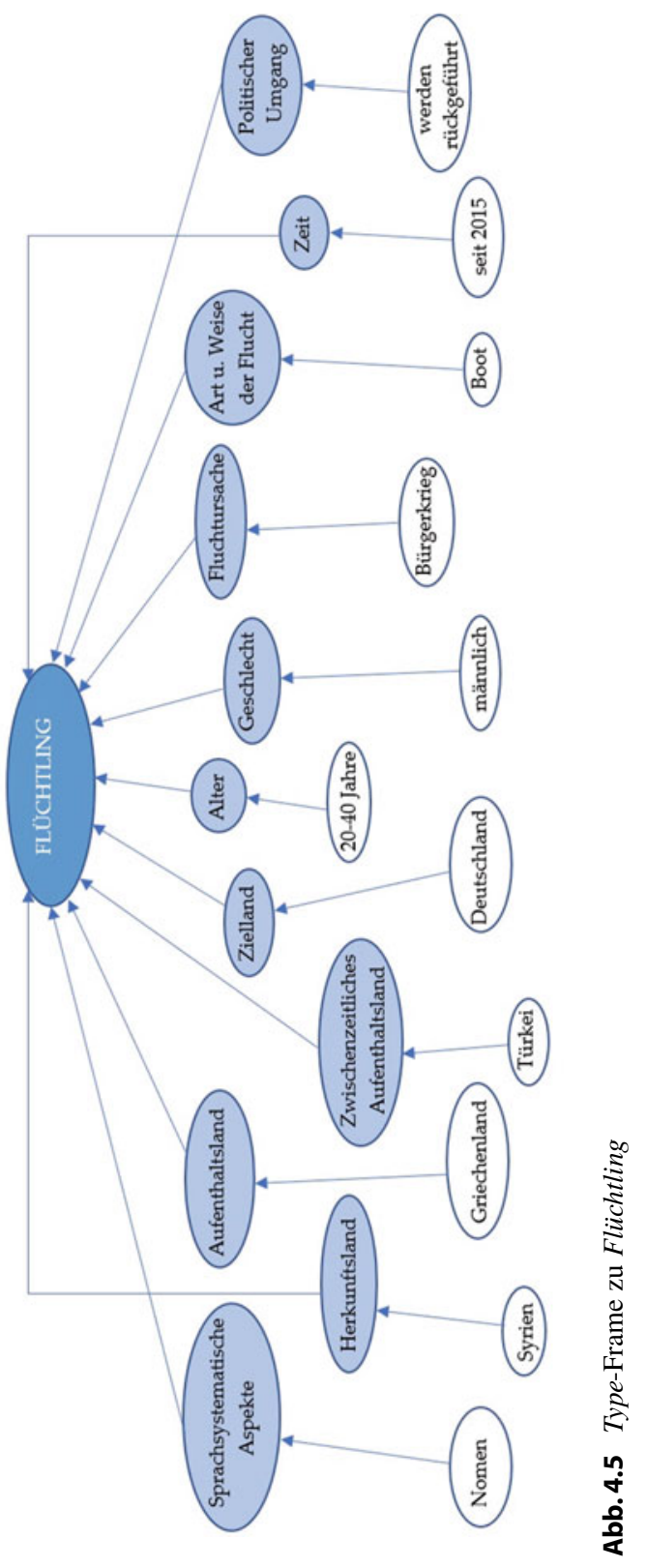


An ihn angeschlossen ist alsdann ein übergeordneter Wissensrahmen, der das (instantiierte) Dasein des frame-evozierenden Ausdrucks als juristisch-politische Kategorie repräsentiert. Sollte der Text weitere konkrete Füllungen nicht zulassen, können Informationen wie Herkunftsland oder Fluchtursache (je nach Grad des Wissens über die GFK leicht oder weniger leicht) sodann inferiert werden.

Abb. 4.6 zeigt eine graphische Darstellung des type-Frames zu Geflüchtete_r:

Der in der Frame-Analyse gewonnenen Erkenntnis, dass mit diesem Ausdruck überaus häufig Personen bezeichnet werden, die sich auf einer Skala der Fluchtbewegung in einer ,höheren“ Position befinden, d. h. sich näher an der Lebenswelt der Sprachproduzent_innen sowie Verstehenden befinden, wird durch den Standardwert „Deutschland“ der Leerstelle „Aufenthaltsland“ Rechnung getragen. Zudem entsprechen das Zielland und das Aufenthaltsland im Frame einander, was die gestrichelte Linie zwischen den betreffenden Leerstellen und Standardwerten anzeigt. Daran gekoppelt kann die Konnotation (das konnotative Wissen, die Produzent_innenseitige politische Einstellungsbekundung) sein, dass sich die Flucht in der Vergangenheit befindet, die wiederum mit der Wortform (Leerstelle „Sprachsystematische Aspekte") verbunden sein mag.

Aufgrund der hohen Auftretenshäufigkeit des Ausdrucks in Umgebung von Wörtern, die dem Konzept Integration zugeschrieben werden können, wurde dieses Konzept als Standardwert der Leerstellen „Politischer Umgang“ und „mikrosozialer Umgang“ gefasst (in beiden Fällen tritt die Bezeichnung im Satz in Patiens-Funktion auf). Konkrete Füllwerte der Leerstelle ,mikrosozialer Umgang“ sind etwa „werden ins Stadion eingeladen“ und „werden unterrichtet“.

Ein weiterer zentraler Unterschied zu Flüchtling ist das Auftauchen des MetaFrame-Elements „Einstellung des_der Sprecher_in zum Referenzobjekt““. Als Standardwert fungiert eine eher positive Einstellung gegenüber den Personen, auf die Bezug genommen wird. Man betrachte:

(88) Die Geflüchteten sind doch nichts anderes als Sozialschmarotzer! (eigenes Beispiel)

Dieser Satz scheint aus grammatikalischer und auch semantischer Sicht einwandfrei. Doch aus pragmatischer Sicht mutet er eher schief an (unter der Annahme, der_die Sprecher_in verwendet die Personenbezeichnung Geflüchtete nicht als Zitat eines politisch ungleich eingestellten Gegenübers). Erklärbar ist dies dadurch, dass der evozierte Frame die Information in sich trägt, dass der Gebrauch des frame-evozierenden Ausdrucks zugleich den Gebrauch der als politisch korrekt geltenden Bezeichnung bedeutet. Menschen mit Vorurteilen zu begegnen oder, wie in (88), gar zu beleidigen, ist jedoch mit dem Zweck politisch 


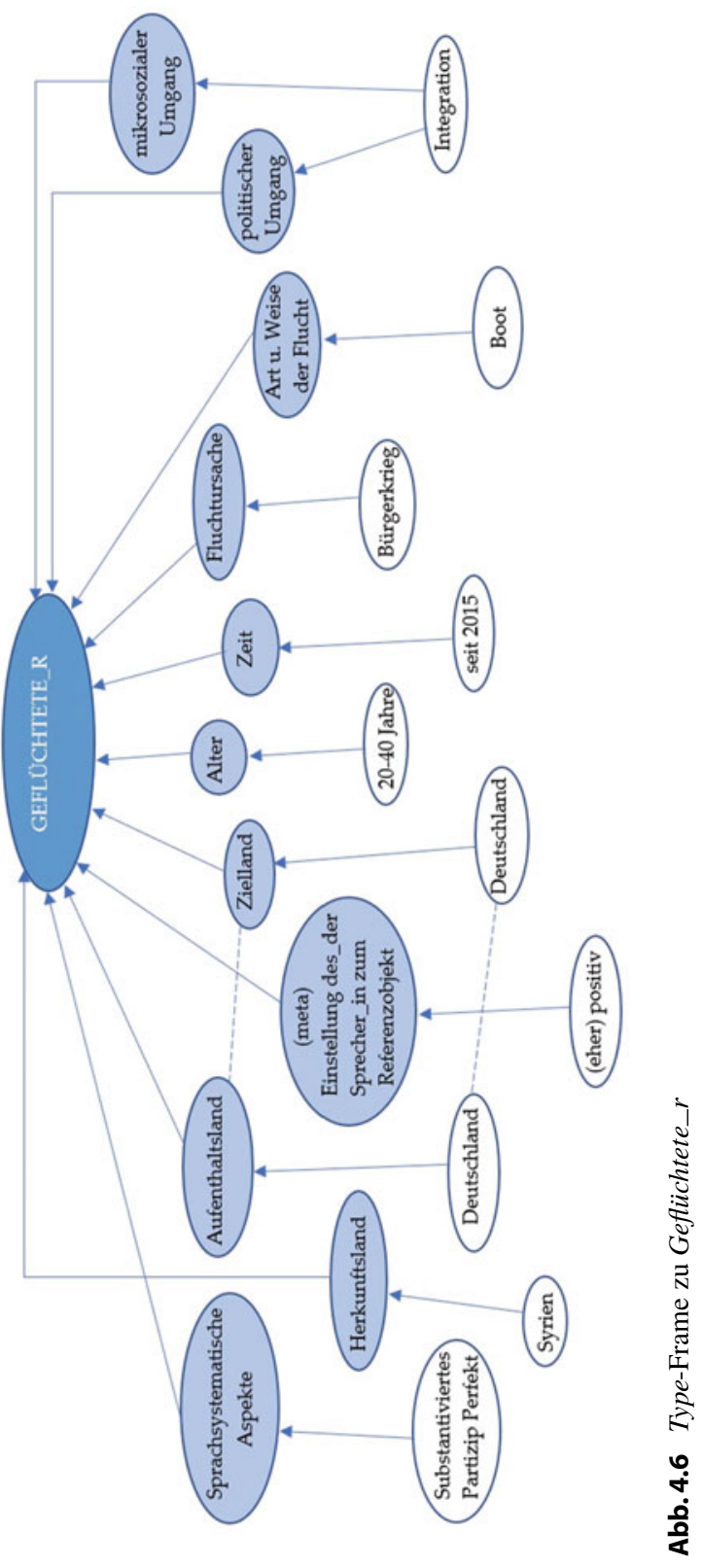


korrekter Sprache nicht vereinbar. Dieses Gebrauchswissen stellt dabei möglicherweise ein Meta-Frame-Element dar (s. o.), da es sich hier um Wissen um die Konnotation des frame-evozierenden Ausdrucks handelt. Die durch den_die Sprecher_in vorgenommene (eher) positive Bewertung des Referenzobjektes wäre dann auf Seiten des_der Rezipient_in eine Schlussfolgerung aus diesem Wissen. Das Wissenselement operiert demnach über den Frame hinweg und beeinflusst die Ausgestaltung anderer Frame-Elemente. Wird der Ausdruck in (88) durch Flüchtlinge oder Migranten substituiert, wirkt die Äußerung dagegen pragmatisch unproblematisch. Zu beachten ist jedoch: Hinsichtlich Produzent_innen als auch Rezipient_innen sollte das Frame-Element, das das Wissen um die politische Korrektheit des Ausdrucks repräsentiert, nicht mit dem Frame-Element, das das Wissen um die Einstellung des_der Sprecher_in gegenüber dem Referenzobjekt repräsentiert, gleichgesetzt werden. Differenzstiftend wirkt einstweilen ein übergeordneter Bezugsrahmen: Wird der Ausdruck z. B. von Behörden der Bundesrepublik Deutschland gebraucht, wird bei den Verstehenden wohl zwar dasjenige Frame-Element aktiviert, das das Wissen um politische Korrektheit einschließt, jedoch kaum dasjenige, das eine eher positive Einstellung des_der Sprecher_in zum Referenzobjekt umfasst. In der gesprochenen Sprache käme dagegen der Gebrauch des Ausdrucks gerade in der Alltagssprache einer Mitteilung über die eigene politische Tendenz gleich, die Sprecher_inneneinstellung ist durchaus Teil des evozierten Frames - weswegen Satz (88) eben problematisch ist. Welche Information evoziert wird, hängt also in hohem Maße sowohl davon ab, wer als Sprecher_innen auftritt und den frame-evozierenden Ausdruck gebraucht, als auch davon, wie sich der situative Kontext gestaltet, in dem der Ausdruck gebraucht wird, wobei diese beiden Faktoren natürlich miteinander verschränkt sind.

Der Frame zu Migrant_in integriert im vorliegenden Textkorpus, d. h. im untersuchten Diskursausschnitt, sämtliche relevanten Frame-Elemente, die auch der Frame zu Flüchtling integriert, wie Abb. 4.7 zeigt:

Der Aspekt der Freiwilligkeit, der dem Ausdruck möglicherweise innewohnt, kann anhand der vorliegenden sprachlichen Daten nicht bestätigt werden. Dies bedeutet jedoch nicht, dass er beim Sprachverstehen nicht kognitiv aktiviert wird; vielmehr ist es möglich, dass dieser bereits einen Standardwert darstellt, der - wie bei den Frames zu Flüchtling und Geflüchtete_r das Herkunftsland - nicht mehr expliziert werden muss, sondern stillschweigend vorausgesetzt werden kann.

Sollte der Ausdruck in seiner Funktion als Lebensrolle (etwa Sie ist Migrantin) gebraucht werden, stellt dies eine Instantiierung des allgemeinen type-Frames dar, weswegen, wie bei Flüchtling, die potenzielle Bedeutung des Ausdrucks als Lebensrolle in der graphischen Darstellung des type-Frames fehlt. Im Falle des 


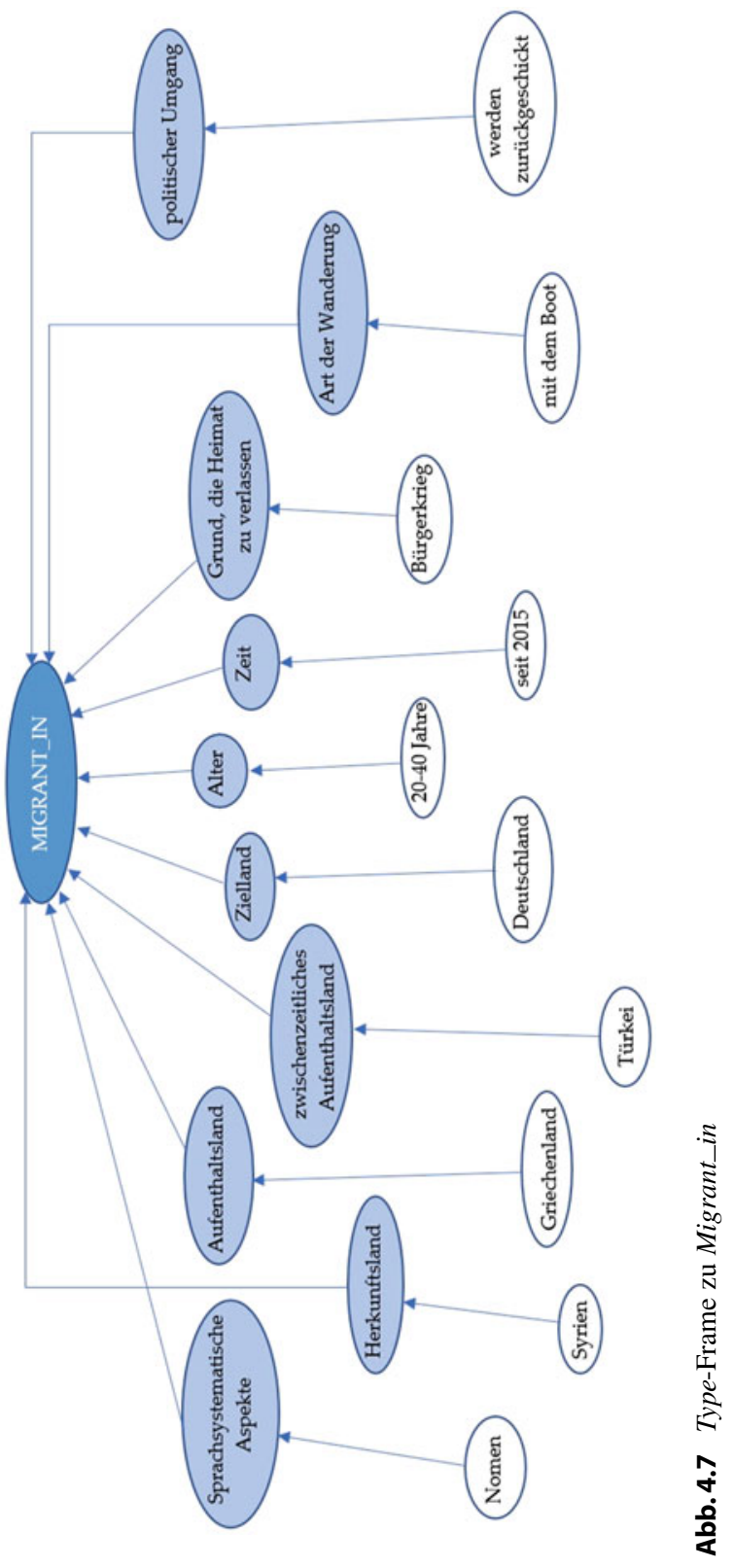


instantiierten Frames ist sodann von einem übergeordneten Wissensrahmen auszugehen, der die epistemische Information integriert, dass bzgl. des Ausdrucks eine soziale Kategorie vorliegt.

Open Access Dieses Kapitel wird unter der Creative Commons Namensnennung 4.0 International Lizenz (http://creativecommons.org/licenses/by/4.0/deed.de) veröffentlicht, welche die Nutzung, Vervielfältigung, Bearbeitung, Verbreitung und Wiedergabe in jeglichem Medium und Format erlaubt, sofern Sie den/die ursprünglichen Autor(en) und die Quelle ordnungsgemäß nennen, einen Link zur Creative Commons Lizenz beifügen und angeben, ob Änderungen vorgenommen wurden.

Die in diesem Kapitel enthaltenen Bilder und sonstiges Drittmaterial unterliegen ebenfalls der genannten Creative Commons Lizenz, sofern sich aus der Abbildungslegende nichts anderes ergibt. Sofern das betreffende Material nicht unter der genannten Creative Commons Lizenz steht und die betreffende Handlung nicht nach gesetzlichen Vorschriften erlaubt ist, ist für die oben aufgeführten Weiterverwendungen des Materials die Einwilligung des jeweiligen Rechteinhabers einzuholen. 